Ágatha Cristhina Oliveira Faria

\title{
FATORES DE SUSCEPTIBILIDADE ÀS FISSURAS OROFACIAIS
}

SUSCEPTIBILITY FACTORS TO OROFACIAL CLEFTS

São Paulo

2019 


\section{Ágatha Cristhina Oliveira Faria}

\section{FATORES DE SUSCEPTIBILIDADE ÀS FISSURAS OROFACIAIS}

SUSCEPTIBILITY FACTORS TO OROFACIAL CLEFTS

Tese apresentada ao Instituto de Biociências da Universidade de São Paulo, para a obtenção de Título de Doutor em Ciências, na Área de Biologia/Genética.

Orientador(a): Prof ${ }^{-a}$ Dr $^{\text {a }}$ Maria Rita dos Santos e Passos Bueno

São Paulo

2019 


\section{Ficha Catalográfica}

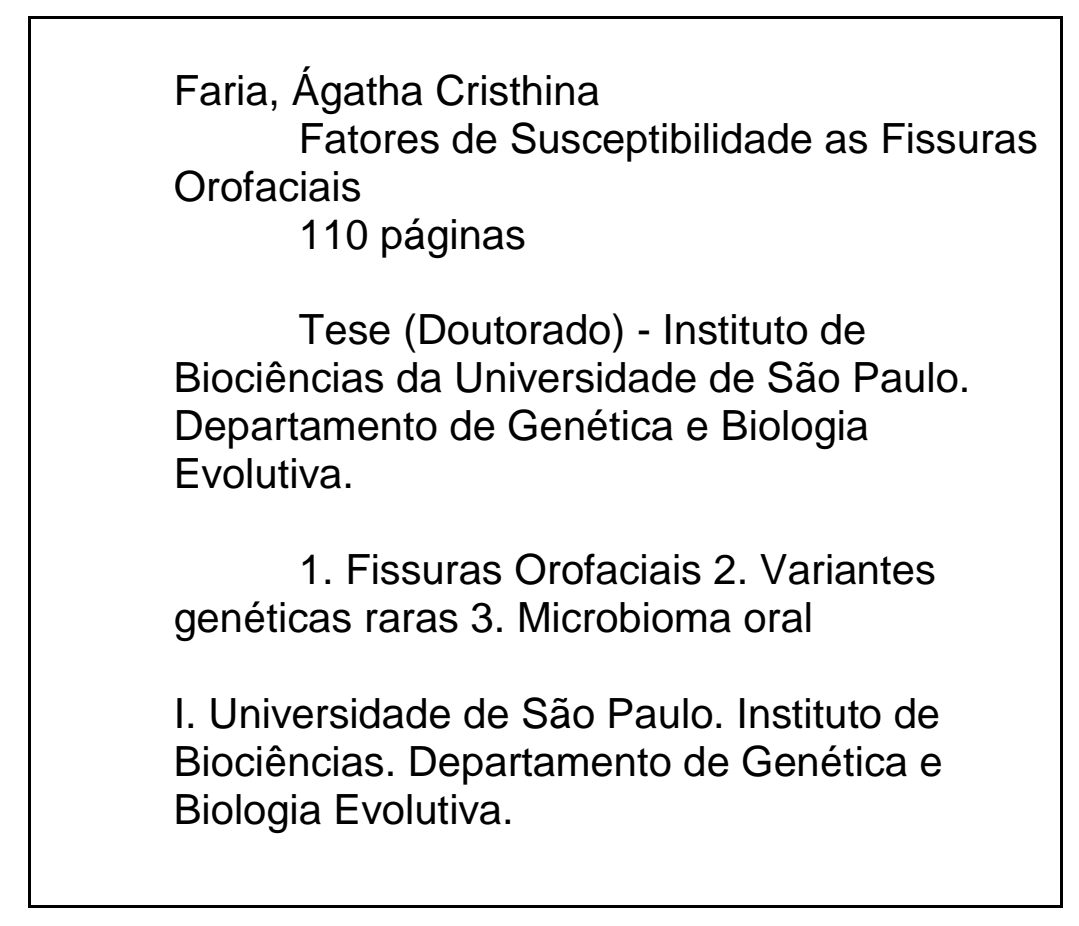

Comissão Julgadora:

Prof(a). Dr(a)

Prof(a). Dr(a)
Prof(a). Dr(a)

Prof(a). Dr(a)

\footnotetext{
Prof(a).Dr(a). Maria Rita dos

Santos e Passos Bueno

Orientador(a)
} 
A todos os pós-graduandos do Brasil, que por amor ao saber e sonho de tornar o mundo melhor dedicam sua juventude à ciência, quase sempre sem nenhum reconhecimento. 
"Para que todos vejam e saibam, considerem e juntamente entendam que a mão do SENHOR fez isso..." 


\section{Agradecimentos}

Agradeço a minha família, minha genética, pelo exemplo, suporte, apoio e amor em todos os momentos. Mãe, pai e irmã, isso é para vocês.

Agradeço a Rita pela oportunidade, orientação e disponibilidade durante esses anos e por contribuir com meu amadurecimento e crescimento pessoal.

Agradeço as pessoas incríveis que o Lab200 me proporcionou conhecer e conviver e que fizeram minha vida em São Paulo feliz. Sem exagero nenhum, sem o apoio de vocês eu não teria conseguido chegar até aqui.

Em especial:

- Às minhas queridas amigas e consultoras de tudo Carol, Clarice, Duda, Cami e Pri (e seus respectivos companheiros), amo vocês. Obrigada por tudo sempre. \#Proibidão

- À pessoa que me trouxe o sentido da palavra 'lar' em São Paulo, que me fez ter qualidade de vida e aumentar meu nível de cultura exponencialmente rs, minha companheira de sopa de lentilha no inverno, piscina no verão, parceira de coleção de selinhos do Pão de Açucar e de discussões sobre ciência, política, culinária e novelas, minha querida amiga e roommate, Karina. (Serei eternamente grata).

- Ao Luciano, meu pós-doc, pai dos meus projetos, meu melhor parceiro de Operação Sorriso, meu exemplo de tranquilidade, senso de humor, trolagens e cinismo. Muito obrigada por tudo sempre. \#TimeFissuras

- À Tati, por sempre estar disponível para me ajudar e ensinar bioinformática e programação além de compartilhar comigo as dores do doutorado. Muito obrigada!

- Aos demais colegas do Lab200, que fizeram o ambiente de trabalho ficar leve e divertido, sempre dispostos a ajudar: Pontinho, Claudinha, Bela, Robs, Naila, Simone, Camila B., May, Dani, Van, Arthur e os maravilhosos patriarcas do lab: Lucas e Xérson. Vocês são pessoas incríveis. À Aluna da Dra. Débora, Elisa Varicela, Juninha pela companhia e amizade nessa reta final. 
Agradeço a toda equipe do Genoma em especial ao Guilherme e a Suzana por toda ajuda e paciência para me ensinar o básico da bioinformática e rodar meus arquivos inúmeras vezes.

Agradeço a todos os colaboradores desse trabalho, em especial a Dani Bueno e Gislene, e também aos voluntários e organizadores da Operação Sorriso que tornaram esse trabalho viável e propriciaram momentos muito importantes de crescimento pessoal.

Agradeço a USP pela oportunidade em ter acesso a um acompanhamento psicológico excelente e à minha brilhante psicóloga, Miriam, que me acompanhou e foi essencial no meu processo de autoconhecimento, amadurecimento e sobrevivência ao doutorado durante esses anos.

Agradeço aos meus amigos e amigas de longe: Vitória, Rio de Janeiro, Hawaii, Hamburgo que, apesar da distância, nunca me deixaram e sempre compartilharam comigo os momentos felizes e amargos (e sempre escutam meus áudios 10 minutos).

Ágradeço as minhas parceiras de Crossfit, que contribuíram no alívio do estresse quando as coisas estavam difíceis, em especial a minha dupla Robin. \#amorlivre. Obrigada pela amizade verdadeira e por me dar o melhor presente que eu já ganhei.

Agradeço ao meu melhor presente, minha cereja do bolo e poesia diária, pela constante paz, tranquilidade e amor de I Coríntios 13:4-7, fundamental no caos dessa reta final.

Agradeço à Fundação de Amparo à Pesquisa do Estado de São Paulo (FAPESP, no processo: 2016/17392-7) e ao Conselho Nacional de Desenvolvimento Cientifico e Tecnológico (CNPq, no processo: 158773/2015-2) pelo apoio financeiro.

E, por fim, agradeço imensamente aos pacientes e seus familiares pela doação das amostras sem as quais esse projeto não poderia ser realizado. 


\section{Notas}

A presente tese de doutorado diz respeito a um trabalho desenvolvido durante três anos e seis meses (entre 2015 e 2018), no Laboratório de Genética do Desenvolvimento do Centro de Estudos do Genoma Humano e Células Tronco, Instituto de Biociências, Universidade de são Paulo.

A tese foi redigida no modelo de artigos e capítulos com seu idioma principal sendo português, porém, os capítulos centrais, que descrevem artigos científicos publicados ou submetidos, foram redigidos em inglês.

As publicações em que colaborei como co-autora, mesmo aquelas não relacionadas ao tema principal da tese, encontram-se sumarizadas nos Apêndices, ao final da tese. 


\section{Índice}

Capítulo 1. Introdução geral....................................................................

As fissuras orofaciais........................................................................ 9

Fatores genéticos de susceptibilidade as FO-NS................................. 14

Fatores ambientais de susceptibilidade as FO-NS................................ 17

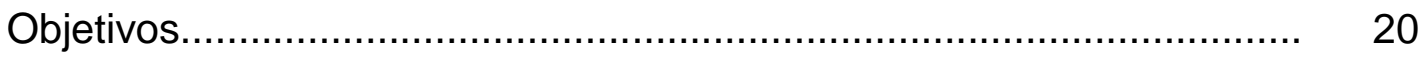

Capítulo 2. Non-syndromic orofacial clefts: enrichment of rare loss-of-function variants in genes under selective constraint.

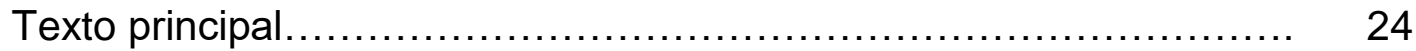

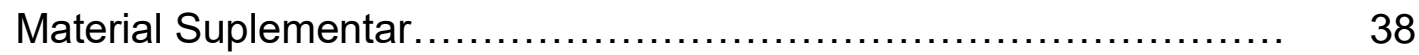

Capítulo 3. Non-syndromic orofacial clefts: enrichment of rare loss-of-function variants in genes under selective constraint....................................... 63

Texto principal........................................................ 66

Material Suplementar................................................ 75

Capítulo 4. Estudo de micro-organismos presentes na cavidade oral de mães com filhos portadores de fissuras labiais.

Texto principal.

Capítulo 5. Discussão geral e conclusão.

Capítulo 6. Referências.

Capítulo 7. Resumo e Abstract..

Apêndice. Publicações adicionais. 


\section{Capítulo 1}

\section{Introdução Geral}

\section{AS FISSURAS OROFACIAIS}

\section{Classificação clínica e epidemiologia}

As fissuras orofaciais (FO) representam um grupo de malformações congênitas que caracterizam-se pela separação incompleta das cavidades oral e nasal, formando uma ruptura nos tecidos acima do lábio. Essa ruptura ocorre em forma de fenda e possui grande variabilidade clínica, podendo ser unilateral ou bilateral, e afetar apenas o lábio, como também as regiões dente-alveolares e o palato. As formas mais comuns das FO incluem as fissuras de lábio (FL), com ou sem acometimento de palato (FL/P), e as fissuras de palato (FP). Outras alterações da face ou da boca também podem estar presentes em indivíduos afetados pelas fissuras orofaciais, como fissura de linha média, fissuras de Tessier e fissura de palato submucosa (Figura 1) (Elizabeth $\mathrm{J}$. Leslie \& Marazita, 2015; Watkins et al., 2014). Embora todos os tipos de FO se desenvolvam no início da gravidez, como será abordado adiante, a maioria dos dados epidemiológicos é baseada nas frequências de crianças com FL/P (que incluem FL e fissuras de lábio e palato, FLP), ou apenas FP ao nascimento, devido às diferenças na embriologia dessas duas formas. 

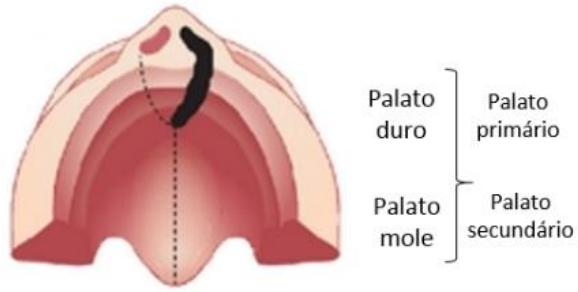

(a)

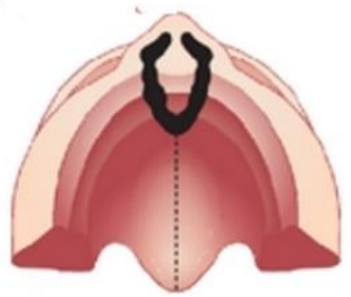

(b)

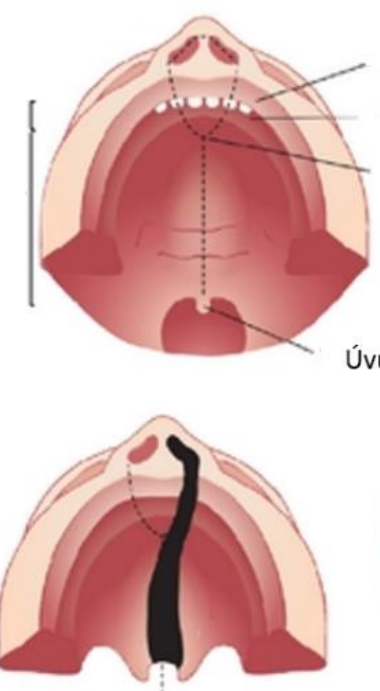

(c)

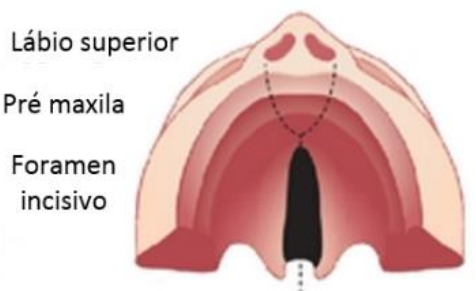

(e)

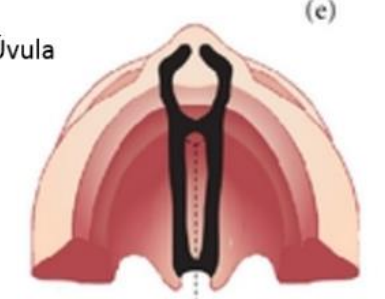

(d)

Figura 1: Representação dos tipos mais comuns de fissuras orofaciais. (a) Fissura labial unilateral com envolvimento alveolar; (b) fissura labial bilateral com envolvimento alveolar; (c) fissura labial unilateral associada com fissura de palato; (d) fissura bilateral de lábio e palato; (e) fissura de palato (adaptado de Luciano Abreu Brito, Meira, Kobayashi, \& Passos-Bueno, 2012).

As FL/P são as malformações congênitas craniofaciais mais comuns, sendo sua prevalência mundial estimada em 9.9 em 10.000 nascidos vivos podendo variar a depender da etnia, origem geográfica e nível socioeconômico (Terri H Beaty, Marazita, \& Leslie, 2016; IPDTOC Working Group, 2011; Watkins, Meyer, Strauss, \& Aylsworth, 2014). Em geral, as populações do leste asiático e dos nativos americanos têm taxas de prevalência substancialmente elevadas ( 20/10.000 e 10,2/10.000) em relação às populações da Europa ( 8/10.000) e às populações de ancestralidade africana ( 2,8/10.000) (IPDTOC Working Group, 2011). Já a prevalência das FP, excluindo desordens cromossômicas, se difere consideravelmente em cada região geográfica variando de 1,2/10.000 nascimentos na África subsaariana, 6/10.000 na Ásia central, nos Estados Unidos, e na Europa e 11,3/10.000 na Oceania (P A Mossey \& Modell, 2012).

As FO podem ser classificadas de diversas formas sendo mais interessante, do ponto de vista genético, dividi-las de acordo com sua associação a outras malformações cognitivas e/ou físicas, envolvendo mais de uma região ou órgão do corpo. A grande maioria ( 70\%) dos afetados com FL/P e a metade dos afetados com FP não apresenta nenhuma outra anormalidade associada e são denominadas fissuras orofaciais não sindrômicas (FO-NS). Contudo, uma parcela significativa dos casos de FL/P e FP, 30\% e 50\%, respectivamente, apresentam outras malformações 
associadas e podem caracterizar uma síndrome (FO-S) (IPDTOC Working Group, 2011; Stanier \& Moore, 2004). Cerca de 330 síndromes possuem FL ou FP como uma característica clínica, de acordo com o banco de dados Online Mendelian Inheritance in Man (OMIM) (Elizabeth J. Leslie \& Marazita, 2015; McKusick, 2007).

Indivíduos afetados com FO necessitam de um cuidado multidisciplinar durante

toda a vida, envolvendo cirurgias plásticas, tratamento odontológico e fonoaudiológico, aconselhamento genético, acompanhamento psicológico, entre outros. É estimado que uma criança com FO necessite realizar em média 6 cirurgias plásticas, ser hospitalizada por cerca de 30 dias e realizar um tratamento odontológico de 5 anos, o que leva a um custo de aproximadamente 200.000 mil dólares de tratamento por criança afetada. Além disso, as FO estão associadas com elevada mortalidade infantil. Dessa forma, as FO representam um importante problema de saúde pública e estudos que colaborem com o entendimento dos fatores etiológicos das FO são essenciais para identificação de alvos terapêuticos, assim como prevenção dessas condições (Luciano Abreu Brito et al., 2012; Dixon, Marazita, Beaty, \& Murray, 2011; Elizabeth J. Leslie \& Marazita, 2015; Peter A Mossey, Little, Munger, Dixon, \& Shaw, 2009; Watkins et al., 2014).

\section{Embriologia}

O desenvolvimento da face, mais especificamente do lábio e do palato, é um processo complexo que envolve uma série de eventos coordenados de migração, crescimento, diferenciação e apoptose celular (Peter A Mossey et al., 2009). Cinco estruturas, que são formadas a partir da migração das células de crista neural, estão envolvidas nesses processos: a proeminência frontonasal, o par de proeminências maxilares e o par de proeminências mandibulares, ambas derivadas do primeiro arco branquial fetal (Figura 2) (Peter A Mossey et al., 2009).

A formação do lábio superior e do palato primário se inicia por volta da $4^{0}$ semana do desenvolvimento embrionário e se completa na 6을 semana, quando as proeminências maxilares e os tecidos nasais mediais, originados a partir da proeminência frontonasal, crescem e se fundem precisamente (Figura 2a, 2b e 2c). Quaisquer distúrbios durante esse processo de crescimento ou fusão podem levar a falhas no mecanismo de fechamento e resultar em FL que pode atingir o alvéolo e o palato primário (E J Leslie \& Murray, 2013). 
No momento do término do desenvolvimento do palato primário, na $6^{\circ}$ semana da embriogênese, ocorre o início do desenvolvimento do palato secundário, quando os processos maxilares começam a se desenvolver no sentido medial, lançando os processos palatinos (ou lâminas horizontais) em direção à linha média em busca de seu contralateral (Figura $2 \mathrm{~d}$ ). Durante a $7^{\circ}$ semana do desenvolvimento, os processos palatinos crescem horizontalmente acima da língua, se encontram e se fundem formando uma linha epitelial de linha média, que posteriormente se degenera para permitir a continuidade mesenquimal no palato (Figura 2 e e 2f). O mesênquima do palato se diferencia em tecido ósseo e muscular que se correlacionam com a posição dos palatos duro e mole, respectivamente. $\mathrm{Na} 10^{\circ}$ semana da embriogênese a linha média se funde completamente ao palato secundário, que também se funde com 0 palato primário e o septo nasal. A partir desse momento, as cavidades oral e nasal estão separadas, o que permite a mastigação e a respiração ocorram ao mesmo tempo. Falhas durante esse processo ocasionará em FP (E J Leslie \& Murray, 2013; Peter A Mossey et al., 2009).

a

b
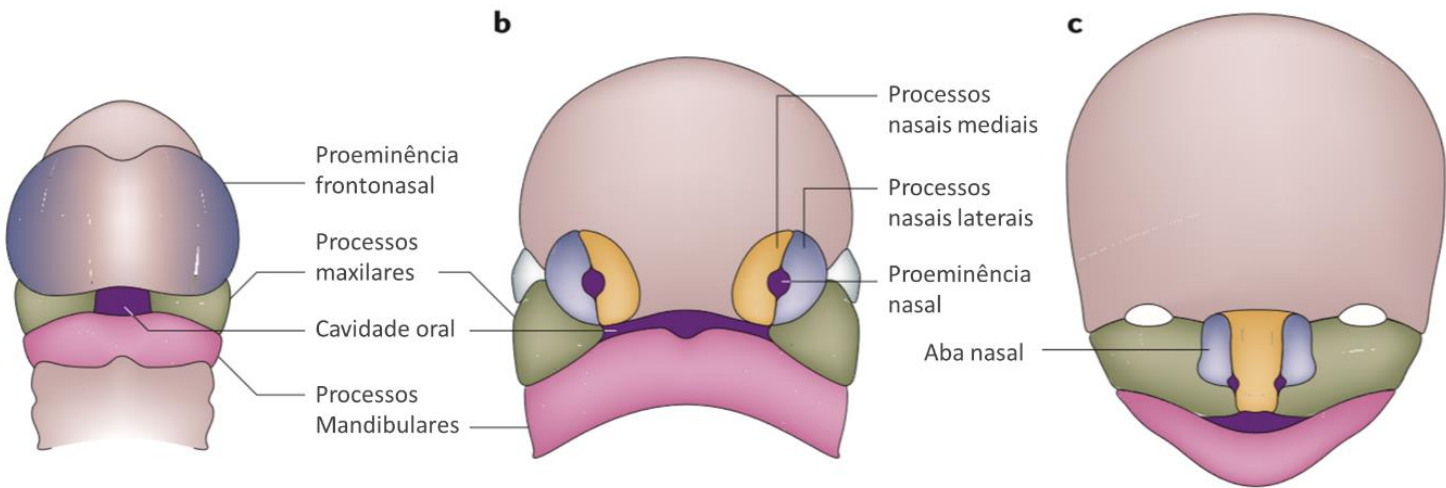

d

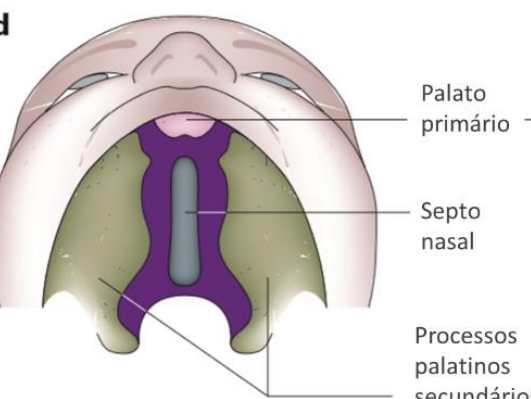

e
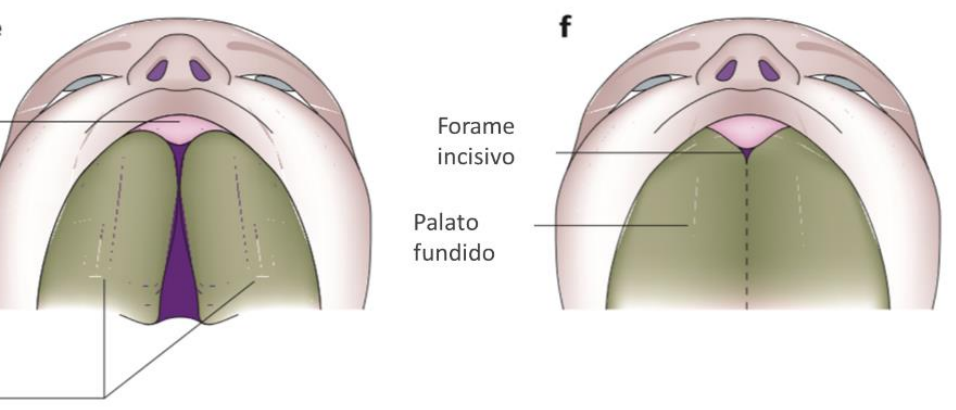

Figura 2: Representação das diferentes fases do desenvolvimento embrionário do lábio e do palato em humanos. a) 4⿳a semana: ocorre o desenvolvimento da proeminência frontonasal, os processos maxilares, os processos mandibulares pareados e a cavidade oral primitiva ao centro; b) $5^{\text {a }}$ semana: acontece a formação das fossas nasais e dos processos nasais mediais e laterais pareados; c) $6^{\underline{a}}$ semana: ocorre a fusão dos processos nasais mediais com os processos maxilares. A formação do lábio superior e palato primário. Os processos nasais laterais se fundem e formam a aba nasal e os 
processos mandibulares formam a máxima inferior; d) ainda durante a $6^{\text {a }}$ semana: ocorre 0 desenvolvimento do palato secundário com o crescimento bilateral dos processos maxilares; e) em sequência, a elevação e início da fusão das lâminas palatinas; f) por fim, ocorre a fusão das lâminas palatinas, dividindo o espaço oronasal nas cavidades oral e nasal separadas (modificado de Dixon et al., 2011).

\section{Fatores etiológicos}

A grande maioria das FO-S descritas já possui sua etiologia elucidada podendo ser causadas majoritariamente ( 75\%) por fatores genéticos que incluem anormalidades cromossômicas e mutações em um único gene, ou fatores ambientais, como a exposição a fatores teratogênicos (Dixon et al., 2011; E J Leslie \& Murray, 2013).

Como exemplos clássicos de FO-S com causa genética conhecida podemos citar a síndrome Velocardiofacial ou DiGeorge (VCF; OMIM \#188400), causada pela deleção intersticial do braço longo do cromossomo 22 (22q11.2), e a síndrome de Van der Woude (VW; OMIM \#119300) causada por mutações no IRF6 (Monteiro et al., 2013; Watkins et al., 2014).

Em relação aos fatores teratogênicos, o consumo materno de álcool, cigarro e uso de ácido valpróico ou outros anticonvulsivantes já foram associados com algumas síndromes envolvendo FO (Dixon et al., 2011; Koo \& Zavras, 2013).

As FO-NS, ao contrário, possuem etiologia complexa e pouco compreendida. Seu modelo de herança mais aceito é o multifatorial, baseado na interação de múltiplos fatores genéticos e fatores ambientais (Dixon et al., 2011).

Diversos estudos epidemiológicos suportam o importante papel dos fatores de risco ambientais no desenvolvimento das FO-NS, como baixo nível socioeconômico, exposições a agentes infecciosos, o uso materno de álcool, tabaco, desnutrição prénatal, e deficiência de vitamina B6 e ácido fólico na gravidez, por exemplo (AcuñaGonzález et al., 2011; Dixon et al., 2011; Munger et al., 2004).

A contribuição dos fatores genéticos na etiologia das FO-NS é suportada por evidências epidemiológicas consistentes, como: recorrência familial aumentada - em geral, parentes de primeiro grau de casos de FL/P tem o risco aumentado em 32x e em casos de FP o risco é 56x (T H Beaty et al., 2013; Sivertsen et al., 2008); concordância entre gêmeos monozigóticos maior (40-60\%) do que entre dizigóticos (3-8\%) (Christensen \& Fogh-Andersen, 1993; Grosen et al., 2011) e altas taxas de 
herdabilidade em diferentes populações do mundo como na população brasileira, a qual varia de $45 \%$ a $85 \%$ (Luciano A Brito et al., 2011).

Os fatores etiológicos das FO-NS têm sido foco de diversos estudos nos últimos anos e os principais fatores genéticos e ambientais associados às fissuras serão abordados nos tópicos seguintes.

\section{FATORES GENÉTICOS DE SUSCEPTIBILIDADE ÀS FO-NS}

Há décadas, numerosos estudos estão sendo conduzidos buscando a identificação de genes associados à FO-NS. Diversas técnicas e abordagens foram desenvolvidas e utilizadas para esse fim, como os estudos de ligação e os estudos de associação. Os estudos de ligação, investigando marcadores multialélicos, buscam identificar regiões cromossômicas que são compartilhadas entre afetados e não compartilhadas com controles. No estudo de FO-NS, tal abordagem já evidenciou diversas regiões cromossômicas, tais como 1q32, 2p, 3q27-28, 9q21, 14q21-24 e 16q24 (E J Leslie \& Murray, 2013; Zucchero et al., 2004). Os estudos de associação, por sua vez, baseiam-se na hipótese de "doença comum - variante comum" (do inglês, common disease-common variant ou CDCV; variantes alélicas presentes em mais que $1-5 \%$ da população), ou seja, a doença é causada por um conjunto de variantes de efeito baixo e de origem comum entre os afetados de uma população (Reich \& Lander, 2001). Com exceção do gene IRF6 (1q32), a maioria das associações positivas detectadas por estudos de genes candidatos não foram replicadas (E J Leslie \& Murray, 2013; Zucchero et al., 2004).

A introdução dos estudos de associação genômicos (do inglês "Genome-Wide Association Study" ou GWAS) nas pesquisas em doenças complexas foi um importante avanço comparado aos antigos estudos de associação de genes candidatos, limitados ao pequeno número de variantes estudadas (Elizabeth J. Leslie \& Marazita, 2015; Marazita et al., 2009). Estudos de GWAS em pacientes com FO-NS levaram à replicação de alguns loci associados à predisposição a FO-NS (Leslie e Marazita, 2013), alguns destes inclusive (IRF6 e região 8q24) validados na população brasileira pelo nosso grupo (Luciano A Brito et al., 2012)

Entretanto, apesar dos imensos esforços, as variantes genéticas associadas conferem um baixo risco e não explicam o total da herdabilidade estimada. Há, então, fatores genéticos desconhecidos ou algum outro mecanismo que, por alguma razão, 
ainda não foram identificados. Esse fenômeno também ocorre em várias outras doenças complexas, como diabetes tipo 2, e foi denominado herdabilidade perdida (“missing heritability") (Maher, 2008; Visscher, Hill, \& Wray, 2008).

Acredita-se que algumas causas poderiam explicar a herdabilidade perdida: 1) há um grande número de variantes de baixo risco ainda não descobertas, que não foram detectadas por limitações técnicas e/ou custo alto, como aquelas localizadas em regiões não codificadoras ou CNVs pequenos (do inglês - "copy number variation", microdeleções ou microduplicações); 2) existência de variantes raras de grande efeito que não são facilmente detectadas pelas tecnologias utilizadas; e, ainda 3) influência de importantes fatores ambientais compartilhados pela família, como o consumo de álcool, fumo ou outras drogas, e medicamentos, que não são identificados pelos pesquisadores e assim não levados em consideração nos estudos (Maher, 2008; Manolio et al., 2009).

\section{O papel das variantes raras na etiologia das FO-NS}

Estudos no genoma humano revelaram que grande parte (mais de 50\%) das variantes genéticas dos cromossomos humanos são raras (com frequência menor que 1\%) nas populações (1000 Genomes Project Consortium et al., 2015; Zhang, 2015). Recentes trabalhos sugerem que a hipótese "variante rara - doença comum" (do inglês, common disease-rare variant ou CDRV) seja uma explicação plausível para a herdabilidade perdida (Dickson, Wang, Krantz, Hakonarson, \& Goldstein, 2010). Ademais, dados em genética de populações sugerem que a recente expansão da população humana pode ter resultado em um grande número de variantes raras de susceptibilidade a doenças (1000 Genomes Project Consortium et al., 2015) e, por isso, análises de tais variantes é de extrema relevância nos estudos de associação genética (Bansal, Libiger, Torkamani, \& Schork, 2010).

O avanço nas tecnologias de sequenciamento de nova geração (do inglês, next generation sequencing ou NGS) facilitou o descobrimento e tornou a busca por variantes raras, de efeito moderado a grande, o foco dos estudos de associação genética em doenças comuns e raras. Com o uso dessa tecnologia é possível sequenciar tanto o genoma completo, ou apenas sua porção codificante (exoma), ou ainda, apenas um conjunto de genes específicos de interesse, tendo cada uma dessas 
abordagens um grau decrescente de custo e complexidade de análise (Aschard et al., 2011).

Variantes raras já foram associadas com algumas doenças humanas complexas, incluindo hipertrigliceridemia (Johansen et al., 2010), doença autoimunes (Hunt et al., 2012), doenças do neurodesenvolvimento (Jiang et al., 2013; Vissers et al., 2010) e até baixos níveis de lipoproteína de alta densidade (colesterol HDL) no plasma (Cohen et al., 2004), o que corrobora a necessidade de busca desse tipo de variantes para as $\mathrm{FO}$.

Estudos demonstraram a contribuição de variantes raras em FO-NS: E J Leslie and Murray (2013) analisaram in silico 25 genes candidatos a FO-NS em estudos prévios e encontraram que $71 \%$ de variantes raras eram potencialmente causais, 0 que corrobora a hipótese da contribuição de variantes raras para o fenótipo. Variantes raras no gene $C D H 1$, por exemplo, já foram associadas com uma variedade de cânceres e recentemente foram associadas a FO-NS pelo nosso grupo (Luciano Abreu Brito et al., 2015; Bureau et al., 2014; Vogelaar et al., 2013). Outro trabalho recente demonstrou forte associação de FO-NS e variantes raras no gene GREM1 (AI Chawa et al., 2014).

Uma boa abordagem para aumentar o poder do estudo, ou seja, a probabilidade de encontrar variantes raras associadas à $F O$, é realizar o resequenciamento de genes ou regiões alvo que já foram associados a FO em estudos de GWAS. Essa abordagem já vem sendo usada para outras doenças, como doença de Crohn e hipertrigliceridemia (Johansen et al., 2010; Rivas et al., 2011) com resultados positivos. Além disso, apesar da possibilidade de penetrância incompleta e da grande heterogeneidade genética das FO, a investigação de pacientes com histórico familiar de FO também aumenta o poder do estudo, já que nesses pacientes as chances de fatores genéticos terem contribuído mais fortemente do que fatores ambientais para o desenvolvimento da FO são maiores.

Diante disso, estudos de associação de variantes raras a FO-NS são promissores e podem contribuir para o entendimento da etiologia das FO, com a detecção de novos fatores que expliquem a herdabilidade perdida. Ainda, o sequenciamento de genes já associados a FO-NS, além de ser mais viável do ponto de vista financeiro, também aumenta significativamente a probabilidade de se encontrar variantes raras de risco. Neste modelo é possível que uma ou poucas variantes raras por indivíduo sejam suficientes para explicar o fenótipo. 


\section{FATORES AMBIENTAIS DE SUSCEPTIBILIDADE ÀS FO-NS}

A identificação dos fatores ambientais de susceptibilidade as $\mathrm{FO}$ e suas interações com os genes é limitada pois esse tipo de estudo exige uma abordagem complexa, com uma excelente coleta de dados, acesso ao material genético e um tamanho amostral expressivo (Peter A Mossey et al., 2009; Watkins et al., 2014).

Apesar disso, alguns fatores de risco ambientais às FO-NS já foram relacionados e replicados. Tabagismo, consumo de álcool e a nutrição materna são os três fatores de risco mais considerados (Dixon et al., 2011; Peter A Mossey et al., 2009; Vieira, 2012; Watkins et al., 2014). Baixo nível socioeconômico também já foi associado às FO em algumas populações (Alfwaress, Khwaileh, Rawashdeh, Alomari, \& Nazzal, 2017; Clark, Mossey, Sharp, \& Little, 2003; Damiano et al., 2009). Populações em tais condições são mais expostas a agentes infecciosos, devido à insalubridade de moradia e situação de saneamento básico precárias.

Os estudos envolvendo as presentes associações não abordaram os mecanismos celulares e moleculares envolvidos na exposição a esses fatores de risco para que possam ocasionar as FO, porém, já se sabe que alguns desses fatores de risco influenciam a expressão gênica através de mudanças epigenéticas (Hou, Zhang, Wang, \& Baccarelli, 2012; Lee \& Pausova, 2013).

Nesse contexto, com o objetivo de associar fatores epigenéticos com as FONS, nosso grupo recentemente conduziu um trabalho de associação epigenômica em que se concluiu que indivíduos com FO-NS possuem um padrão epigenético distinto de indivíduos controle (Alvizi et al., 2017). Foram associados e replicados em amostras independentes 11 sítios com metilação diferencial entre pacientes e controles em genes pertencentes a vias importantes para o desenvolvimento craniofacial (Alvizi et al., 2017). Por fim, também foi observado que o padrão de metilação de DNA se correlaciona com a penetrância do fenótipo em casos segregando FO-NS e mutações no CDH1 (Alvizi et al., 2017).

Esses dados reforçam a importância de investigar fatores ambientais que podem estar contribuindo, por exemplo, através de alterações epigenéticas, com a etiologia das FO-NS. 


\section{O microbioma oral como fator etiológico de susceptibilidade às FO-NS}

O microbioma oral é um ecossistema complexo que inclui milhares de tipos bacterianos presentes na boca humana, e a transição entre o estado sadio e a doença (devido à mudança do microbioma) ainda não é bem compreendida. Estudos mostraram que a microbiota oral predominante é largamente consistente entre indivíduos sadios (Bik et al., 2010; Wade, 2013), e embora esta microbiota seja considerada não patogênica e comensal, algumas bactérias podem ser prejudiciais e são responsáveis por doenças orais como cáries e infecção periodontal. Além disso, há evidências de que alterações de composição do microbioma humano podem estar envolvidas na etiologia de vários cânceres, alergia, arteriosclerose, obesidade e doenças cardiovasculares (Feil \& Fraga, 2012; Handel, Ebers, \& Ramagopalan, 2010). (Bánhidy, Acs, Puhó, \& Czeizel, 2010).

Acredita-se que o mecanismo pelo qual a composição do microbioma poderia estar relacionada a uma doença séria através da sua influência sobre modificações epigenéticas, o que, por sua vez, levaria a alterações de expressão gênica. A microbiota produz importantes subprodutos bioativos e outros compostos de baixo peso molecular que, além de atuarem diretamente nos processos epigenéticos, também contribuem para a absorção e excreção de minerais e outros co-fatores de enzimas participantes destes processos. Esses subprodutos bioativos, ao promoverem modificações epigenéticas, poderiam consequentemente atuar e regular diversos processos celulares como apoptose, diferenciação e inflamação celular (Feil \& Fraga, 2012; Handel, Ebers, \& Ramagopalan, 2010). Diferentemente do que se sempre acreditou, estudos recentes demonstraram que a placenta não é um órgão estéril (Aagaard et al., 2012, 2013, 2014; Fardini, Chung, Dumm, Joshi, \& Han, 2010; Guttmacher, Maddox, \& Spong, 2014; Proctor, 2011) e que, além disso, sua microbiota é muito similar a microbiota oral (Aagaard et al., 2014). Paralelo a esse fato, outros estudos observaram que alguns microrganismos comumente presentes em infecções na boca, podem modular a permeabilidade dos vasos sanguíneos permitindo que outros microrganismos alcancem a corrente sanguínea (Fardini et al., 2010) e assim possam semear a placenta.

Infecções periodontais são comuns em mulheres grávidas e estes microrganismos têm o potencial de se disseminar através do corpo sendo associados a parto prematuro, baixo peso fetal, doença cardiovascular, diabetes mellitus e 
infecções respiratórias (Mor \& Kwon, 2015). Foi visto que mulheres que tiveram infecção bacteriana durante o primeiro e segundo trimestre de gestação tem "impressões digitais" dos microrganismos em suas placentas e que a microbiota de placentas de bebês prematuros tinha diferente coleção de microrganismos quando comparados com placentas de bebês com gestação normal (Aagaard et al., 2012, 2014). Além disso, um outro estudo mostrou que infecção periodontal materna durante a gestação aumenta o risco de o embrião ter FO-NS (Bánhidy et al., 2010).

Assim, levanta-se a hipótese de que agentes infecciosos poderiam representar um fator de risco para o desenvolvimento embrionário, uma vez que poderiam levar a alterações epigenéticas do embrião, particularmente em casos de mulheres expostas a ambientes adversos durante a gestação (Gur et al., 2017). 


\section{Objetivos}

O principal objetivo desse estudo foi a busca por novos fatores de susceptibilidade às FO-NS, focando em variantes genéticas raras e microbioma oral dentre os fatores genéticos e ambientais, respectivamente.

Os objetivos específicos foram:

1. Identificar variantes genéticas raras de susceptibilidade às FO-NS, utilizando sequenciamento de nova geração para investigar um painel de genes candidatos.

2. Verificar se há enriquecimento de variantes raras presentes em genes candidatos que ainda não foram associados a FO-NS em indivíduos com FO-NS;

3. Verificar se há enriquecimento de variantes raras presentes em genes associados a FO-S em indivíduos com FO-NS;

4. Verificar se o microbioma oral de mães de crianças FO-NS é distinto do microbioma de mães de crianças não afetadas. 


\section{Capítulo 2}

\section{Non-syndromic orofacial clefts: enrichment of rare loss-of-function variants in genes under selective constraint}

Faria, Ágatha Cristhina ${ }^{1}$; Savastano, Clarice Pagani1; Almeida, Tatiana Ferreira ${ }^{1}$;

Ezquina, Suzana ${ }^{1}$; Yamamoto, Guilherme Lopes ${ }^{1}$; Passos-Bueno, M.R. ${ }^{1}$; Brito, Luciano Abreu ${ }^{1}$

${ }^{1}$ Centro de Pesquisa sobre o Genoma Humano e Células-Tronco, Departamento de Genética e Biologia Evolutiva, Instituto de Biociências, Universidade de São Paulo, São Paulo, Brazil. 


\begin{abstract}
A worldwide effort has been done to dissect the genetic architecture of nonsyndromic orofacial clefts (nsOFC), a group of common and heterogeneous disorders. In addition to common susceptibility variants, rare variants have been identified through next-generation sequencing, and have also shown to contribute to nsOFC etiology. However, the identification of truly pathogenic rare variants remains elusive in most cases. Here, our aim was to verify the contribution of rare missense and lossof-function (LoF) variants in candidate genes to nsOFC. We analyzed targeted sequencing of 68 genes in 193 nsOFC probands belonging to multiplex families, using in silico tools and the variant interpretation guidelines of the American College of Medical Genetics and Genomics (ACMG). We identified 72 rare variants predicted in silico as pathogenic, of which 9 variants (4.6\% of the probands), in 7 genes (ARHGAP29, BMP4, BRCA1, CDH1, EVC, SHH and TFAP2A), were classified as pathogenic according to ACMG framework. We observed an enrichment of LoF rare variants in genes under selective constraint in nsOFC individuals. Our data, together with the current literature, support the important role of that LoF variants in nsOFC etiology, and suggest the use of gene constraint metrics as filtering parameter in NGS studies of familial nsOFC.
\end{abstract}

Keywords: Exome. ExAC. Next-Generation Sequencing. Pathogenicity. Protein-disrupting variants. ACMG. Syndromic Cleft Lip and/or Palate. 


\section{Resumo}

Diversos estudos em todo o mundo sido realizados na tentativa de elucidar a arquitetura genética das fissuras orofaciais não sindrômicas (nsFO). Além das variantes de suscetibilidade comuns, variantes raras têm sido identificadas, através do sequenciamento de nova geração (NGS), e também mostraram contribuir para a etiologia das nsFO. No entanto, a identificação de variantes raras verdadeiramente patogênicas permanece indefinida na maioria dos casos. Nosso objetivo nesse estudo foi verificar a contribuição de variantes raras do tipo missense e de perda de função (LoF) em genes candidatos para nsFO. Para isso, analisamos o sequenciamento de 68 genes em 193 indivíduos com nsFO pertencentes a famílias multiplex, usando ferramentas de predição in silico juntamente com as diretrizes de interpretação de variantes do American College of Medical Genetics and Genomics (ACMG). Foram identificadas 72 variantes raras preditas in silico como patogênicas, das quais 9 variantes (4,6\% dos probandos), em 7 genes (ARHGAP29, BMP4, BRCA1, CDH1, EVC, SHH e TFAP2A), foram classificadas como patogênicas de acordo com os critérios ACMG. Observamos um enriquecimento de variantes raras do tipo LoF em genes sob pressão seletiva em indivíduos com nsFO. Nossos dados, juntamente com a literatura atual, apoiam o importante papel das variantes de LoF na etiologia das nsFO e sugerem o uso de métricas de intolerância a mutações como parâmetro de filtragem em estudos utilizando NGS em nsFO familial.

Palavras-chave: Exoma. ExAC. Sequenciamento de Nova Geração. Patogenicidade. Variantes disruptivas de proteínas. ACMG. Fissura de Lábio e/ou Palato Sindrômico. 


\section{Introduction}

Orofacial clefts (OFC) are the most prevalent human craniofacial malformation affecting about 1/700 live born children worldwide, varying according to ethnicity, gender and socio-economic status (Mossey, Little, Munger, Dixon, \& Shaw, 2009). OFC includes isolated cleft palate (CP), and cleft lip with or without cleft palate (CL/P), which are believed to represent etiologically distinct malformations. Approximately $30 \%$ of $\mathrm{CL} / \mathrm{P}$ and $50 \%$ of $\mathrm{CP}$ are syndromic (sOFC), occurring in combination with other cognitive or developmental anomalies, and may be caused by teratogens, chromosomal anomalies or pathogenic variants in single genes with strongly deleterious effect on the protein's function (Mossey et al., 2009). In contrast, the remaining $70 \%$ of $\mathrm{CL} / \mathrm{P}$ and $50 \%$ of $\mathrm{CP}$ are non-syndromic, occurring as isolated defects with no other apparent cognitive or craniofacial abnormalities or craniofacial dysmorphisms (Mossey et al., 2009).

Non-syndromic OFC (nsOFC) etiology is complex and heterogeneous and multifactorial pattern of inheritance is the most likely scenario for the majority of cases (Dixon, Marazita, Beaty, \& Murray, 2011; Mossey et al., 2009). Despite several genomic loci associated with risk for nsOFC (particularly for non-syndromic CL/P, $n s C L / P$ ), identified through linkage and genome-wide association studies (GWAS), only a small percentage of their heritability can be explained (Terri $\mathrm{H}$ Beaty, Marazita, \& Leslie, 2016; Losee \& Kirschner, 2015). Next-generation sequencing (NGS) have accelerated the discovery of new rare variants of moderate-to-high effect in nsOFC patients, which may help to explain the disease's heritability (Basha et al., 2018; Cox et al., 2018; Holzinger et al., 2017; Elizabeth J. Leslie \& Marazita, 2015; Mangold et al., 2016; Rodriguez et al., 2018; Takahashi et al., 2018; Zhao et al., 2018). However, the success of these approaches has been limited, in part, due to the complex inheritance of nsOFC and the difficulty to define the pathogenicity of variants, especially for missense variants. It is of note that most pathogenic rare variants recently identified in nsOFC are loss-of-function (LoF) variants, as in the case for CDH1 and ARHGAP29 (Brito et al., 2015; Savastano et al., 2017).

Our aim is to verify the contribution of rare missense and LoF variants in 68 
candidate genes to nsOFC segregating under autosomal dominant model with variable penetrance.

\section{Methods}

\section{Ethical compliance}

This study was approved by the Ethics Committee of the Instituto de Biociências (Universidade de São Paulo, Brazil) (CAAE: 37287314.6.0000.5464). Biological samples were obtained after signed informed consent by the patients, parents or legal guardians.

\section{Sample collection and DNA extraction}

One hundred ninety-three unrelated Brazilian multiplex families segregating nsOFC (181 CL/P and $12 \mathrm{CP}$ ) were included in this study (Table S1, Supporting information). Patients were ascertained at the Hospital das Clínicas of Universidade de São Paulo (São Paulo; n=24), Hospital Sobrapar (University of Campinas, São Paulo; $n=1$ ), Hospital Menino Jesus (São Paulo; $n=8$ ), Hospital Universitário Clementino Fraga Filho (Rio de Janeiro; $n=7$ ), and during medical programs of Operation Smile Brazil in the cities of Fortaleza-CE $(n=46)$, Maceió-AL $(n=12)$, Porto Velho-RO $(n=4)$, Rio de Janeiro-RJ $(n=38)$, Santarém-PA $(n=53)$ (Table S1, Supporting information). Clinical evaluation was performed for all probands, and only non-syndromic patients were included in this study. Affected relatives were not ascertained by us, and their clinical data were reported by the probands or their parents during the consultation. The number of families presenting one, two and three or more affected relatives, in addition to the proband, was, respectively, $126(67 \%)$, $46(22 \%)$ and $21(11 \%)$. Among all affected relatives, the proportion of first, second and third-degree relationships with the probands were, respectively, $26 \%(n=76), 17 \%$ $(n=49)$ and $18 \%(n=54) ; 39 \%(n=116)$ were related with the proband in fourth or higher degree (Table S1, Supporting information). Informed consent was obtained prior to 
sample collection (whole blood or saliva). Whenever possible, DNA samples were also obtained from the parents or affected relatives.

DNA samples were extracted either from whole blood (collected with BD Vacutainer® EDTA tubes; Becton, Dickinson and Company, Bergen County, NJ, United States of America) or saliva (collected with Oragene® DNA Collection Kits OG500 and OG-575; DNA Genotek, Ottawa, ON, Canada) and purified following manufacturer's instructions.

\section{Targeted sequencing of OFC patients}

Targeted sequencing of 68 candidate genes (coding regions and exon-intron boundaries; Table S2, Supporting information) were performed with Illumina MiSeq sequencer (Illumina, San Diego, CA), using Nextera XT DNA Library Prep Kit (Illumina, San Diego, CA). Of these 68 genes, 47 are associated with of monogenic syndromes involving orofacial clefts. The other genes were mapped within GWAS-associated regions $(n=7)$ or play roles in craniofacial development $(n=12)$. We have also included two genes that were considered candidates based on transcriptome analysis of stem cells of OFC patients as compared to controls (BRCA1; (Kobayashi et al., 2013)) or based on the eQTL study conducted by our group (NOL8, (Masotti et al., 2018)) (Table S2, Supporting information).

KAPA Library Quantification kit (KAPA Biosystems, Wilmington, MA) was used to quantify the libraries by real-time quantitative PCR. Sequence reads were aligned to the human reference genome (assembly GRCh37/hg19) using Burrows-Wheeler Aligner (BWA; http://bio-bwa.sourceforge.net). Data processing, variant calling, and variant annotation were performed with Picard (http://broadinstitute.github.io/picard/), Genome Analysis Toolkit package (GATK; https://www.broadinstitute.org/gatk/) and ANNOVAR (http://www.openbioinformatics.org/annovar/), respectively. Whole exome and targeted sequencing mean coverage for these 68 genes were, respectively, $69 x$ and 136x; percentage of bases presenting minimal coverage of 20x were, respectively, $63 \%$ and $88 \%$ 


\section{Variant filtering and in silico analysis of probands and controls data}

We used, as controls, in-house whole exome sequencing data of 609 healthy Brazilians from ABraOM database, which are quite representative of the Brazilian population (Naslavsky et al., 2017), and retrieved all variants present in the 68 genes. For patients and controls, all variants located within exons and in two intronic bases adjacent to exons (both 5' and 3' boundaries) were called. Consequently, the same genomic regions were analyzed independently of the sequencing methodology (whole exome or targeted sequencing).

Rare variants (minor allele frequency $<0.5 \%$ ) were prioritized according to frequencies in public databases (1000 Genomes Project Consortium (1000g), Exome Sequencing Project (esp6500, NHLBI Exome Variant Server (ESP), http://evs.gs.washington.edu/EVS), Exome Aggregation Consortium (ExAC, http://exac.broadinstitute.org) and gnomAD (Genome Aggregation Database http://gnomad.broadinstitute.org/).

As quality control (QC) of heterozygous variants, we retained for further analysis only those with minimum coverage of 20 reads, Phred score $(Q)>30$ and allelic balance between $0.3-0.7$; for homozygous variants, minimum coverage of 10 reads, $Q>30$ and at least $90 \%$ of reads for the alternative allele were used as inclusion criteria.

We also removed variants presenting strand bias, i.e., variants which read are mapped preferentially to forward or reverse strand, according to (Yamamoto, 2017). Subsequently, the selected variants from both patients and controls were visually inspected on the IGV in order to assure against false positives.

For all coding genes, only missense and loss-of-function variants (nonsense, canonical splice sites - splice dinucleotides: $+1,+2,-1,-2$ - and frameshift indels) were included in our analyses. We also classified these variants based on in silico pathogenicity scores: we considered as "predicted damaging" (PD) all missense variants predicted to be "possibly damaging" or "probably damaging" by Polyphen-2, "deleterious" by SIFT, and with CADD score reported to be greater than 20; all LoF variants were also considered as PD. We checked gene intolerance for missense and 
loss-of-function variants using, respectively, the z-scores and pLI (probability of intolerance to a LoF variant), available on ExAC database (Lek et al., 2016). PD variants were further classified following the guidelines for interpretation of genetic variants established by the American College of Medical Genetics and Genomics (ACMG) (Richards et al., 2015) as "likely pathogenic" or "pathogenic" and "benign", "likely benign" or "variant of uncertain significance" (VUS). Variants classified by ACMG guidelines as "likely pathogenic" or "pathogenic" were described here as pathogenic/ACMG-pathogenic.

\section{Segregation analysis}

Of the probands with ACMG-pathogenic variants, we were able to do segregation analysis in two families of which DNA samples from relatives were available. We investigated variant segregation by Sanger sequencing, using BigDye ${ }^{\circledR}$ Terminator v3.1 Cycle Sequencing Kit (Thermo Fisher Scientific, Waltham, MA, USA). Products were sequenced in an ABI 3730 DNA Analyzer (Thermo Fisher Scientific, Waltham, MA, USA) and data were analyzed with the Sequencher ${ }^{\circledR}$ version 5.1 DNA sequence analysis Software (Gene Codes Corporation, Ann Arbor, MI, USA, http://www.genecodes.com). The genomic position of variants are based on the hg19/GRCH37 version of the human reference genome (Genome Reference Consortium - http://www.ncbi.nlm.nih.gov/projects/genome/assembly/grc/) and cDNA positions refer to the sequences NM_007297 (BRCA1) and NM_000193 (SHH) (NCBI Reference Sequence Database - http://www.ncbi.nlm.nih.gov/refseq/).

\section{Statistical analysis}

We used a Two-tailed Fisher's exact to compare the proportion of patients and controls carrying rare variants and a Cohort Allelic Sums Test (CAST) (Morgenthaler \& Thilly, 2007) to investigate the burden of rare pathogenic variants identified in these groups. 


\section{Results}

\section{Rare variant analysis in OFC probands as compared to controls}

Among the 6 miRNAs included in the panel, no rare variant passed the quality controls, neither for patients or controls. Among the 62 coding genes analyzed, we identified 72 rare variants (62 missense and $10 \mathrm{LoF}$ ) predicted as damaging (referred as PD) by in silico tools in 36 genes, in 59 out of 193 nsOFC probands (ratio of 0.37 variant:proband). In ABraOM controls, we identified 285 PD variants (265 missense and 20 LoF) in 46 genes, in 232 out of 609 individuals (ratio of 0.47 variant:control). Pathogenicity classification of these PD variants according to the ACMG variant classification guidelines showed that only 9 variants in patients were classified as “likely pathogenic” or 'pathogenic' (herein referred as ACMG-pathogenic variants): 7 LoF located in ARHGAP29, BRCA1, CDH1, EVC and SHH and 2 missense variants located in BMP4 and TFAP2A (Table 1). All individuals harboring ACMG-pathogenic variants are affected by nsCL/P (Table S1, Supporting information). Among controls, 8 ACMG-pathogenic variants were identified: 3 LoF, located in DYNC2H1 and SLC26A2, and 5 missense variants, located in DYNC2H1, GNAI3, POLR1D and TP63 (Table 1).

Frequency of ACMG-pathogenic variants was significantly higher in OFC probands $(9 / 193=4.7 \%)$, as compared to controls $(8 / 609=1.31 \%$; CAST: $p=0.0005$; Fisher's exact test: $p=0.0089)$. Splitting this analysis by variant type, the difference remains significant for LoF variants (patients: $7 / 193=3.62 \%$; controls: $3 / 609=0.49 \%$; CAST: $p=0.000256$ Fisher's exact test: $p=0.0026)$, but not for missense variants (patients: $2 / 193=1 \%$; controls: 5/609, 0.82\%; CAST: $p=0.23$; Fisher's exact test: $p=0.67)$.

We next investigated if the ACMG-pathogenic variants occurred preferentially in genes under selective pressure, based on ExAC gene constraint scores. We noticed that 5 out of the 7 LoF ACMG-pathogenic variants in nsOFC probands were in genes with $\mathrm{pLI}>=0.3$ (SHH,CDH1, and ARHGAP29), while the 3 LoF-ACMG-pathogenic variants in controls were in genes with $\mathrm{pLI}=0$. This difference was statistically 
significant (patients: $5 / 193=2.6 \%$; controls: $0 / 609$; CAST: $p=4.3 e-05$; Fisher's exact test: $p=0.0008$ ). For ACMG-pathogenic missense variants, one out of 2 variants in patients and none of 5 variants in controls were in genes with Z score $>3$ (Table 1), which represents a non-significant difference (patients: 1/193, 0.5\%; controls: 0/609; Fisher's exact test: $p=0.24$ ). 
Table 1 - Rare, ACMG-pathogenic variants identified in probands and controls

\begin{tabular}{|c|c|c|c|c|c|c|c|c|}
\hline Family & Variant type & Gene & Variant & ExAC frequency ${ }^{\dagger}$ & $\mathrm{pLI}^{\dagger}$ & Z-score ${ }^{\dagger}$ & ACMG $^{\ddagger}$ & ACा \\
\hline F4861 & stop-gain & ARHGAP29 & NM_004815:c.1475C>A:p.Ser492* & 0 & 1 & $-0,27$ & PVS1/PM2/PP3/PP5: Pathogenic & 1 \\
\hline F9121 & splicing & ARHGAP29 & NM_004815:c.2109+1G>A & $8.24 \mathrm{e}-06$ & 1 & $-0,27$ & PVS1/PM2/PP3: Likely pathogenic & 1 \\
\hline F4118 & splicing & ARHGAP29 & NM_004815:c.698-1G>C & 0 & 1 & $-0,27$ & PVS1/PM2/PP3: Likely pathogenic & 1 \\
\hline F7787 & missense & BMP4 & NM_001202:c.244T>C:p.Tyr82His & 0 & 0,97 & 1,91 & PM1/PM2/PP2/PP3: Likely pathogenic & 1 \\
\hline F10378 & frameshift insertion & $B R C A 1$ & NM_007297:c.5125dup:p.Gln1709Profs*74 & 0 & 0 & $-1,26$ & PVS1/PM2/PP1/PP3/PP5: Pathogenic & 1 \\
\hline F7606 & stop-gain & $C D H 1$ & NM_001317184:c.1023T>G:p.Tyr341* & 0 & 0,34 & 0,81 & PVS1/PM2/PP5/BP6: Pathogenic & 1 \\
\hline F8104 & stop-gain & $E V C$ & NM_001306090:c.1678G>T:p.Glu560* & 0 & 0 & $-1,4$ & PVS1/PM2/PP3: Pathogenic & 1 \\
\hline F9112 & splicing & $\mathrm{SHH}$ & NM_000193:c.300+1G>A & 0 & 0,9 & 4,42 & PVS1/PS3/PS4/PP1/PP4/PM2: Pathogenic & 1 \\
\hline F2670 & missense & TFAP2A & NM_001032280:c.1163C>T:p.Ala388Val & 0.0001 & 0,99 & 4,04 & PM1/PM2/PP2/PP3: Likely pathogenic & 1 \\
\hline Control & stop-gain & DYNC2H1 & NM_001080463:c.6181G>T:p.Glu2061* & 0 & 0 & $-2,46$ & PVS1/PM2/PP3: Pathogenic & 1 \\
\hline Control & missense & DYNC2H1 & NM_001080463:c.9044A>G:p.Asp3015Gly & 0.0003 & 0 & $-2,46$ & PM1/PM2/PP3/PP5: Likely Pathogenic & 1 \\
\hline Control & missense & GNAI3 & NM_006496:c.1028T>C:p.lle343Thr & 0 & 0,04 & 1,85 & PM1/PM2/PP2/PP3: Likely pathogenic & 1 \\
\hline Control & missense & POLR1D & NM_015972:c.329T>C:p.Val110Ala & 0.0002 & 0,26 & 0,19 & PM1/PM2/PP2/PP3/BS2: Likely Pathogenic & 1 \\
\hline Control & stop-gain & SLC26A2 & NM_000112:c.532C>T:p.Arg178* & 0.0001 & 0 & $-1,37$ & PVS1/PS3/PM2/PP3/PP5: Pathogenic & 2 \\
\hline Control & missense & TP63 & NM_003722:c.1136G>A:p.Arg379His & 0.0165 & 0,98 & 2,65 & PM1/PP2/PP3: Likely Pathogenic & 1 \\
\hline Control & missense & TP63 & NM_003722:c.1814G>A:p.Arg605GIn & 0.0001 & 0,98 & 2,65 & PM1/PM2/PP2/PP3: Likely Pathogenic & 1 \\
\hline
\end{tabular}

Legend: $\dagger=$ Populational frequency and probability of intolerance to loss-of-function (LoF) (pLI) and missense (Z-score) variants available in Exome Aggregation Consortium (ExAC) database. $¥=$ variant classification following ACMG guidelines. PVS1: null variant in a gene where LoF is a known mechanism of disease. PM1: Located in a mutational hot spot and/or critical and well-established functional domain) without benign variation. PM2: Absent from controls in databases.

PP1: Cosegregation with disease in multiple affected family members in a gene definitively known to cause the disease. PP2: Missense variant in a gene that has a low rate of benign missense variation and in which missense variants are a common mechanism of disease. PP3: Multiple lines of computational evidence support a deleterious effect on the gene or gene product. PP4: Patient's phenotype or family history is highly specific for a disease with a single genetic etiology PP5: Reputable source recently reports variant as pathogenic, but the evidence is not available to the laboratory to perform an independent evaluation. PS3: Well-established in vitro or in vivo functional studies supportive of a damaging effect on the gene or gene product. PS4: Prevalence of the variant in affected individuals significantly increased compared with controls. BS2: Observed in a healthy adult individual for a recessive (homozygous), dominant (heterozygous), or X-linked (hemizygous) disorder, with full penetrance expected at an early age. BP6: Reputable source recently reports variant as benign, but the evidence is not available to the laboratory to perform an independent evaluation. $\mathbb{I}$ = number of alleles counted in each group (probands or controls). 


\section{Families with ACMG-pathogenic variants}

Segregation analysis was only possible to be performed in four of the families harboring ACMG-pathogenic variants (Figure 1). The frameshift insertion in BRCA1 (NM_007297:c.5125dup:p.Gln1709profs*74), present in patient F10378, was not inherited from the proband's mother, whose aunt presents nsOFC. The splicing variant in SHH (NM_000193:C.300+1G>A), present in F9112, was inherited from the affected father. In light of these findings, we reevaluated this family, and verified that a child has been born with clinical signs compatible with holoprosencephaly (midline CL and hypotelorism), and in which the variant also segregated. Pathogenic variants of F4118 and F7606 segregated with the phenotype, under autosomal dominant model with incomplete penetrance, as reported elsewhere (Brito et al., 2015; Savastano et al., 2017) 
F4861-ARHGAP29
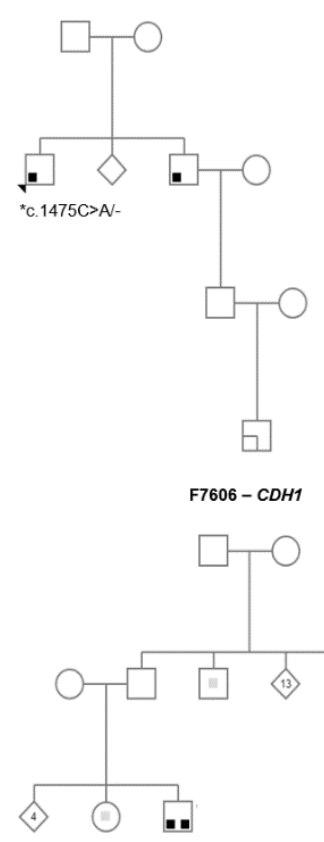

$\approx 0.1023 T>\mathrm{G} /-$
F9121 - ARHGAP29

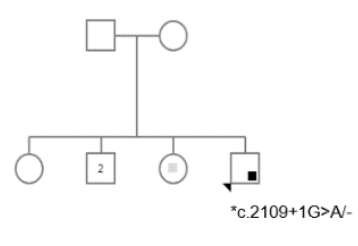

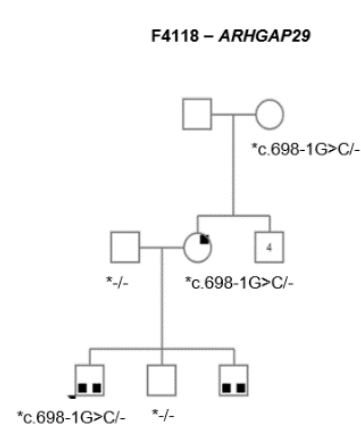

F8104-EVC

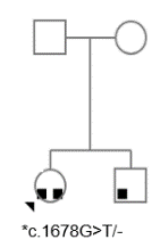

F7787-BMP4

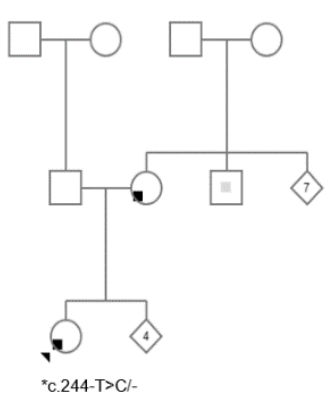

F2670 - TFAP2A

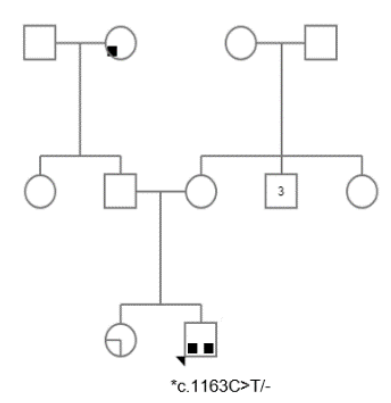

F10378- BRCA1

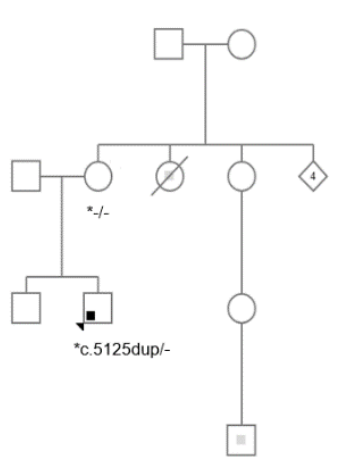
- Uniateral cleft lip with or without palate
Unilateral cleft lip with or without palate
(left)
Cleft lip with or without deff palate (for
specifed)
- Midline cleft lip with or without palate
.. Biateral deft lip w
$\square$ Healed cleft lip

Figure 1 - Pedigrees of families harboring ACMG-pathogenic variants 


\section{Discussion}

The use of high throughput sequencing technologies, as targeted sequencing of candidate genes, has allowed the discovery of private and rare pathogenic variants in individuals with nsOFC, providing elements to explore monogenic and oligogenic disease models. However, despite the in silico pathogenicity prediction tools available, which helps the prioritization of candidate pathogenic variants, a major bottleneck in this field still relates to interpret which of them are indeed involved in the pathogenesis of the disease (Ernst et al., 2018; Maxwell et al., 2016; Richards et al., 2015; Shah et al., 2018).

We identified 9 rare ACMG-pathogenic variants in 68 genes in 193 probands of multiplex families with nsOFC. Two variants were missense, in BMP4 (NM_001202:c.244T>C:p.Tyr82His) and TFAP2A (NM_001032280:c.1163C>T:p.Ala388Val). Haploinsufficiency of these genes has been implicated with syndromic forms of CP: microphthalmia type 6 (BMP4, OMIM: 607932), and Branchiooculofacial syndrome (TFAP2A; OMIM:113620). Nevertheless, they have also been associated with $\mathrm{nsCL} / \mathrm{P}$, either by association (BMP4, TFAP2A), linkage (BMP4) and sequencing studies (BMP4) (Babu Gurramkonda, Syed, Murthy, \& V K S Lakkakula, 2016; Terri H Beaty et al., 2016; de Araujo et al., 2016; Marazita et al., 2009; Martinelli et al., 2011). In addition, a microdeletion encompassing TFAP2A was found in a patient affected by CL/P and congenital heart defect (Shi et al., 2009) while six rare missense BMP4 variants have been reported in conserved regions of TGF beta polypeptide domain of BMP4, in individuals with microforms of nsCL/P (Suzuki et al., 2009). Interestingly, the BMP4 variant here reported falls in this same protein domain. It is thus possible that the pathogenic variants identified in BMP4 and TFAP2A contribute, with unknown size effect, to nsCL/P phenotype, rather than to a mild phenotype of syndromic forms.

The other ACMG-pathogenic variants in patients include 7 heterozygous LoF variants in 5 genes. Three of these variants are in ARHGAP29 and one in CDH1. ARHGAP29 was first implicated with nsCL/P by GWAS studies (Terri H Beaty et al., 
2010) and, most recently, by NGS studies. To date, all cases of LoF variants reported in ARHGAP29 are represented by familial nsOFC (Liu et al., 2017; Savastano et al., 2017). On the other hand, LoF variants in $C D H 1$ have been associated both with familial nsOFC and Blepharocheilodontic syndrome (OMIM: 119580), which includes OFC in the phenotype and could be mistaken by nsOFC in mild cases (Brito et al., 2015; Ittiwut et al., 2016; E J Leslie \& Murray, 2013). The molecular mechanisms responsible for the spectrum of clinical variability caused by LoF heterozygous variants in $C D H 1$ are still unknown, but epigenetics seems to be involved (Alvizi et al., 2017).

Lastly, 3 variants were identified in two genes associated with sOFC ( $\mathrm{SHH}$ and $E V C)$ and in one gene associated with nsOFC by functional and case-control studies (BRCA1) (Kobayashi et al., 2013; Rodriguez et al., 2018). The variant in $S H H$ is within a canonical splice site (NM_000193:c.300+1G>A) and segregates with OFC in the family F9112 (Figure 1). Although the proband had initially been classified as nonsyndromic unilateral $\mathrm{CL} / \mathrm{P}$, we observed, during a clinical reassessment, mild nonsyndromic holoprosencephaly (HPE, OMIM: 142945) in the affected relatives. In view of this findings, this variant is therefore implicated with familial HPE with intra-familial clinical variability. Clinical variability due to LoF variants in $S H H$ has been reported elsewhere, and includes unilateral cleft lip (Dubourg et al., 2018; Kruszka, Martinez, \& Muenke, 2018). Our results further illustrate the difficulties in recognizing mild syndromic forms of OFC, particularly in very young children. The stop-gain variant in EVC(NM_001306090:c.1678G>T;p.Glu560*), found in heterozigosity in patient F8104 and predicted to generate a 431-amino acid shortened protein, has previously been described in a compound heterozygous individual with Ellis-van Creveld syndrome (EvC, OMIM: 225500) (Valencia et al., 2009), a recessive skeletal dysplasia with presentation of CL/P in some patients. Given our patient presents only bilateral cleft lip and palate, it is unlikely to be affected by a mild form of EvC; however, the role of this variant as a modifier or contributing locus in an oligogenic or multifactorial model for nsCL/P cannot be discarded.

The remaining variant, a frameshift insertion in BRCA1 in patient F10378 (NM_007297:c.5125dup:p.Gln1709profs`74; rs80357906) have previously been 
reported as pathogenic in hereditary breast and ovarian cancer (Simard et al., 1994; Trujillano et al., 2015). There has been increasing support that BRCA1 may be involved with the etiology of nsOFC (Kobayashi et al., 2013; Rodriguez et al., 2018). As the variant do not segregate with the phenotype in this family, it could either represent an incidental finding (unrelated to the disease) or a contributing locus under oligogenic or multifactorial model for nsCL/P. Further studies are necessary to elucidate the role of rare BRCA1 variant in nsCL/P etiology.

Pathogenic variants found among controls include 3 heterozygous LoF variants in genes implicated with autosomal recessive OFC syndromes (SLC26A and $D Y N C 2 H 1$, two variants) and 4 missense variants implicated in autosomal recessive (DYNC2H1, POLR1D) and dominant (TP63, two variants) syndromic OFC. The TP63 variants here reported are located out of the DNA-binding domain (DBD), where most of the pathogenic missense mutations were described for TP63 syndromes (Basha et al., 2018). While one variant is located in an unconserved region - p.(Arg279His) - , the other is located in the conserved Sterile Alpha Motif (SAM) - p.(Arg605GIn). However, as both variants have previously been described in databases, they seem to have no clinical relevance.

Apart from ARHGAP29, no pathogenic variant was found in the other genes in GWAS loci, including genes nearby the most important associated locus in 8q24 (Birnbaum et al., 2009) (MYC, PVT1 and the regulatory MIR1205, MIR1206, MIR1207 and MIR1208. Although recent evidences points to an important role of $M Y C$ enhancers in $8 q 24$, no rare, large effect variant has been found in the region in patients with nsCL/P.

Overall, we have found, in nsOFC patients, a higher frequency of ACMGpathogenic variants in a set of genes associated to syndromic OFC or to nsCL/P by GWAS. Among these ACMG-pathogenic variants, an enrichment of LoF variants in LoF-intolerant genes could also be observed in patients, as compared to controls, endorsing that LoF variants, in average, have a greater impact on liability than missense ones. It has been shown that all known genes involved with human disease caused by haploinsufficiency of gene product have a pLI score >0.9 (Lek et al., 2016). 
Moreover, despite clear evidence for extreme selective constraint, $72 \%$ of LoFintolerant genes have not yet been assigned to any human disease (Lek et al., 2016). In the present study, we observed that about $70 \%$ (5/7, 71.4\%) of the rare ACMGpathogenic variants found in probands were located in genes with $\mathrm{pLI}$ ranging from 0.3 $(C D H 1)$ to 1 (ARHGAP29). In agreement with this observation, all rare variants reported as causative of familial nsOFC that segregates as autosomal dominant with incomplete penetrance have been located in genes with $\mathrm{pLI}$ that varies from 0.3 to 1 (CDH1, ARHGAP29, IRF6, TP63, TBX1, LRP6, GRHL3, CTNND1, PLEKHA5, ESRP2) (Basha et al., 2018; Brito et al., 2015; Cox et al., 2018; Eshete et al., 2018; Khandelwal et al., 2017; Liu et al., 2017; Mangold et al., 2016; Savastano et al., 2017; Zhao et al., 2018). We thus highlight the use of a cutoff based on pLI score as a parameter to prioritize variants in NGS studies of familial nsOFC, assuming mono or oligogenic model of inheritance. 
Supplementary table 1 - Clinical information of the families segregating non-syndromic orofacial clefts

\begin{tabular}{|c|c|c|c|c|c|c|c|c|}
\hline \multirow[t]{2}{*}{ Probands } & \multirow[t]{2}{*}{ Cleft Type } & \multirow[t]{2}{*}{ Gender } & \multirow[t]{2}{*}{ Consanguinity } & \multicolumn{4}{|c|}{ Affected Relatives } & \multirow[b]{2}{*}{ Origin } \\
\hline & & & & $\begin{array}{l}\text { First } \\
\text { degree }\end{array}$ & $\begin{array}{l}\text { Second } \\
\text { degree }\end{array}$ & $\begin{array}{l}\text { Third } \\
\text { degree }\end{array}$ & $\begin{array}{l}\text { Fourth degree or } \\
\text { more }\end{array}$ & \\
\hline \multicolumn{9}{|c|}{ Patients harboring ACMG-pathogenic variants } \\
\hline F4861.1 & Left cleft lip and palate & M & No & $1(\mathrm{CL} / \mathrm{P})$ & & $1(\mathrm{CL} / \mathrm{P})$ & & Operation Smile, Rio de Janeiro \\
\hline F9121.1 & Left cleft lip and palate & M & No & $1(\mathrm{CL} / \mathrm{P})$ & & & & Operation Smile, Santarém \\
\hline F4118.1 & Bilateral cleft lip and palate & M & No & $2(\mathrm{CL} / \mathrm{P})$ & & & & Operation Smile, Santarém \\
\hline F7787.1 & $\begin{array}{l}\text { Left cleft lip and palate } \\
\text { Left cleft lip and incomplete cleft }\end{array}$ & $\mathrm{F}$ & No & $1(\mathrm{CL} / \mathrm{P})$ & $1(\mathrm{CL} / \mathrm{P})$ & & & Operation Smile, Rio de Janeiro \\
\hline F10378.1 & palate (hard palate) & M & No & & $1(\mathrm{CL} / \mathrm{P})$ & & $1(\mathrm{CL} / \mathrm{P})$ & Operation Smile, Fortaleza \\
\hline F7606.1 & Bilateral cleft lip and palate & M & No & & & $1(\mathrm{CL} / \mathrm{P})$ & $2(\mathrm{CL} / \mathrm{P})$ & Operation Smile, Fortaleza \\
\hline F8104.1 & Bilateral cleft lip and palate & $\mathrm{F}$ & No & $1(\mathrm{CL} / \mathrm{P})$ & & & & Operation Smile, Santarém \\
\hline F9112.1 & Left cleft lip and palate & $\mathrm{F}$ & No & $2(\mathrm{CL} / \mathrm{P})$ & & & & Operation Smile, Santarém \\
\hline F2670.1 & Bilateral cleft lip and palate & $\mathrm{M}$ & No & $1(\mathrm{CL} / \mathrm{P})$ & $1(\mathrm{CL} / \mathrm{P})$ & & & Operation Smile, Santarém \\
\hline \multicolumn{9}{|c|}{ Patients harboring predicted damaging variants } \\
\hline F7218.1 & Left cleft lip and palate & $\mathrm{M}$ & No & & $1(\mathrm{CL} / \mathrm{P})$ & & & UFRJ, Rio de Janeiro \\
\hline F10318.1 & Left cleft lip and palate & M & No & & & $1(\mathrm{CL} / \mathrm{P})$ & $2(\mathrm{CL} / \mathrm{P})$ & Hospital das Clínicas, São Paulo \\
\hline F10347.1 & Bilateral cleft lip and palate & M & No & & & $1(\mathrm{CL} / \mathrm{P})$ & & Operation Smile, Fortaleza \\
\hline F10473.1 & Right cleft lip and palate & $\mathrm{F}$ & No & & $1(\mathrm{CL} / \mathrm{P})$ & & & Operation Smile, Porto Velho \\
\hline F1773.4 & Cleft palate & $\mathrm{F}$ & No & $3(\mathrm{CL} / \mathrm{P})$ & & $1(\mathrm{CL} / \mathrm{P})$ & & Hospital Menino Jesus, São Paulo \\
\hline F185.1 & Right cleft lip and palate & M & No & $1(\mathrm{CL} / \mathrm{P})$ & & $1(\mathrm{CL} / \mathrm{P})$ & & Hospital das Clínicas, São Paulo \\
\hline F2633.1 & Bilateral cleft lip and palate & M & No & & & & $1(\mathrm{CL} / \mathrm{P})$ & Operation Smile, Santarém \\
\hline F2680.1 & Right cleft lip and palate & M & No & $1(\mathrm{CL} / \mathrm{P})$ & & $1(\mathrm{CL} / \mathrm{P})$ & $1(\mathrm{CL} / \mathrm{P})$ & Operation Smile, Santarém \\
\hline F3171.1 & Right cleft lip and palate & $\mathrm{F}$ & No & & & & $3(\mathrm{CL} / \mathrm{P})$ & Operation Smile, Fortaleza \\
\hline F4089.1 & Left cleft lip and palate & M & No & & & & $1(\mathrm{CL} / \mathrm{P})$ & Operation Smile, Santarém \\
\hline
\end{tabular}


F4135.1

F5129.1

F5232.1

F5326.1

F5534.1

F6073.1

F6208.1

F6389.1

F6390.1

F6395.1

F6445.1

F6464.1

F6603.1

F6634.1

F7391.1

F7398.1

F7399.1

F7412.1

F7564.1

F7591.1

F7620.1

F7648.1

F7782.1

F7783.1

F7786.1

F7788.1
Left cleft lip and palate

Bilateral cleft lip and palate

Left cleft lip and palate

Bilateral cleft lip and palate

Right cleft lip

Right cleft lip and palate

Right cleft lip and palate

Unilateral cleft lip

Left cleft lip and palate

Right cleft lip

Right cleft lip

Bilateral cleft lip and palate

Bilateral cleft lip and palate

Bilateral cleft lip and palate

Bilateral cleft lip and palate

Right cleft lip and palate

Bilateral cleft lip

Left cleft lip and palate

Right cleft lip and palate

Bilateral cleft lip and palate

Left cleft lip and palate

Bilateral cleft lip and palate

Right cleft lip and palate

Submucous cleft palate

Cleft palate

Bilateral cleft lip and palate
$2(\mathrm{CL} / \mathrm{P})$

$1(\mathrm{CL} / \mathrm{P})$

1 (NA)

$1(\mathrm{CL} / \mathrm{P})$

$1(\mathrm{CL} / \mathrm{P}) \quad 1(\mathrm{CL} / \mathrm{P})$

No

No

No

No

No

No

No

No

Yes (third

cousins)

No

No

No

No

No

No

No

No

No

No

No

No

No

\begin{tabular}{|c|c|c|c|}
\hline & & $2(\mathrm{CL} / \mathrm{P})$ & \\
\hline & & & $1(\mathrm{CL} / \mathrm{P})$ \\
\hline & & 1 (NA) & \\
\hline & & & $1(\mathrm{CL} / \mathrm{P})$ \\
\hline $1(\mathrm{CL} / \mathrm{P})$ & $1(\mathrm{CL} / \mathrm{P})$ & & \\
\hline & & & $1(\mathrm{CL} / \mathrm{P})$ \\
\hline & $1(\mathrm{CL} / \mathrm{P})$ & & \\
\hline 2 (CL/P) & & & \\
\hline $1(\mathrm{CL} / \mathrm{P})$ & & & \\
\hline & & $1(\mathrm{CL} / \mathrm{P})$ & \\
\hline 1 (CL/P) & $2(\mathrm{CL} / \mathrm{P})$ & $2(\mathrm{CL} / \mathrm{P})$ & \\
\hline & $1(\mathrm{CL} / \mathrm{P})$ & & $1(\mathrm{CL} / \mathrm{P})$ \\
\hline & $1(\mathrm{CL} / \mathrm{P})$ & $1(\mathrm{CL} / \mathrm{P})$ & $3(\mathrm{CL} / \mathrm{P})$ \\
\hline & $1(\mathrm{CL} / \mathrm{P})$ & & \\
\hline 1 (CL/P) & & $1(\mathrm{CL} / \mathrm{P})$ & \\
\hline & & $1(\mathrm{CL} / \mathrm{P})$ & \\
\hline 1 (NA) & & & \\
\hline & & 1 (NA) & \\
\hline 1 (CL/P) & & & \\
\hline & & & 2 (NA) \\
\hline & & & 2 (CP) \\
\hline & & 1 (NA) & $3(\mathrm{CL} / \mathrm{P})$ \\
\hline & 1 (CL/P) & & \\
\hline 1 (CP) & & & \\
\hline 1 (CP) & & & \\
\hline $1(\mathrm{CL} / \mathrm{P})$ & & & \\
\hline
\end{tabular}

Operation Smile, Santarém Operation Smile, Fortaleza Operation Smile, Fortaleza Operation Smile, Santarém Hospital das Clínicas, São Paulo Operation Smile, Santarém Operation Smile, Maceió Operation Smile, Rio de Janeiro Operation Smile, Rio de Janeiro Operation Smile, Rio de Janeiro Operation Smile, Rio de Janeiro Operation Smile, Rio de Janeiro

Hospital das Clínicas, São Paulo Operation Smile, Santarém Operation Smile, Maceió Operation Smile, Maceió Operation Smile, Maceió Operation Smile, Maceió Operation Smile, Fortaleza Operation Smile, Rio de Janeiro Operation Smile, Fortaleza Operation Smile, Fortaleza Operation Smile, Rio de Janeiro Operation Smile, Rio de Janeiro Operation Smile, Rio de Janeiro Operation Smile, Rio de Janeiro 


\begin{tabular}{|c|c|c|c|c|c|c|}
\hline F7789.1 & Left cleft lip & $\mathrm{F}$ & No & $1(\mathrm{CL} / \mathrm{P})$ & & \\
\hline F7810.3 & Cleft palate & M & No & $1(\mathrm{CP})$ & & \\
\hline F7822.1 & Cleft palate & $\mathrm{F}$ & No & & & $1(\mathrm{CL} / \mathrm{P})$ \\
\hline F7840.1 & Left cleft lip and palate & $\mathrm{F}$ & No & & & 2 (NA) \\
\hline F7928.3 & $\begin{array}{l}\text { Left cleft lip } \\
\text { Right cleft lip and incomplete cleft }\end{array}$ & $M$ & No & $1(\mathrm{CL} / \mathrm{P})$ & & \\
\hline F8073.1 & palate (hard palate) & $\mathrm{F}$ & No & & $1(\mathrm{CL} / \mathrm{P})$ & \\
\hline F8077.1 & Bilateral cleft lip and palate & M & No & & & $1(\mathrm{CL} / \mathrm{P})$ \\
\hline F8422.1 & Left cleft lip and palate & $M$ & No & 1 (NA) & & \\
\hline F8581.1 & Left cleft lip and palate & M & No & $2(\mathrm{CL} / \mathrm{P})$ & & \\
\hline F9064.1 & Left cleft lip and palate & $\mathrm{F}$ & No & $1(\mathrm{CL} / \mathrm{P})$ & & \\
\hline F9074.1 & Right cleft lip & $\mathrm{F}$ & No & & & $2(\mathrm{CL} / \mathrm{P})$ \\
\hline F9109.1 & Left cleft lip and palate & M & No & & & $2(\mathrm{CL} / \mathrm{P})$ \\
\hline F9116.1 & Left cleft lip and palate & $\mathrm{M}$ & No & & & $2(\mathrm{CL} / \mathrm{P})$ \\
\hline \multicolumn{7}{|c|}{$\begin{array}{l}\text { Patients without predicted damaging or ACMG- } \\
\text { pathogenic variants }\end{array}$} \\
\hline F1412.1 & Bilateral cleft lip and palate & $\mathrm{F}$ & Yes (first cousins) & $1(\mathrm{CL} / \mathrm{P})$ & & \\
\hline F5680.1 & Right cleft lip and palate & M & No & & $3(\mathrm{CL} / \mathrm{P})$ & $2(\mathrm{CL} / \mathrm{P})$ \\
\hline F7180.1 & Left cleft lip and palate & M & No & & $1(\mathrm{CL} / \mathrm{P})$ & \\
\hline F7366.1 & Bilateral cleft lip & M & No & $1(\mathrm{CL} / \mathrm{P})$ & & \\
\hline F7828.1 & Left cleft lip and palate & $\mathrm{F}$ & No & & & $1(\mathrm{CL} / \mathrm{P})$ \\
\hline F7948.1 & Right cleft lip and palate & $\mathrm{F}$ & No & & $1(\mathrm{CL} / \mathrm{P})$ & \\
\hline F8010.1 & Right cleft lip and palate & $\mathrm{F}$ & No & & $1(\mathrm{CL} / \mathrm{P})$ & \\
\hline F8041.1 & Right cleft lip and palate & M & No & $\begin{array}{l}1(\mathrm{CL} / \mathrm{P}+\text { intellectual } \\
\text { disability) }\end{array}$ & & 1 (NA) \\
\hline F8175.1 & Bilateral cleft lip and palate & $\mathrm{F}$ & No & & & $1(\mathrm{CL} / \mathrm{P})$ \\
\hline F10225.1 & Left cleft lip and palate & $\mathrm{F}$ & Unknown & & $1(\mathrm{CL} / \mathrm{P})$ & \\
\hline
\end{tabular}

Operation Smile, Rio de Janeiro Hospital Menino Jesus, São Paulo Hospital Menino Jesus, São Paulo Operation Smile, Rio de Janeiro Hospital Menino Jesus, São Paulo

Operation Smile, Santarém Operation Smile, Santarém Hospital das Clínicas, São Paulo Hospital das Clínicas, São Paulo Operation Smile, Santarém Operation Smile, Santarém Operation Smile, Santarém Operation Smile, Santarém

Hospital das Clínicas, São Paulo Hospital das Clínicas, São Paulo UFRJ, Rio de Janeiro UFRJ, Rio de Janeiro UFRJ, Rio de Janeiro UFRJ, Rio de Janeiro UFRJ, Rio de Janeiro

Operation Smile, Santarém UFRJ, Rio de Janeiro

Operation Smile, Santarém 


\begin{tabular}{ll} 
F10237.1 & Cleft palate \\
F10247.1 & Right cleft lip and palate \\
F10249.1 & Left cleft lip and palate \\
F10344.1 & Left cleft lip and palate \\
F10349.3 & $\begin{array}{l}\text { Right cleft lip and palate } \\
\text { Right cleft lip and incomplete cleft }\end{array}$ \\
F10359.1 & palate (hard palate) \\
F10383.1 & Bilateral cleft lip and palate \\
F10419.1 & Bilateral cleft lip and palate \\
F10472.1 & Left cleft lip and palate \\
F10516.1 & Bilateral Cleft lip and palate \\
F10521.1 & Bilateral Cleft lip and palate \\
F1347.1 & Bilateral cleft lip and palate \\
F1843.1 & Bilateral cleft lip and palate \\
F2634.1 & Left cleft lip \\
F2642.1 & Unilateral cleft lip \\
F2659.1 & Left cleft lip \\
F2666.1 & Left cleft lip and palate \\
F2674.1 & Bilateral cleft lip and palate \\
F2848.1 & Right cleft lip \\
F2895.1 & Left cleft lip and palate \\
F3210.1 & Bilateral cleft lip and palate \\
F3723.1 & Left cleft lip and palate \\
F3962.1 & Left cleft lip and palate \\
F3990.1 & Bilateral cleft lip and palate \\
F4033.1 & Left cleft lip and palate \\
F4121.1 & Left cleft lip and palate \\
\hline
\end{tabular}

\section{No}

No

No

No

Yes (third

cousins)

No

No

No

No

No

No

No

No

No

No

No

No

No

No

No

No

No

No

No

No
$1(\mathrm{CL} / \mathrm{P})$

$2(\mathrm{CL} / \mathrm{P})$

$1(\mathrm{CL} / \mathrm{P})$

$1(\mathrm{CL} / \mathrm{P})$

$1(\mathrm{CL} / \mathrm{P})$

$1(\mathrm{CL} / \mathrm{P})$

$1(\mathrm{CL} / \mathrm{P})$

$1(\mathrm{CL} / \mathrm{P})+1$ (NA)

2 (NA)

2 (NA)

$1(\mathrm{CL} / \mathrm{P})$

$\begin{array}{ll}4(\mathrm{CL} / \mathrm{P}) & 1(\mathrm{CL} / \mathrm{P}) \\ & 1(\mathrm{CL} / \mathrm{P})\end{array}$

2 (NA)

$1(\mathrm{CL} / \mathrm{P})$

$1(\mathrm{CL} / \mathrm{P})$

$1(\mathrm{CL} / \mathrm{P})$

1 (NA)

$1(\mathrm{CL} / \mathrm{P}) \quad 1(\mathrm{CL} / \mathrm{P})$

$1(\mathrm{CL} / \mathrm{P})$

$1(\mathrm{CL} / \mathrm{P}) \quad 3(\mathrm{CL} / \mathrm{P})$

$1(\mathrm{CL} / \mathrm{P}) \quad 1(\mathrm{CL} / \mathrm{P})$

$1(\mathrm{CL} / \mathrm{P})$

$1(\mathrm{CL} / \mathrm{P})$

$2(\mathrm{CL} / \mathrm{P})$

$1(\mathrm{CL} / \mathrm{P})$
Operation Smile, Santarém Operation Smile, Santarém Operation Smile, Santarém Operation Smile, Fortaleza Operation Smile, Fortaleza

Operation Smile, Fortaleza Operation Smile, Fortaleza Operation Smile, Fortaleza Operation Smile, Porto Velho Operation Smile, Porto Velho Operation Smile, Porto Velho Hospital das Clínicas, São Paulo Hospital Sobrapar, Campinas Operation Smile, Santarém Operation Smile, Santarém Operation Smile, Santarém Operation Smile, Santarém Operation Smile, Santarém Operation Smile, Fortaleza Operation Smile, Fortaleza Operation Smile, Fortaleza Operation Smile, Fortaleza Operation Smile, Santarém Operation Smile, Santarém Operation Smile, Maceió Operation Smile, Santarém 
F4407.1

F4418.1

F4580.1

F4827.1

F4889.1

F4984.1

F5118.1

F5134.1. Bilateral cleft lip and palate

F5147.1 Left cleft lip and palate

F5153.1 Bilateral cleft lip and palate

F5163.1 Left cleft lip and palate

F5325.1 Right cleft lip and palate

F5337.2 Bilateral cleft lip and palate

F5763.1 Left cleft lip and palate

F5796.1 Right cleft lip and palate

Right cleft lip and incomplete cleft

F5797.1

F5821.1

F5869.1

F6157.1

palate (hard palate)

Bilateral cleft lip and palate

Right cleft lip and palate

Left cleft lip and palate

Right cleft lip and incomplete cleft

F6394.1 palate (hard palate)

F6403.1 Right cleft lip and palate

F6410.1 Unilateral left cleft lip

F6411.1 Cleft soft palate

F6420.1 Left cleft lip

\section{No}

No

No

No

No

No

No

Yes (third

cousins)

No

No

No

No

No

No

No

No

No

No

No

No

No

No

No
$1(\mathrm{CL} / \mathrm{P})$

$1(\mathrm{CL} / \mathrm{P})$

$1(\mathrm{CL} / \mathrm{P})$

$1(\mathrm{CL} / \mathrm{P})$

$1(\mathrm{CL} / \mathrm{P}) \quad 1(\mathrm{CL} / \mathrm{P})$

$1(\mathrm{CL} / \mathrm{P})$

1 (NA)

$1(\mathrm{CL} / \mathrm{P})$

$1(\mathrm{CL} / \mathrm{P})$

1 (NA)

1 (NA)

1 (NA)

$1(\mathrm{CL} / \mathrm{P})$

1 (NA)

2 (NA)

$1(\mathrm{CL} / \mathrm{P})$

3 (NA)

$1(\mathrm{CL} / \mathrm{P})$

$1(\mathrm{CL} / \mathrm{P})$

1 (NA)

1 (NA)

$1(\mathrm{CL} / \mathrm{P})$

$1(\mathrm{CL} / \mathrm{P})$
Operation Smile, Fortaleza Operation Smile, Fortaleza Operation Smile, Rio de Janeiro Operation Smile, Rio de Janeiro Operation Smile, Rio de Janeiro Operation Smile, Rio de Janeiro Operation Smile, Fortaleza

Operation Smile, Fortaleza Operation Smile, Fortaleza Operation Smile, Fortaleza Operation Smile, Fortaleza Operation Smile, Santarém Operation Smile, Santarém Operation Smile, Fortaleza Operation Smile, Fortaleza

Operation Smile, Fortaleza Operation Smile, Fortaleza Operation Smile, Maceió Hospital das Clínicas, São Paulo

Operation Smile, Rio de Janeiro Operation Smile, Rio de Janeiro Operation Smile, Rio de Janeiro Operation Smile, Rio de Janeiro Operation Smile, Rio de Janeiro 
Left cleft lip and incomplete cleft

F6450.1

F6466.1

F6474.1

F6484.1

F6543.1

F6604.1

F6620.1

F6672.1

F6673.1

F6725.1

F6726.1

F7321.1

7408.1

F7420.1

F7430.1

F7431.1

F7463.1

F7475.1

F7516.3

F7568.1

F7569.1

F7584.1

palate (hard palate)

Cleft palate

Bilateral cleft lip and palate

Left cleft lip

Left cleft lip and palate

Cleft soft palate

Right cleft lip and palate

Left cleft lip

Left cleft lip

Left cleft lip and palate

Left cleft lip and palate

Right cleft lip and palate

Bilateral cleft lip and incomplete

cleft palate (hard palate)

Bilateral cleft lip and palate

Bilateral cleft lip and palate

Bilateral cleft lip and palate

Left cleft lip and palate

Left cleft lip and palate

Left cleft lip and palate

Bilateral cleft lip and palate

eft cleft lip and incomplete cleft

palate (hard palate)

Left cleft lip
Yes (third

cousins)

No

No

No

No

No

No

No

No

No

Yes (third

cousins)

No

No

Yes (second

cousins)

No

Yes (third

cousins)

No

No

No

No

No

Yes (unknown

degree)

No
$1(\mathrm{CL} / \mathrm{P})$

$1(\mathrm{CP}) \quad 1(\mathrm{CL} / \mathrm{P}) \quad 1(\mathrm{CL} / \mathrm{P})$

$1(\mathrm{CL} / \mathrm{P})$

$1(\mathrm{CL} / \mathrm{P})$

1 (CP)

$1(\mathrm{CL} / \mathrm{P})$

$1(\mathrm{CL} / \mathrm{P})$

$1(\mathrm{CL} / \mathrm{P})$

$1(\mathrm{CL} / \mathrm{P})$

$1(\mathrm{CL} / \mathrm{P})$

$1(\mathrm{CL} / \mathrm{P}) \quad 1(\mathrm{CL} / \mathrm{P})$

1 (NA)

1 (NA)

$1(\mathrm{CL} / \mathrm{P})$

$1(\mathrm{CL} / \mathrm{P}) \quad 1(\mathrm{CL} / \mathrm{P})$

$2(\mathrm{CL} / \mathrm{P})$

1 (NA)

$1(\mathrm{CL} / \mathrm{P})$

$1(\mathrm{CL} / \mathrm{P}) \quad 1$ (NA)

1 (NA)
Operation Smile, Rio de Janeiro Operation Smile, Rio de Janeiro Operation Smile, Rio de Janeiro Operation Smile, Rio de Janeiro Operation Smile, Rio de Janeiro Hospital das Clínicas, São Paulo Hospital das Clínicas, São Paulo Operation Smile, Santarém Operation Smile, Santarém

Operation Smile, Santarém Operation Smile, Santarém Operation Smile, Maceió

Operation Smile, Maceió Operation Smile, Maceió

Operation Smile, Maceió Operation Smile, Maceió Hospital das Clínicas, São Paulo Hospital das Clínicas, São Paulo Hospital Menino Jesus, São Paulo Operation Smile, Fortaleza

Operation Smile, Fortaleza Operation Smile, Fortaleza 
Bilateral cleft lip and incomplete

F7592.1

F7595.1

F7610.1

F7612.1

F7619.1

F7650.2

F7691.1

F7693.1

F7697.1

7752.1

F7755.1

F7756.1

7761.1

F7762.1

F7763.1

F7764.1

F7768.1

F7770.1

F7785.1

F7790.1

F7792.1 cleft palate (hard palate)

Right cleft lip and palate

Bilateral cleft lip and palate

Bilateral cleft lip and palate

Bilateral cleft lip and palate

Left cleft lip and palate

Right cleft lip and incomplete cleft

palate (hard palate)

Left cleft lip

eft cleft lip and palate

Left cleft lip and incomplete cleft

palate (hard palate)

Bilateral cleft lip and palate

Left cleft lip

Left cleft lip and incomplete cleft

palate (hard palate)

Right cleft lip and palate

Left cleft lip and palate

eft cleft lip and incomplete cleft

palate (hard palate)

Left cleft lip and incomplete cleft

palate (hard palate)

Left cleft lip and palate

Cleft hard palate

eft cleft lip and palate

Left cleft lip and palate
Yes (third

cousins)

No

No

No

No

No

No

No

No
$1(\mathrm{CL} / \mathrm{P})$

$1(\mathrm{CP})$

2 (NA)

$1(\mathrm{CL} / \mathrm{P}) \quad 1(\mathrm{CL} / \mathrm{P})$

$1(\mathrm{CL} / \mathrm{P})$

$1(\mathrm{CL} / \mathrm{P})$

$2(\mathrm{CL} / \mathrm{P}) \quad 1(\mathrm{CL} / \mathrm{P})$

$1(\mathrm{CL} / \mathrm{P})$

1 (NA)

$1(\mathrm{CL} / \mathrm{P})$

$1(\mathrm{CL} / \mathrm{P})$

$1(\mathrm{CL} / \mathrm{P})$

1 (NA)

1 (NA)

$1(\mathrm{CL} / \mathrm{P})$

$1(\mathrm{CL} / \mathrm{P})$

$1(\mathrm{CL} / \mathrm{P})$

1 (CP)

Operation Smile, Rio de Janeiro Operation Smile, Rio de Janeiro Operation Smile, Fortaleza Operation Smile, Fortaleza Operation Smile, Fortaleza Operation Smile, Fortaleza

Operation Smile, Rio de Janeiro Operation Smile, Rio de Janeiro Operation Smile, Rio de Janeiro

Operation Smile, Fortaleza Operation Smile, Fortaleza

Operation Smile, Fortaleza

Operation Smile, Fortaleza Operation Smile, Fortaleza Operation Smile, Fortaleza

Operation Smile, Fortaleza

Operation Smile, Fortaleza Operation Smile, Fortaleza Operation Smile, Rio de Janeiro $1(\mathrm{CL} / \mathrm{P})+1(\mathrm{CP})$ Operation Smile, Rio de Janeiro 2 (NA) Operation Smile, Rio de Janeiro 
Bilateral cleft lip and palate Left cleft lip and incomplete cleft

F7843.1

F7867.1 palate (soft palate)

Left cleft lip

Left cleft lip and incomplete cleft

F7907.1

F7939.1

F8026.1

F8027.1

F8034.1

F8039.1

F8060.1

F8083.1

F8085.1

F8089.1

F8092.1

F8105.1

F8157.3

ate (hard palate)

Left cleft lip and palate

Left cleft lip and palate

Left cleft lip and palate

Right cleft lip and palate

Left cleft lip and palate

Left cleft lip and palate

Left cleft lip and palate

Left cleft lip and palate

Bilateral cleft lip and palate

Bilateral cleft lip and palate

Left cleft lip and palate

Left cleft lip and incomplete cleft

F8379.1

palate (hard palate)

eft cleft lip and incomplete cleft

F8418.1 palate (hard palate)

F8504.1 Right cleft lip

F8505.1 Left cleft lip and palate

F8596.1 Left cleft lip and palate

F9081.1 Bilateral cleft lip and palate
Yes (first cousins)

No

No

No

No

No

No

No

No

Yes (unknown degree)

No

No

No

No

Yes (third

cousins)

No

No
Hospital Menino Jesus, São Paulo

Operation Smile, Rio de Janeiro Operation Smile, Rio de Janeiro

Hospital Menino Jesus, São Paulo Hospital das Clínicas, São Paulo Operation Smile, Santarém Operation Smile, Santarém Operation Smile, Santarém Operation Smile, Santarém Operation Smile, Santarém Operation Smile, Santarém Operation Smile, Santarém Operation Smile, Santarém Operation Smile, Santarém Operation Smile, Santarém

$1(\mathrm{CL} / \mathrm{P})+1$

$1(\mathrm{CL} / \mathrm{P})$

Hospital Menino Jesus, São Paulo

Hospital das Clínicas, São Paulo

Hospital das Clínicas, São Paulo Hospital das Clínicas, São Paulo

Hospital das Clínicas, São Paulo Hospital das Clínicas, São Paulo Operation Smile, Santarém 


\begin{tabular}{|c|c|c|c|c|c|c|c|c|}
\hline F9093.1 & Bilateral cleft lip & M & No & 1 (NA) & & & & Operation Smile, Santarém \\
\hline F9108.1 & Bilateral cleft lip and palate & $\mathrm{F}$ & No & $2(\mathrm{CL} / \mathrm{P})$ & $1(\mathrm{CL} / \mathrm{P})$ & & & Operation Smile, Santarém \\
\hline F9113.1 & $\begin{array}{l}\text { Right cleft lip and incomplete cleft } \\
\text { palate (hard palate) }\end{array}$ & M & No & & 1 (NA) & & & Operation Smile, Santarém \\
\hline F9119.3 & Cleft palate & M & No & $2(\mathrm{CP})$ & $1(\mathrm{CP})$ & & & Operation Smile, Santarém \\
\hline F9129.1 & Bilateral cleft lip and palate & M & No & & $1(\mathrm{CL} / \mathrm{P})$ & & & Operation Smile, Santarém \\
\hline F9211.1 & $\begin{array}{l}\text { Right cleft lip and palate } \\
\text { Left cleft lip and incomplete cleft }\end{array}$ & M & No & $2(\mathrm{CL} / \mathrm{P})$ & & & & Operation Smile, Fortaleza \\
\hline F9291.1 & palate (hard palate) & M & No & & & 1 (NA) & & Hospital das Clínicas, São Paulo \\
\hline F9739.1 & $\begin{array}{l}\text { Bilateral cleft lip and palate } \\
\text { Bilateral cleft lip and incomplete }\end{array}$ & M & $\begin{array}{l}\text { No } \\
\text { Yes (unknown }\end{array}$ & & & & $2(\mathrm{CL} / \mathrm{P})$ & Hospital das Clínicas, São Paulo \\
\hline F991.1 & $\begin{array}{l}\text { cleft palate (hard palate) } \\
\text { Right scar cleft lip and submucous }\end{array}$ & $\mathrm{F}$ & degree) & $1(\mathrm{CL} / \mathrm{P})$ & & & $3(\mathrm{CL} / \mathrm{P})$ & Hospital das Clínicas, São Paulo \\
\hline F9785.1 & cleft palate & M & No & $1(\mathrm{CL} / \mathrm{P})$ & & & & Hospital das Clínicas, São Paulo \\
\hline
\end{tabular}

M: male. F: female. ACMG-Pathogenic variants: variant classification following American College of Medical Genetics and Genomics (ACMG) guidelines. CL/P: Cleft lip with or without cleft palate. CP: cleft palate. NA: Data not available. UFRJ: Federal University of Rio de Janeiro. 


\begin{tabular}{|c|c|c|c|c|c|}
\hline Genes & $\begin{array}{c}\text { Genomic } \\
\text { region }\end{array}$ & Inclusion criteria & Associated diseases (OMIM) ${ }^{17}$ & pLI & Z-score \\
\hline ARHGAP29 & $\begin{array}{c}1 \mathrm{p} 22.1- \\
21.3\end{array}$ & GWAS locus (Terri H Beaty et al., 2010) & - & 1 & -0.27 \\
\hline BMP4 & $14 q 22.2$ & Syndromic OFC & Microphthalmia, syndromic 6, 607932 (3); Orofacial cleft 11, 600625 (3) & 0.97 & 1.91 \\
\hline BRCA1 & $17 q 21.31$ & $\begin{array}{l}\text { Expressed in embryonic orofacial primordia; } \\
\text { expression is dysregulated in nsCL/P dental pulp stem } \\
\text { cells (Kobayashi et al., 2013) }\end{array}$ & - & 0 & -1.26 \\
\hline $\mathrm{CDH} 1$ & $16 \mathrm{p} 13.3$ & Syndromic OFC & $\begin{array}{l}\text { Blepharocheilodontic syndrome, } 119580 \text { (3); Endometrial carcinoma, somatic, } 608089 \text { (3); Ovarian carcinoma, } \\
\text { somatic, } 167000 \text { (3); \{Breast cancer, lobular\}, } 114480 \text { (3); Gastric cancer, familial diffuse, with or without cleft lip } \\
\text { and/or palate, } 137215 \text { (3); \{Prostate cancer, susceptibility to\}, } 176807 \text { (3) }\end{array}$ & 0.34 & 0.81 \\
\hline CHST14 & $15 q 15.1$ & Syndromic OFC & Ehlers-Danlos syndrome, musculocontractural type , 601776 (3) & 0.59 & 3.68 \\
\hline CLPTM1L & $5 p 15.33$ & $\begin{array}{l}\text { Microduplication in pacient with CLP and neuro- } \\
\text { psychomotor developmental delay (Izzo et al., 2013) }\end{array}$ & - & 0.31 & 1.2 \\
\hline COL11A1 & $1 \mathrm{p} 21.1$ & Syndromic OFC & $\begin{array}{l}\text { Stickler syndrome, type II, } 604841 \text { (3); Marshall syndrome, } 154780 \text { (3); \{Lumbar disc herniation, susceptibility to\}, } \\
603932 \text { (3); Fibrochondrogenesis, } 228520 \text { (3) }\end{array}$ & 1 & -0.66 \\
\hline COL11A2 & $6 p 21.32$ & Syndromic OFC & \begin{tabular}{|l|} 
Stickler syndrome, type III, 184840 (3); Otospondylomegaepiphyseal dysplasia, 215150 (3); Weissenbacher- \\
Zweymuller syndrome, 277610 (3); Deafness, autosomal dominant 13, 601868 (3); Deafness, autosomal recessive 53, \\
609706 (3); Fibrochondrogenesis 2, 614524 (3)
\end{tabular} & 1 & 2.04 \\
\hline COL2A1 & $12 q 13.11$ & Syndromic OFC & $\begin{array}{l}\text { Stickler syndrome, type I, } 108300 \text { (3); Kniest dysplasia, } 156550 \text { (3); Achondrogenesis, type II or hypochondrogenesis, } \\
200610 \text { (3); SED congenita, } 183900 \text { (3); SMED Strudwick type, } 184250 \text { (3); Epiphyseal dysplasia, multiple, with myopia } \\
\text { and deafness, } 132450 \text { (3); Spondyloperipheral dysplasia, } 271700 \text { (3); SED, Namaqualand type (3); Osteoarthritis with } \\
\text { mild chondrodysplasia, } 604864 \text { (3); Vitreoretinopathy with phalangeal epiphyseal dysplasia (3); Platyspondylic skeletal } \\
\text { dysplasia, Torrance type, } 151210 \text { (3); Otospondylomegaepiphyseal dysplasia, } 215150 \text { (3); Avascular necrosis of the } \\
\text { femoral head, } 608805 \text { (3); Legg-Calve-Perthes disease, } 150600 \text { (3); Stickler sydrome, type I, nonsyndromic ocular, } \\
609508 \text { (3); Czech dysplasia, } 609162 \text { (3) }\end{array}$ & 1 & 3.03 \\
\hline COL9A1 & $6 q 13$ & Syndromic OFC & Epiphyseal dysplasia, multiple, 6, 614135 (3); Stickler syndrome, type IV, 614134 (3) & 0 & -1.15 \\
\hline COL9A2 & $1 \mathrm{p} 34.2$ & Syndromic OFC & $\begin{array}{l}\text { Epiphyseal dysplasia, multiple, 2, } 600204 \text { (3); \{Intervertebral disc disease, susceptibility to\}, } 603932 \text { (3); Stickler } \\
\text { syndrome, type V, } 614284 \text { (3) }\end{array}$ & 0.18 & 0.77 \\
\hline
\end{tabular}




\begin{tabular}{|c|c|c|c|c|c|}
\hline CRISPLD2 & $16 \mathrm{q} 24.1$ & $\begin{array}{l}\text { Independent associations with NSCL/P (Ge et al., } \\
\text { 2018) }\end{array}$ & e & 0 & -1.29 \\
\hline DYNC2H1 & $11 \mathrm{q} 22.3$ & Syndromic OFC & $\begin{array}{l}\text { Asphyxiating thoracic dystrophy 3, } 613091 \text { (3); Short rib-polydactyly syndrome, type III, } 263510 \text { (3); Short rib- } \\
\text { polydactyly syndrome, type IIB, } 615087 \text { (3) }\end{array}$ & 0 & -2.46 \\
\hline EFNB1 & Xq13.1 & Syndromic OFC & Craniofrontonasal dysplasia, $304110(3)$ & 0.78 & 1.23 \\
\hline EPHA3 & $3 p 11.1$ & GWAS locus (Ludwig et al., 2012) & - & 0.02 & 0.28 \\
\hline EVC & $4 \mathrm{p} 16.2$ & Syndromic OFC & Ellis-van Creveld syndrome, 225500 (3); Weyers acrodental dysostosis, 193530 (3) & 0 & -1.4 \\
\hline EVC2 & $4 \mathrm{p} 16.2$ & Syndromic OFC & Ellis-van Creveld syndrome, 225500 (3) & 0 & -3.2 \\
\hline FAF1 & $1 \mathrm{p} 32.3$ & Syndromic OFC & Evidence of gene disrpution in Pierre Robin family (Ghassibe-Sabbagh et al., 2011) & 1 & 2.24 \\
\hline FGF8 & $10 q 24.32$ & Syndromic OFC & Hypogonadotropic hypogonadism 6 with or without anosmia, 612702 (3) & 0.93 & 2.44 \\
\hline FGFR1 & $\begin{array}{c}8 p 11.23- \\
11.22\end{array}$ & Syndromic OFC & $\begin{array}{l}\text { Pfeiffer syndrome, } 101600 \text { (3); Jackson-Weiss syndrome, } 123150 \text { (3); Hypogonadotropic hypogonadism } 2 \text { with or } \\
\text { without anosmia, } 147950 \text { (3); Osteoglophonic dysplasia, } 166250 \text { (3); Trigonocephaly 1, } 190440 \text { (3) }\end{array}$ & 0.99 & 2.8 \\
\hline FGFR2 & $10 q 26.13$ & Syndromic OFC & $\begin{array}{l}\text { Crouzon syndrome, } 123500 \text { (3); Jackson-Weiss syndrome, } 123150 \text { (3); Beare-Stevenson cutis gyrata syndrome, } 123790 \\
\text { (3); Pfeiffer syndrome, } 101600 \text { (3); Apert syndrome, } 101200 \text { (3); Saethre-Chotzen syndrome, } 101400 \text { (3); } \\
\text { Craniosynostosis, nonspecific (3); Gastric cancer, somatic, } 613659 \text { (3); Craniofacial-skeletal-dermatologic dysplasia, } \\
101600 \text { (3); Antley-Bixler syndrome without genital anomalies or disordered steroidogenesis, } 207410 \text { (3); } \\
\text { Scaphocephaly and Axenfeld-Rieger anomaly (3); LADD syndrome, } 149730 \text { (3); Scaphocephaly, maxillary retrusion, and } \\
\text { mental retardation, } 609579 \text { (3); Bent bone dysplasia syndrome, } 614592 \text { (3) }\end{array}$ & 1 & 2.74 \\
\hline FGFR3 & $4 \mathrm{p} 16.3$ & Syndromic OFC & $\begin{array}{l}\text { Achondroplasia, } 100800 \text { (3); Hypochondroplasia, } 146000 \text { (3); Thanatophoric dysplasia, type I, } 187600 \text { (3); Crouzon } \\
\text { syndrome with acanthosis nigricans, } 612247 \text { (3); Muenke syndrome, } 602849 \text { (3); Bladder cancer, somatic, } 109800 \text { (3); } \\
\text { Colorectal cancer, somatic, } 114500 \text { (3); Cervical cancer, somatic, } 603956 \text { (3); LADD syndrome, } 149730 \text { (3); CATSHL } \\
\text { syndrome, } 610474 \text { (3); Nevus, epidermal, somatic, } 162900 \text { (3); Thanatophoric dysplasia, type II, } 187601 \text { (3); } \\
\text { Spermatocytic seminoma, somatic, } 273300 \text { (3) }\end{array}$ & 0 & 1.39 \\
\hline FILIP1L & $3 q 12.1$ & GWAS locus (T H Beaty et al., 2013) & - & 0 & -0.36 \\
\hline FLNA & Xq28 & Syndromic OFC & $\begin{array}{l}\text { Heterotopia, periventricular, } 300049 \text { (3); Otopalatodigital syndrome, type I, } 311300 \text { (3); Otopalatodigital syndrome, } \\
\text { type II, } 304120 \text { (3); Intestinal pseudoobstruction, neuronal, } 300048 \text { (3); Melnick-Needles syndrome, } 309350 \text { (3); } \\
\text { Frontometaphyseal dysplasia, } 305620 \text { (3); Heterotopia, periventricular, ED variant, } 300537 \text { (3); FG syndrome 2, } \\
300321 \text { (3); Cardiac valvular dysplasia, X-linked, } 314400 \text { (3); Terminal osseous dysplasia, } 300244 \text { (3); Congenital short } \\
\text { bowel syndrome, } 300048 \text { (3) }\end{array}$ & 1 & 4.95 \\
\hline FLNB & $3 p 14.3$ & Syndromic OFC & $\begin{array}{l}\text { Spondylocarpotarsal synostosis syndrome, } 272460 \text { (3); Larsen syndrome, } 150250 \text { (3); Atelosteogenesis, type I, } 108720 \\
\text { (3); Atelosteogenesis, type III, } 108721 \text { (3); Boomerang dysplasia, } 112310 \text { (3) }\end{array}$ & 0 & 2.14 \\
\hline GADD45G & $9 q 22.2$ & GWAS locus (T H Beaty et al., 2013) & - & 0.72 & 2.98 \\
\hline GDF6 & $8 q 22.1$ & Syndromic OFC & $\begin{array}{l}\text { Klippel-Feil syndrome 1, autosomal dominant, } 118100 \text { (3); Microphthalmia, isolated 4, } 613094 \text { (3); Microphthalmia } \\
\text { with coloboma 6, digenic, } 613703 \text { (3) }\end{array}$ & 0.91 & 3.46 \\
\hline
\end{tabular}




\begin{tabular}{|c|c|c|c|c|c|}
\hline GLI2 & $2 q 14.2$ & Syndromic OFC & Holoprosencephaly-9, 610829 (3) & 1 & 2.17 \\
\hline GLI3 & 7p14.1 & Syndromic OFC & $\begin{array}{l}\text { Greig cephalopolysyndactyly syndrome, } 175700 \text { (3); Pallister-Hall syndrome, } 146510 \text { (3); Polydactyly, preaxial, type IV, } \\
174700 \text { (3); Polydactyly, postaxial, types A1 and B, } 174200 \text { (3); \{Hypothalamic hamartomas, somatic\}, } 241800 \text { (3) }\end{array}$ & 1 & 1.52 \\
\hline GNAI3 & $1 \mathrm{p} 13.3$ & Syndromic OFC & Auriculocondylar syndrome $1,602483(3)$ & 0.04 & 1.85 \\
\hline IFT80 & $3 q 25.33$ & Syndromic OFC & Asphyxiating thoracic dystrophy 2, 611263 (3) & 0 & -0.08 \\
\hline IRF6 & $1 \mathrm{q} 32.2$ & Syndromic OFC; GWAS locus (Rahimov et al., 2008) & Van der Woude syndrome, 119300 (3); Popliteal pterygium syndrome 1, 119500 (3); Orofacial cleft 6, 608864 (3) & 0.98 & 2.17 \\
\hline MIR1205 & $8 q 24.21$ & GWAS locus; PVT1 regulator (Birnbaum et al., 2009) & - & NR & NR \\
\hline MIR1206 & $8 q 24.21$ & GWAS locus; PVT1 regulator (Birnbaum et al., 2009) & - & NR & NR \\
\hline MIR1207 & $8 q 24.21$ & GWAS locus; PVT1 regulator (Birnbaum et al., 2009) & - & NR & NR \\
\hline MIR1208 & $8 q 24.21$ & GWAS locus; PVT1 regulator(Birnbaum et al., 2009) & - & NR & NR \\
\hline MIR140 & $16 q 22.1$ & Expressed during palatogenesis (Schoen et al., 2017) & - & NR & NR \\
\hline MIR200B & $1 \mathrm{p} 36.33$ & Expressed during palatogenesis(Schoen et al., 2017) & - & NR & NR \\
\hline MSX1 & $4 \mathrm{p} 16.2$ & Syndromic OFC & Ectodermal dysplasia 3, Witkop type, 189500 (3); Tooth agenesis, selective 1 with or without orofacial cleft (3) & 0.28 & 2.47 \\
\hline MSX2 & $5 q 35.2$ & Syndromic OFC & $\begin{array}{l}\text { Craniosynostosis, type 2, } 604757 \text { (3); Parietal foramina 1, } 168500 \text { (3); Parietal foramina with cleidocranial dysplasia, } \\
168550 \text { (3) }\end{array}$ & 0.42 & 1.07 \\
\hline MYC & $8 q 24.21$ & GWAS locus (Birnbaum et al., 2009; Uslu et al., 2014) & - & NR & NR \\
\hline NOG & $17 q 22$ & GWAS locus(Mangold et al., 2010) & - & 0.68 & 2.34 \\
\hline NOL8 & $9 q 22.31$ & $\begin{array}{l}\text { Harbors eQTLs identified in orbicularis oris muscle } \\
\text { from NSCL/P patients, in a block also encompassing } \\
\text { ROR2 and OGN(Masotti et al., 2018) }\end{array}$ & - & 0 & -1.51 \\
\hline OGN & 9q22.31 & $\begin{array}{l}\text { Harbors eQTLs identified in orbicularis oris muscle } \\
\text { from NSCL/P patients, in a block also encompassing } \\
\text { ROR2 and NOL8(Masotti et al., 2018) }\end{array}$ & - & 0.01 & 0.66 \\
\hline PHF8 & Xp11.22 & Syndromic OFC & Mental retardation syndrome, X-linked, Siderius type, 300263 (3) & 1 & 4.59 \\
\hline PLCB4 & 20p12.2 & Syndromic OFC & Auriculocondylar syndrome 2, 614669 (3) & 0.27 & 2.78 \\
\hline POLR1C & $6 \mathrm{p} 21.1$ & Syndromic OFC & Treacher Collins syndrome 3, 248390 (3) & 0 & -0.64 \\
\hline POLR1D & $13 q 12.2$ & Syndromic OFC & Treacher Collins syndrome 2, 613717 (3) & 0.26 & 0.19 \\
\hline PTCH1 & $9 q 22.32$ & Syndromic OFC & Basal cell nevus syndrome, 109400 (3); Basal cell carcinoma, somatic, 605462 (3); Holoprosencephaly-7, 610828 (3) & 1 & 2.86 \\
\hline PVRL1 & $11 \mathrm{q} 23.3$ & Syndromic OFC & Cleft lip/palate-ectodermal dysplasia syndrome, 225060 (3); Orofacial cleft 7, 225060 (3) & 0.5 & 1.8 \\
\hline
\end{tabular}




\begin{tabular}{|c|c|c|c|c|c|}
\hline PVT1 & $8 q 24.21$ & GWAS locus; MYC regulator(Birnbaum et al., 2009) & - & NR & NR \\
\hline RARA & $17 q 21.2$ & $\begin{array}{l}\text { Association studies(Chenevix-Trench, Jones, Green, } \\
\text { Duffy, \& Martin, 1992; Shaw, Ray, Marazita, \& Field, } \\
\text { 1993) }\end{array}$ & - & 0.93 & 3.59 \\
\hline RECQL4 & $8 \mathrm{q} 24.3$ & Syndromic OFC & Rothmund-Thomson syndrome, 268400 (3); RAPADILINO syndrome, 266280 (3); Baller-Gerold syndrome, 218600 (3) & NR & NR \\
\hline ROR2 & 9q22.31 & Syndromic OFC & Brachydactyly, type B1, 113000 (3); Robinow syndrome, autosomal recessive, 268310 (3) & 0.46 & 0.5 \\
\hline RPS27L & $15 q 22.2$ & GWAS locus(Ludwig et al., 2012) & - & 0.34 & 0.03 \\
\hline RUNX2 & 6p21.1 & Syndromic OFC & $\begin{array}{l}\text { Cleidocranial dysplasia, } 119600 \text { (3); Cleidocranial dysplasia, forme fruste, with brachydactyly, } 119600 \text { (3); Cleidocranial } \\
\text { dysplasia, forme fruste, dental anomalies only, } 119600 \text { (3); Metaphyseal dysplasia with maxillary hypoplasia with or } \\
\text { without brachydactyly, } 156510 \text { (3) }\end{array}$ & 1 & 2.56 \\
\hline SHH & $7 q 36.3$ & Syndromic OFC & $\begin{array}{l}\text { Holoprosencephaly-3, } 142945 \text { (3); Single median maxillary central incisor, } 147250 \text { (3); Microphthalmia with coloboma } \\
\text { 5, } 611638 \text { (3); Schizencephaly, } 269160 \text { (3) }\end{array}$ & 0.9 & 4.42 \\
\hline SIX3 & $2 \mathrm{p} 21$ & Syndromic OFC & Holoprosencephaly-2, 157170 (3); Schizensephaly, 269160 (3) & 0.35 & 3.95 \\
\hline$S L C 26 A 2$ & $5 q 32$ & Syndromic OFC & $\begin{array}{l}\text { Diastrophic dysplasia, } 222600 \text { (3); Atelosteogenesis II, } 256050 \text { (3); Achondrogenesis Ib, } 600972 \text { (3); Epiphyseal } \\
\text { dysplasia, multiple, 4, } 226900 \text { (3); Diastrophic dysplasia, broad bone-platyspondylic variant, } 222600 \text { (3); De la Chapelle } \\
\text { dysplasia, } 256050 \text { (3) }\end{array}$ & 0 & -1.37 \\
\hline soxg & $17 q 24.3$ & Syndromic OFC & $\begin{array}{l}\text { Campomelic dysplasia with autosomal sex reversal, } 114290 \text { (3); Acampomelic campomelic dysplasia, } 114290 \text { (3); } \\
\text { Campomelic dysplasia, } 114290 \text { (3) }\end{array}$ & 0.98 & 4.11 \\
\hline SUMO1 & $2 q 33.1$ & $\begin{array}{l}\text { Disrupted in nsCL/P patient; role in craniofacial } \\
\text { development. (Alkuraya et al., 2006; Stanier \& Pauws, } \\
\text { 2012) }\end{array}$ & e & 0.8 & 1.69 \\
\hline TCOF1 & $5 q 32$ & Syndromic OFC & Treacher Collins syndrome 1, 154500 (3) & 0.77 & -1.24 \\
\hline TFAP2A & $6 p 24.3$ & Syndromic OFC & Branchiooculofacial syndrome, 113620 (3 & 0.99 & 4.04 \\
\hline TGFBR1 & $9 q 22.33$ & Syndromic OFC & $\begin{array}{l}\text { Loeys-Dietz syndrome, type 1A, } 609192 \text { (3); Loeys-Dietz syndrome, type 2A, } 608967 \text { (3); \{Multiple self-healing } \\
\text { squamous epithelioma, susceptiblity to\}, } 132800 \text { (3) }\end{array}$ & 0.95 & 2.81 \\
\hline TGFBR2 & $3 p 24.1$ & Syndromic OFC & $\begin{array}{l}\text { Colorectal cancer, hereditary nonpolyposis, type 6, } 614331 \text { (3); Esophageal cancer, somatic, } 133239 \text { (3); Loeys-Dietz } \\
\text { syndrome, type 1B, } 610168 \text { (3); Loeys-Dietz syndrome, type 2B, } 610380 \text { (3) }\end{array}$ & 0.04 & -0.53 \\
\hline TGIF1 & $18 p 11.31$ & Syndromic OFC & Holoprosencephaly-4, $142946(3)$ & 0.09 & 1.26 \\
\hline TP63 & $3 q 26$ & Syndromic OFC & $\begin{array}{l}\text { Ectrodactyly, ectodermal dysplasia, and cleft lip/palate syndrome 3, } 604292 \text { (3); Split-hand/foot malformation 4, } \\
605289 \text { (3); Hay-Wells syndrome, } 106260 \text { (3); ADULT syndrome, } 103285 \text { (3); Limb-mammary syndrome, } 603543 \text { (3); } \\
\text { Rapp-Hodgkin syndrome, } 129400 \text { (3); Orofacial cleft 8, } 129400 \text { (3) }\end{array}$ & 0.98 & 2.65 \\
\hline WNT3 & $17 q 21.31$ & Syndromic OFC & Tetra-amelia, autosomal recessive, 273395 (3) & 0.95 & 4.23 \\
\hline
\end{tabular}


Legend: OFC: orofacial clefts. nsCL/P: non-syndromic cleft lip with or without palate. CLP: cleft lip and palate. pLi: probability of intolerance to loss-of-function variants. Z-score: probability of intolerance to missense (Z-score) variants available in Exome Aggregation Consortium (ExAC) database. 


\section{References (main text)}

Alkuraya, F. S., Saadi, I., Lund, J. J., Turbe-Doan, A., Morton, C. C., \& Maas, R. L. (2006). SUMO1 haploinsufficiency leads to cleft lip and palate. Science, 313(5794), 1751. doi:10.1126/science.1128406

Alvizi, L., Ke, X., Brito, L. A., Seselgyte, R., Moore, G. E., Stanier, P., \& PassosBueno, M. R. (2017). Differential methylation is associated with non-syndromic cleft lip and palate and contributes to penetrance effects. Scientific Reports, 7(1), 2441. doi:10.1038/s41598-017-02721-0

Babu Gurramkonda, V., Syed, A. H., Murthy, J., \& V K S Lakkakula, B. (2016). Association of TFAP2A gene polymorphism with susceptibility to nonsyndromic cleft lip with or without palate risk in south Indian population. Meta Gene, 9, 181-184. doi:10.1016/j.mgene.2016.07.007

Basha, M., Demeer, B., Revencu, N., Helaers, R., Theys, S., Bou Saba, S., ... Vikkula, M. (2018). Whole exome sequencing identifies mutations in $10 \%$ of patients with familial non-syndromic cleft lip and/or palate in genes mutated in well-known syndromes. Journal of Medical Genetics, 55(7), 449-458. doi:10.1136/jmedgenet-2017-105110

Beaty, T H, Taub, M. A., Scott, A. F., Murray, J. C., Marazita, M. L., Schwender, H., ... Ruczinski, I. (2013). Confirming genes influencing risk to cleft lip with/without cleft palate in a case-parent trio study. Human Genetics, 132(7), 771-781. doi:10.1007/s00439-013-1283-6

Beaty, Terri H, Marazita, M. L., \& Leslie, E. J. (2016). Genetic factors influencing risk to orofacial clefts: today's challenges and tomorrow's opportunities. [version 1; referees: 2 approved]. F1000Research, 5, 2800.

doi:10.12688/f1000research.9503.1

Beaty, Terri H, Murray, J. C., Marazita, M. L., Munger, R. G., Ruczinski, I., Hetmanski, J. B., ... Fallin, M. D. (2010). A genome-wide association study of cleft lip with and without cleft palate identifies risk variants near MAFB and ABCA4. Nature Genetics, 42(6), 525-529. doi:10.1038/ng.580

Birnbaum, S., Ludwig, K. U., Reutter, H., Herms, S., Steffens, M., Rubini, M., ... Mangold, E. (2009). Key susceptibility locus for nonsyndromic cleft lip with or without cleft palate on chromosome 8q24. Nature Genetics, 41(4), 473-477. doi:10.1038/ng.333

Brito, L. A., Yamamoto, G. L., Melo, S., Malcher, C., Ferreira, S. G., Figueiredo, J., ... Passos-Bueno, M. R. (2015). Rare Variants in the Epithelial Cadherin Gene 
Underlying the Genetic Etiology of Nonsyndromic Cleft Lip with or without Cleft Palate. Human Mutation, 36(11), 1029-1033. doi:10.1002/humu.22827

Chenevix-Trench, G., Jones, K., Green, A. C., Duffy, D. L., \& Martin, N. G. (1992). Cleft lip with or without cleft palate: associations with transforming growth factor alpha and retinoic acid receptor loci. American Journal of Human Genetics, 51(6), 1377-1385.

Cox, L. L., Cox, T. C., Moreno Uribe, L. M., Zhu, Y., Richter, C. T., Nidey, N., ... Roscioli, T. (2018). Mutations in the Epithelial Cadherin-p120-Catenin Complex Cause Mendelian Non-Syndromic Cleft Lip with or without Cleft Palate. American Journal of Human Genetics, 102(6), 1143-1157. doi:10.1016/j.ajhg.2018.04.009

de Araujo, T. K., Secolin, R., Félix, T. M., de Souza, L. T., Fontes, M. Í. B., Monlleó, I. L., ... Gil-da-Silva-Lopes, V. L. (2016). A multicentric association study between 39 genes and nonsyndromic cleft lip and palate in a Brazilian population. Journal of Cranio-maxillo-facial Surgery: Official Publication of the European Association for Cranio-Maxillo-Facial Surgery, 44(1), 16-20. doi:10.1016/j.jcms.2015.07.026

Dixon, M. J., Marazita, M. L., Beaty, T. H., \& Murray, J. C. (2011). Cleft lip and palate: understanding genetic and environmental influences. Nature Reviews. Genetics, 12(3), 167-178. doi:10.1038/nrg2933

Dubourg, C., Kim, A., Watrin, E., de Tayrac, M., Odent, S., David, V., \& Dupé, V. (2018). Recent advances in understanding inheritance of holoprosencephaly. American Journal of Medical Genetics. Part C, Seminars in Medical Genetics, 178(2), 258-269. doi:10.1002/ajmg.c.31619

Ernst, C., Hahnen, E., Engel, C., Nothnagel, M., Weber, J., Schmutzler, R. K., \& Hauke, J. (2018). Performance of in silico prediction tools for the classification of rare BRCA1/2 missense variants in clinical diagnostics. BMC Medical Genomics, 11(1), 35. doi:10.1186/s12920-018-0353-y

Eshete, M. A., Liu, H., Li, M., Adeyemo, W. L., Gowans, L. J. J., Mossey, P. A., ... Butali, A. (2018). Loss-of-Function GRHL3 Variants Detected in African Patients with Isolated Cleft Palate. Journal of Dental Research, 97(1), 41-48. doi:10.1177/0022034517729819

Ge, X., Shi, Q.-M., Ding, Z., Ju, Q., Wang, H., Wang, Q., .. Xu, L.-C. (2018). Association Between CRISPLD2 Polymorphisms and the Risk of Nonsyndromic Clefts of the Lip and/or Palate: A Meta-analysis. The Cleft Palate-Craniofacial Journal, 55(3), 328-334. doi:10.1177/1055665617738995 
Holzinger, E. R., Li, Q., Parker, M. M., Hetmanski, J. B., Marazita, M. L., Mangold, E., ... Bailey-Wilson, J. E. (2017). Analysis of sequence data to identify potential risk variants for oral clefts in multiplex families. Molecular Genetics \& Genomic Medicine, 5(5), 570-579. doi:10.1002/mgg3.320

Ittiwut, R., Ittiwut, C., Siriwan, P., Chichareon, V., Suphapeetiporn, K., \& Shotelersuk, V. (2016). Variants of the CDH1 (E-Cadherin) Gene Associated with Oral Clefts in the Thai Population. Genetic Testing and Molecular Biomarkers, 20(7), 406-409. doi:10.1089/gtmb.2015.0325

Izzo, G., Freitas, É. L., Krepischi, A. C. V., Pearson, P. L., Vasques, L. R., PassosBueno, M. R. S., ... Rosenberg, C. (2013). A microduplication of 5p15.33 reveals CLPTM1L as a candidate gene for cleft lip and palate. European Journal of Medical Genetics, 56(4), 222-225. doi:10.1016/j.ejmg.2013.01.002

Khandelwal, K. D., Ishorst, N., Zhou, H., Ludwig, K. U., Venselaar, H., Gilissen, C., ... Carels, C. E. L. (2017). Novel IRF6 mutations detected in orofacial cleft patients by targeted massively parallel sequencing. Journal of Dental Research, 96(2), 179-185. doi:10.1177/0022034516678829

Kobayashi, G. S., Alvizi, L., Sunaga, D. Y., Francis-West, P., Kuta, A., Almada, B. V. P., ... Passos-Bueno, M. R. (2013). Susceptibility to DNA damage as a molecular mechanism for non-syndromic cleft lip and palate. Plos One, 8(6), e65677. doi:10.1371/journal.pone.0065677

Kruszka, P., Martinez, A. F., \& Muenke, M. (2018). Molecular testing in holoprosencephaly. American Journal of Medical Genetics. Part C, Seminars in Medical Genetics, 178(2), 187-193. doi:10.1002/ajmg.c.31617

Lek, M., Karczewski, K. J., Minikel, E. V., Samocha, K. E., Banks, E., Fennell, T., ... Cummings, B. B. (2016). Analysis of protein-coding genetic variation in 60,706 humans. Nature, 536(7616), 285-291. doi:10.1038/nature19057

Leslie, E J, \& Murray, J. C. (2013). Evaluating rare coding variants as contributing causes to non-syndromic cleft lip and palate. Clinical Genetics, 84(5), 496500. doi:10.1111/cge.12018

Leslie, Elizabeth J., \& Marazita, M. L. (2015). Genetics of orofacial cleft birth defects. Current Genetic Medicine Reports, 3(3), 118-126. doi:10.1007/s40142-0150074-x

Liu, H., Busch, T., Eliason, S., Anand, D., Bullard, S., Gowans, L. J. J., ... Butali, A. (2017). Exome sequencing provides additional evidence for the involvement of ARHGAP29 in Mendelian orofacial clefting and extends the phenotypic spectrum to isolated cleft palate. Birth Defects Research, 109(1), 27-37. doi:10.1002/bdra.23596 
Losee, J., \& Kirschner, R. E. (Eds.). (2015). Comprehensive Cleft Care, Second Edition: Two Volume Set (2nd ed.). CRC Press.

Ludwig, K. U., Mangold, E., Herms, S., Nowak, S., Reutter, H., Paul, A., ... Nöthen, M. M. (2012). Genome-wide meta-analyses of nonsyndromic cleft lip with or without cleft palate identify six new risk loci. Nature Genetics, 44(9), 968-971. doi:10.1038/ng.2360

Mangold, E., Böhmer, A. C., Ishorst, N., Hoebel, A.-K., Gültepe, P., Schuenke, H., ... Ludwig, K. U. (2016). Sequencing the GRHL3 coding region reveals rare truncating mutations and a common susceptibility variant for nonsyndromic cleft palate. American Journal of Human Genetics, 98(4), 755-762. doi:10.1016/j.ajhg.2016.02.013

Mangold, E., Ludwig, K. U., Birnbaum, S., Baluardo, C., Ferrian, M., Herms, S., ... Nöthen, M. M. (2010). Genome-wide association study identifies two susceptibility loci for nonsyndromic cleft lip with or without cleft palate. Nature Genetics, 42(1), 24-26. doi:10.1038/ng.506

Marazita, M. L., Lidral, A. C., Murray, J. C., Field, L. L., Maher, B. S., Goldstein McHenry, T., ... Arcos-Burgos, M. (2009). Genome scan, fine-mapping, and candidate gene analysis of non-syndromic cleft lip with or without cleft palate reveals phenotype-specific differences in linkage and association results. Human Heredity, 68(3), 151-170. doi:10.1159/000224636

Martinelli, M., Masiero, E., Carinci, F., Morselli, P. G., Palmieri, A., Girardi, A., ... Scapoli, L. (2011). Evidence of an involvement of TFAP2A gene in nonsyndromic cleft lip with or without cleft palate: an Italian study. International Journal of Immunopathology and Pharmacology, 24(2 Suppl), 7-10. doi:10.1177/03946320110240S202

Masotti, C., Brito, L. A., Nica, A. C., Ludwig, K. U., Nunes, K., Savastano, C. P., ... Passos-Bueno, M. R. (2018). MRPL53, a New Candidate Gene for Orofacial Clefting, Identified Using an eQTL Approach. Journal of Dental Research, 97(1), 33-40. doi:10.1177/0022034517735805

Maxwell, K. N., Hart, S. N., Vijai, J., Schrader, K. A., Slavin, T. P., Thomas, T., ... Nathanson, K. L. (2016). Evaluation of ACMG-Guideline-Based Variant Classification of Cancer Susceptibility and Non-Cancer-Associated Genes in Families Affected by Breast Cancer. American Journal of Human Genetics, 98(5), 801-817. doi:10.1016/j.ajhg.2016.02.024

Morgenthaler, S., \& Thilly, W. G. (2007). A strategy to discover genes that carry multi-allelic or mono-allelic risk for common diseases: a cohort allelic sums test (CAST). Mutation Research, 615(1-2), 28-56.

doi:10.1016/j.mrfmmm.2006.09.003 
Mossey, P. A., Little, J., Munger, R. G., Dixon, M. J., \& Shaw, W. C. (2009). Cleft lip and palate. The Lancet, 374(9703), 1773-1785. doi:10.1016/S01406736(09)60695-4

Naslavsky, M. S., Yamamoto, G. L., de Almeida, T. F., Ezquina, S. A. M., Sunaga, D. Y., Pho, N., ... Zatz, M. (2017). Exomic variants of an elderly cohort of Brazilians in the ABraOM database. Human Mutation, 38(7), 751-763. doi:10.1002/humu.23220

Rahimov, F., Marazita, M. L., Visel, A., Cooper, M. E., Hitchler, M. J., Rubini, M., ... Murray, J. C. (2008). Disruption of an AP-2alpha binding site in an IRF6 enhancer is associated with cleft lip. Nature Genetics, 40(11), 1341-1347. doi:10.1038/ng.242

Richards, S., Aziz, N., Bale, S., Bick, D., Das, S., Gastier-Foster, J., ... ACMG Laboratory Quality Assurance Committee. (2015). Standards and guidelines for the interpretation of sequence variants: a joint consensus recommendation of the American College of Medical Genetics and Genomics and the Association for Molecular Pathology. Genetics in Medicine, 17(5), 405-424. doi:10.1038/gim.2015.30

Rodriguez, N., Maili, L., Chiquet, B. T., Blanton, S. H., Hecht, J. T., \& Letra, A. (2018). BRCA1 and BRCA2 gene variants and nonsyndromic cleft lip/palate. Birth Defects Research, 110(12), 1043-1048. doi:10.1002/bdr2.1346

Savastano, C. P., Brito, L. A., Faria, Á. C., Setó-Salvia, N., Peskett, E., Musso, C. M., ... Passos-Bueno, M. R. (2017). Impact of rare variants in ARHGAP29 to the etiology of oral clefts: role of loss-of-function vs missense variants. Clinical Genetics, 91(5), 683-689. doi:10.1111/cge.12823

Schoen, C., Aschrafi, A., Thonissen, M., Poelmans, G., Von den Hoff, J. W., \& Carels, C. E. L. (2017). Micrornas in palatogenesis and cleft palate. Frontiers in Physiology, 8, 165. doi:10.3389/fphys.2017.00165

Shah, N., Hou, Y.-C. C., Yu, H.-C., Sainger, R., Caskey, C. T., Venter, J. C., \& Telenti, A. (2018). Identification of misclassified clinvar variants via disease population prevalence. American Journal of Human Genetics, 102(4), 609619. doi:10.1016/j.ajhg.2018.02.019

Shaw, D., Ray, A., Marazita, M., \& Field, L. (1993). Further evidence of a relationship between the retinoic acid receptor alpha locus and nonsyndromic cleft lip with or without cleft palate (CL +/- P). American Journal of Human Genetics, 53(5), 1156-1157.

Shi, M., Mostowska, A., Jugessur, A., Johnson, M. K., Mansilla, M. A., Christensen, K., ... Murray, J. C. (2009). Identification of microdeletions in candidate genes 
for cleft lip and/or palate. Birth Defects Research. Part A, Clinical and Molecular Teratology, 85(1), 42-51. doi:10.1002/bdra.20571

Simard, J., Tonin, P., Durocher, F., Morgan, K., Rommens, J., Gingras, S., ... Dion, F. (1994). Common origins of BRCA1 mutations in Canadian breast and ovarian cancer families. Nature Genetics, 8(4), 392-398. doi:10.1038/ng1294392

Stanier, P., \& Pauws, E. (2012). Development of the lip and palate: FGF signalling. Frontiers of Oral Biology, 16, 71-80. doi:10.1159/000337618

Suzuki, S., Marazita, M. L., Cooper, M. E., Miwa, N., Hing, A., Jugessur, A., ... Murray, J. C. (2009). Mutations in BMP4 are associated with subepithelial, microform, and overt cleft lip. American Journal of Human Genetics, 84(3), 406-411. doi:10.1016/j.ajhg.2009.02.002

Takahashi, M., Hosomichi, K., Yamaguchi, T., Nagahama, R., Yoshida, H., Maki, K., ... Tajima, A. (2018). Whole-genome sequencing in a pair of monozygotic twins with discordant cleft lip and palate subtypes. Oral Diseases, 24(7), 1303-1309. doi:10.1111/odi.12910

Trujillano, D., Weiss, M. E. R., Schneider, J., Köster, J., Papachristos, E. B., Saviouk, V., ... Rolfs, A. (2015). Next-generation sequencing of the BRCA1 and BRCA2 genes for the genetic diagnostics of hereditary breast and/or ovarian cancer. The Journal of Molecular Diagnostics, 17(2), 162-170. doi:10.1016/j.jmoldx.2014.11.004

Uslu, V. V., Petretich, M., Ruf, S., Langenfeld, K., Fonseca, N. A., Marioni, J. C., \& Spitz, F. (2014). Long-range enhancers regulating Myc expression are required for normal facial morphogenesis. Nature Genetics, 46(7), 753-758. doi:10.1038/ng.2971

Valencia, M., Lapunzina, P., Lim, D., Zannolli, R., Bartholdi, D., Wollnik, B., ... RuizPerez, V. L. (2009). Widening the mutation spectrum of EVC and EVC2: ectopic expression of Weyer variants in NIH 3T3 fibroblasts disrupts Hedgehog signaling. Human Mutation, 30(12), 1667-1675. doi:10.1002/humu.21117

Yamamoto, G. L. (2017). Aplicabilidade clínica da técnica de sequenciamento de nova geração com enfoque em displasias esqueléticas.

Zhao, H., Zhang, M., Zhong, W., Zhang, J., Huang, W., Zhang, Y., ... Chen, F. (2018). A novel IRF6 mutation causing non-syndromic cleft lip with or without cleft palate in a pedigree. Mutagenesis, 33(3), 195-202.

doi:10.1093/mutage/gey012 


\section{References (Supplementary table)}

Alkuraya, F. S., Saadi, I., Lund, J. J., Turbe-Doan, A., Morton, C. C., \& Maas, R. L. (2006). SUMO1 haploinsufficiency leads to cleft lip and palate. Science, 313(5794), 1751. doi:10.1126/science.1128406

Alvizi, L., Ke, X., Brito, L. A., Seselgyte, R., Moore, G. E., Stanier, P., \& Passos-Bueno, M. R. (2017). Differential methylation is associated with non-syndromic cleft lip and palate and contributes to penetrance effects. Scientific Reports, 7(1), 2441. doi:10.1038/s41598-017-02721-0

Babu Gurramkonda, V., Syed, A. H., Murthy, J., \& V K S Lakkakula, B. (2016). Association of TFAP2A gene polymorphism with susceptibility to non-syndromic cleft lip with or without palate risk in south Indian population. Meta Gene, 9, 181-184. doi:10.1016/j.mgene.2016.07.007

Basha, M., Demeer, B., Revencu, N., Helaers, R., Theys, S., Bou Saba, S., ... Vikkula, M. (2018). Whole exome sequencing identifies mutations in $10 \%$ of patients with familial non-syndromic cleft lip and/or palate in genes mutated in well-known syndromes. Journal of Medical Genetics, 55(7), 449-458. doi:10.1136/jmedgenet-2017-105110

Beaty, T H, Taub, M. A., Scott, A. F., Murray, J. C., Marazita, M. L., Schwender, H., ... Ruczinski, I. (2013). Confirming genes influencing risk to cleft lip with/without cleft palate in a caseparent trio study. Human Genetics, 132(7), 771-781. doi:10.1007/s00439-013-1283-6

Beaty, Terri H, Marazita, M. L., \& Leslie, E. J. (2016). Genetic factors influencing risk to orofacial clefts: today's challenges and tomorrow's opportunities. [version 1; referees: 2 approved]. F1000Research, 5, 2800. doi:10.12688/f1000research.9503.1

Beaty, Terri H, Murray, J. C., Marazita, M. L., Munger, R. G., Ruczinski, I., Hetmanski, J. B., ... Fallin, M. D. (2010). A genome-wide association study of cleft lip with and without cleft palate identifies risk variants near MAFB and ABCA4. Nature Genetics, 42(6), 525-529. doi:10.1038/ng.580

Birnbaum, S., Ludwig, K. U., Reutter, H., Herms, S., Steffens, M., Rubini, M., ... Mangold, E. (2009). Key susceptibility locus for nonsyndromic cleft lip with or without cleft palate on chromosome 8q24. Nature Genetics, 41(4), 473-477. doi:10.1038/ng.333

Brito, L. A., Yamamoto, G. L., Melo, S., Malcher, C., Ferreira, S. G., Figueiredo, J., ... Passos-Bueno, M. R. (2015). Rare Variants in the Epithelial Cadherin Gene Underlying the Genetic Etiology of Nonsyndromic Cleft Lip with or without Cleft Palate. Human Mutation, 36(11), 1029-1033. doi:10.1002/humu.22827

Chenevix-Trench, G., Jones, K., Green, A. C., Duffy, D. L., \& Martin, N. G. (1992). Cleft lip with or without cleft palate: associations with transforming growth factor alpha and retinoic acid receptor loci. American Journal of Human Genetics, 51(6), 1377-1385.

Cox, L. L., Cox, T. C., Moreno Uribe, L. M., Zhu, Y., Richter, C. T., Nidey, N., ... Roscioli, T. (2018). Mutations in the Epithelial Cadherin-p120-Catenin Complex Cause Mendelian Non-Syndromic 
Cleft Lip with or without Cleft Palate. American Journal of Human Genetics, 102(6), 11431157. doi:10.1016/j.ajhg.2018.04.009

de Araujo, T. K., Secolin, R., Félix, T. M., de Souza, L. T., Fontes, M. Í. B., Monlleó, I. L., ... Gil-da-SilvaLopes, V. L. (2016). A multicentric association study between 39 genes and nonsyndromic cleft lip and palate in a Brazilian population. Journal of Cranio-maxillo-facial Surgery : Official Publication of the European Association for Cranio-Maxillo-Facial Surgery, 44(1), 16-20. doi:10.1016/j.jcms.2015.07.026

Dixon, M. J., Marazita, M. L., Beaty, T. H., \& Murray, J. C. (2011). Cleft lip and palate: understanding genetic and environmental influences. Nature Reviews. Genetics, 12(3), 167-178. doi:10.1038/nrg2933

Dubourg, C., Kim, A., Watrin, E., de Tayrac, M., Odent, S., David, V., \& Dupé, V. (2018). Recent advances in understanding inheritance of holoprosencephaly. American Journal of Medical Genetics. Part C, Seminars in Medical Genetics, 178(2), 258-269. doi:10.1002/ajmg.c.31619

Ernst, C., Hahnen, E., Engel, C., Nothnagel, M., Weber, J., Schmutzler, R. K., \& Hauke, J. (2018). Performance of in silico prediction tools for the classification of rare BRCA1/2 missense variants in clinical diagnostics. BMC Medical Genomics, 11(1), 35. doi:10.1186/s12920-0180353-y

Eshete, M. A., Liu, H., Li, M., Adeyemo, W. L., Gowans, L. J. J., Mossey, P. A., ... Butali, A. (2018). Lossof-Function GRHL3 Variants Detected in African Patients with Isolated Cleft Palate. Journal of Dental Research, 97(1), 41-48. doi:10.1177/0022034517729819

Ge, X., Shi, Q.-M., Ding, Z., Ju, Q., Wang, H., Wang, Q., ... Xu, L.-C. (2018). Association Between CRISPLD2 Polymorphisms and the Risk of Nonsyndromic Clefts of the Lip and/or Palate: A Meta-analysis. The Cleft Palate-Craniofacial Journal, 55(3), 328-334. doi:10.1177/1055665617738995

Holzinger, E. R., Li, Q., Parker, M. M., Hetmanski, J. B., Marazita, M. L., Mangold, E., ... Bailey-Wilson, J. E. (2017). Analysis of sequence data to identify potential risk variants for oral clefts in multiplex families. Molecular Genetics \& Genomic Medicine, 5(5), 570-579. doi:10.1002/mgg3.320

Ittiwut, R., Ittiwut, C., Siriwan, P., Chichareon, V., Suphapeetiporn, K., \& Shotelersuk, V. (2016). Variants of the CDH1 (E-Cadherin) Gene Associated with Oral Clefts in the Thai Population. Genetic Testing and Molecular Biomarkers, 20(7), 406-409. doi:10.1089/gtmb.2015.0325

Izzo, G., Freitas, É. L., Krepischi, A. C. V., Pearson, P. L., Vasques, L. R., Passos-Bueno, M. R. S., ... Rosenberg, C. (2013). A microduplication of 5p15.33 reveals CLPTM1L as a candidate gene for cleft lip and palate. European Journal of Medical Genetics, 56(4), 222-225. doi:10.1016/j.ejmg.2013.01.002

Khandelwal, K. D., Ishorst, N., Zhou, H., Ludwig, K. U., Venselaar, H., Gilissen, C., ... Carels, C. E. L. (2017). Novel IRF6 mutations detected in orofacial cleft patients by targeted massively 
parallel sequencing. Journal of Dental Research, 96(2), 179-185.

doi:10.1177/0022034516678829

Kobayashi, G. S., Alvizi, L., Sunaga, D. Y., Francis-West, P., Kuta, A., Almada, B. V. P., ... Passos-Bueno, M. R. (2013). Susceptibility to DNA damage as a molecular mechanism for non-syndromic cleft lip and palate. Plos One, 8(6), e65677. doi:10.1371/journal.pone.0065677

Kruszka, P., Martinez, A. F., \& Muenke, M. (2018). Molecular testing in holoprosencephaly. American Journal of Medical Genetics. Part C, Seminars in Medical Genetics, 178(2), 187-193. doi:10.1002/ajmg.c.31617

Lek, M., Karczewski, K. J., Minikel, E. V., Samocha, K. E., Banks, E., Fennell, T., ... Cummings, B. B. (2016). Analysis of protein-coding genetic variation in 60,706 humans. Nature, 536(7616), 285-291. doi:10.1038/nature19057

Leslie, E J, \& Murray, J. C. (2013). Evaluating rare coding variants as contributing causes to nonsyndromic cleft lip and palate. Clinical Genetics, 84(5), 496-500. doi:10.1111/cge.12018

Leslie, Elizabeth J., \& Marazita, M. L. (2015). Genetics of orofacial cleft birth defects. Current Genetic Medicine Reports, 3(3), 118-126. doi:10.1007/s40142-015-0074-x

Liu, H., Busch, T., Eliason, S., Anand, D., Bullard, S., Gowans, L. J. J., ... Butali, A. (2017). Exome sequencing provides additional evidence for the involvement of ARHGAP29 in Mendelian orofacial clefting and extends the phenotypic spectrum to isolated cleft palate. Birth Defects Research, 109(1), 27-37. doi:10.1002/bdra.23596

Losee, J., \& Kirschner, R. E. (Eds.). (2015). Comprehensive Cleft Care, Second Edition: Two Volume Set (2nd ed.). CRC Press.

Ludwig, K. U., Mangold, E., Herms, S., Nowak, S., Reutter, H., Paul, A., ... Nöthen, M. M. (2012). Genome-wide meta-analyses of nonsyndromic cleft lip with or without cleft palate identify six new risk loci. Nature Genetics, 44(9), 968-971. doi:10.1038/ng.2360

Mangold, E., Böhmer, A. C., Ishorst, N., Hoebel, A.-K., Gültepe, P., Schuenke, H., ... Ludwig, K. U. (2016). Sequencing the GRHL3 coding region reveals rare truncating mutations and a common susceptibility variant for nonsyndromic cleft palate. American Journal of Human Genetics, 98(4), 755-762. doi:10.1016/j.ajhg.2016.02.013

Mangold, E., Ludwig, K. U., Birnbaum, S., Baluardo, C., Ferrian, M., Herms, S., ... Nöthen, M. M. (2010). Genome-wide association study identifies two susceptibility loci for nonsyndromic cleft lip with or without cleft palate. Nature Genetics, 42(1), 24-26. doi:10.1038/ng.506

Marazita, M. L., Lidral, A. C., Murray, J. C., Field, L. L., Maher, B. S., Goldstein McHenry, T., ... ArcosBurgos, M. (2009). Genome scan, fine-mapping, and candidate gene analysis of nonsyndromic cleft lip with or without cleft palate reveals phenotype-specific differences in linkage and association results. Human Heredity, 68(3), 151-170. doi:10.1159/000224636 
Martinelli, M., Masiero, E., Carinci, F., Morselli, P. G., Palmieri, A., Girardi, A., ... Scapoli, L. (2011). Evidence of an involvement of TFAP2A gene in non-syndromic cleft lip with or without cleft palate: an Italian study. International Journal of Immunopathology and Pharmacology, 24(2 Suppl), 7-10. doi:10.1177/03946320110240S202

Masotti, C., Brito, L. A., Nica, A. C., Ludwig, K. U., Nunes, K., Savastano, C. P., ... Passos-Bueno, M. R. (2018). MRPL53, a New Candidate Gene for Orofacial Clefting, Identified Using an eQTL Approach. Journal of Dental Research, 97(1), 33-40. doi:10.1177/0022034517735805

Maxwell, K. N., Hart, S. N., Vijai, J., Schrader, K. A., Slavin, T. P., Thomas, T., ... Nathanson, K. L. (2016). Evaluation of ACMG-Guideline-Based Variant Classification of Cancer Susceptibility and NonCancer-Associated Genes in Families Affected by Breast Cancer. American Journal of Human Genetics, 98(5), 801-817. doi:10.1016/j.ajhg.2016.02.024

Morgenthaler, S., \& Thilly, W. G. (2007). A strategy to discover genes that carry multi-allelic or monoallelic risk for common diseases: a cohort allelic sums test (CAST). Mutation Research, 615(12), 28-56. doi:10.1016/j.mrfmmm.2006.09.003

Mossey, P. A., Little, J., Munger, R. G., Dixon, M. J., \& Shaw, W. C. (2009). Cleft lip and palate. The Lancet, 374(9703), 1773-1785. doi:10.1016/S0140-6736(09)60695-4

Naslavsky, M. S., Yamamoto, G. L., de Almeida, T. F., Ezquina, S. A. M., Sunaga, D. Y., Pho, N., ... Zatz, M. (2017). Exomic variants of an elderly cohort of Brazilians in the ABraOM database. Human Mutation, 38(7), 751-763. doi:10.1002/humu.23220

Rahimov, F., Marazita, M. L., Visel, A., Cooper, M. E., Hitchler, M. J., Rubini, M., ... Murray, J. C. (2008). Disruption of an AP-2alpha binding site in an IRF6 enhancer is associated with cleft lip. Nature Genetics, 40(11), 1341-1347. doi:10.1038/ng.242

Richards, S., Aziz, N., Bale, S., Bick, D., Das, S., Gastier-Foster, J., ... ACMG Laboratory Quality Assurance Committee. (2015). Standards and guidelines for the interpretation of sequence variants: a joint consensus recommendation of the American College of Medical Genetics and Genomics and the Association for Molecular Pathology. Genetics in Medicine, 17(5), 405424. doi:10.1038/gim.2015.30

Rodriguez, N., Maili, L., Chiquet, B. T., Blanton, S. H., Hecht, J. T., \& Letra, A. (2018). BRCA1 and BRCA2 gene variants and nonsyndromic cleft lip/palate. Birth Defects Research, 110(12), 1043-1048. doi:10.1002/bdr2.1346

Savastano, C. P., Brito, L. A., Faria, Á. C., Setó-Salvia, N., Peskett, E., Musso, C. M., ... Passos-Bueno, M. R. (2017). Impact of rare variants in ARHGAP29 to the etiology of oral clefts: role of lossof-function vs missense variants. Clinical Genetics, 91(5), 683-689. doi:10.1111/cge.12823

Schoen, C., Aschrafi, A., Thonissen, M., Poelmans, G., Von den Hoff, J. W., \& Carels, C. E. L. (2017). Micrornas in palatogenesis and cleft palate. Frontiers in Physiology, 8, 165. doi:10.3389/fphys.2017.00165 
Shah, N., Hou, Y.-C. C., Yu, H.-C., Sainger, R., Caskey, C. T., Venter, J. C., \& Telenti, A. (2018). Identification of misclassified clinvar variants via disease population prevalence. American Journal of Human Genetics, 102(4), 609-619. doi:10.1016/j.ajhg.2018.02.019

Shaw, D., Ray, A., Marazita, M., \& Field, L. (1993). Further evidence of a relationship between the retinoic acid receptor alpha locus and nonsyndromic cleft lip with or without cleft palate (CL +/- P). American Journal of Human Genetics, 53(5), 1156-1157.

Shi, M., Mostowska, A., Jugessur, A., Johnson, M. K., Mansilla, M. A., Christensen, K., ... Murray, J. C. (2009). Identification of microdeletions in candidate genes for cleft lip and/or palate. Birth Defects Research. Part A, Clinical and Molecular Teratology, 85(1), 42-51. doi:10.1002/bdra.20571

Simard, J., Tonin, P., Durocher, F., Morgan, K., Rommens, J., Gingras, S., ... Dion, F. (1994). Common origins of BRCA1 mutations in Canadian breast and ovarian cancer families. Nature Genetics, 8(4), 392-398. doi:10.1038/ng1294-392

Stanier, P., \& Pauws, E. (2012). Development of the lip and palate: FGF signalling. Frontiers of Oral Biology, 16, 71-80. doi:10.1159/000337618

Suzuki, S., Marazita, M. L., Cooper, M. E., Miwa, N., Hing, A., Jugessur, A., ... Murray, J. C. (2009). Mutations in BMP4 are associated with subepithelial, microform, and overt cleft lip. American Journal of Human Genetics, 84(3), 406-411. doi:10.1016/j.ajhg.2009.02.002

Takahashi, M., Hosomichi, K., Yamaguchi, T., Nagahama, R., Yoshida, H., Maki, K., ... Tajima, A. (2018). Whole-genome sequencing in a pair of monozygotic twins with discordant cleft lip and palate subtypes. Oral Diseases, 24(7), 1303-1309. doi:10.1111/odi.12910

Trujillano, D., Weiss, M. E. R., Schneider, J., Köster, J., Papachristos, E. B., Saviouk, V., ... Rolfs, A. (2015). Next-generation sequencing of the BRCA1 and BRCA2 genes for the genetic diagnostics of hereditary breast and/or ovarian cancer. The Journal of Molecular Diagnostics, 17(2), 162-170. doi:10.1016/j.jmoldx.2014.11.004

Uslu, V. V., Petretich, M., Ruf, S., Langenfeld, K., Fonseca, N. A., Marioni, J. C., \& Spitz, F. (2014). Longrange enhancers regulating Myc expression are required for normal facial morphogenesis. Nature Genetics, 46(7), 753-758. doi:10.1038/ng.2971

Valencia, M., Lapunzina, P., Lim, D., Zannolli, R., Bartholdi, D., Wollnik, B., ... Ruiz-Perez, V. L. (2009). Widening the mutation spectrum of EVC and EVC2: ectopic expression of Weyer variants in NIH 3 T3 fibroblasts disrupts Hedgehog signaling. Human Mutation, 30(12), 1667-1675. doi:10.1002/humu.21117 


\title{
Capítulo 3
}

\section{Impact of rare variants in ARHGAP29 to the etiology of oral clefts: role of loss-of-function vs missense variants}

\author{
C.P. Savastano ${ }^{a}$, L.A. Brito ${ }^{a}$ Á.C. Faria ${ }^{a}$, N. Setó-Salvia ${ }^{b, c}$, E. Peskett ${ }^{b}$, C.M. \\ Musso ${ }^{a}$, L. Alvizia, S.A.M. Ezquina ${ }^{a}$, C. James ${ }^{b}$, GOSgene $^{b}$, P. Beales ${ }^{b}$, M. Lees ${ }^{d}$, \\ G.E. Moore ${ }^{b}$, P. Stanier ${ }^{b}$ and M.R. Passos-Bueno ${ }^{a}$
}

\begin{abstract}
aCentro de Pesquisa sobre o Genoma Humano e Células-Tronco, Departamento de Genética e Biologia Evolutiva, Instituto de Biociências, Universidade de São Paulo, São Paulo, Brazil;

bGenetics and Genomic Medicine, UCL Institute of Child Health, London, UK; 'Department of Molecular Neuroscience, UCL Institute of Neurology, London, UK; 'Department of Clinical Genetics, Great Ormond Street Children's Hospital, London, UK.
\end{abstract}

\section{Nota do autor:}

Esse trabalho foi conduzido pela Dra. Clarice Savastano durante o seu pós-doc no Centro de Pesquisa sobre o Genoma Humano e Células-Tronco (Instituto de Biociências, USP). Ela foi a principal responsável pela elaboração do manuscrito. A terceira autora, Faria, A.C. foi co-responsável pelas entrevistas dos pacientes, coleta de amostras, análises dos dados do sequenciamento de nova geração e sequenciamento de Sanger.

Esse capítulo foi publicado na revista Clinical Genetics: https://doi.org/10.1111/cge.12823 


\begin{abstract}
Non-syndromic cleft lip with or without cleft palate (NSCL/P) is a prevalent, complex congenital malformation. Genome-wide association studies (GWAS) on NSCL/P have consistently identified association for the $1 \mathrm{p} 22$ region, in which $A R H G A P 29$ has emerged as the main candidate gene. ARHGAP29 re-sequencing studies in NSCL/P patients have identified rare variants; however, their clinical impact is still unclear. In this study we identified 10 rare variants in ARHGAP29, including five missense, one in-frame deletion, and four loss-of-function (LoF) variants, in a cohort of 188 familial NSCL/P cases. A significant mutational burden was found for LoF (Sequence Kernel Association Test, $\mathrm{p}=0.0005$ ) but not for missense variants in $R$ HGAP29, suggesting that only LoF variants contribute to the etiology of NSCL/P. Penetrance was estimated as $59 \%$, indicating that heterozygous LoF variants in ARHGAP29 confer a moderate risk to NSCL/P. The GWAS hits in IRF6 (rs642961) and 1p22 (rs560426 and rs4147811) do not seem to contribute to the penetrance of the phenotype, based on co-segregation analysis. Our data show that rare variants leading to haploinsufficiency of ARHGAP29 represent an important etiological clefting mechanism, and genetic testing for this gene might be taken into consideration in genetic counseling of familial cases.
\end{abstract}

Key words: cleft lip and palate. GWAS. haploinsufficiency. IRF6. nonsense mutations. Penetrance. rare variants. $1 \mathrm{p} 22$. 


\section{Resumo}

A fissura labial com ou sem fissura de palato não sindrômica (FL/P-NS) é uma malformação congênita complexa e com alta prevalência. Estudos de associação genômica (GWAS) em FL/P-NS têm consistentemente identificado associação com a região 1p22, na qual o ARHGAP29 emergiu como o principal gene candidato. Estudos de re-sequenciamento do gene ARHGAP29 em pacientes com FL/P-NS identificaram variantes raras; no entanto, o impacto clínico dessas variantes ainda é incerto. Neste estudo, identificamos 10 variantes raras no ARHGAP29, incluindo cinco variantes de missense, uma deleção in-frame e quatro de perda de função (LoF), em uma coorte de 188 casos de FL/P-NS familial. Foi encontrado um enriquecimento significativo de variantes do tipo LoF (Sequence Kernel Association Test, $\mathrm{p}=0,0005$ ), mas não para variantes missense no ARHGAP29, sugerindo que apenas variantes LoF contribuem para a etiologia das FL/P-NS. A penetrância foi estimada em $59 \%$, indicando que as variantes LoF em heterozigose no ARHGAP29 conferem um risco moderado a FL/PNS. Os GWAS-hits em IRF6 (rs642961) e 1 p22 (rs560426 e rs4147811) não parecem contribuir para a penetrância do fenótipo, com base na análise de co-segregação. Nossos dados mostram que as variantes raras que levam à haploinsuficiência de ARHGAP29 representam um importante mecanismo etiológico das fissuras, e testes genéticos para esse gene devem ser levados em consideração no aconselhamento genético de casos familiares. 


\section{Introduction}

Non-syndromic cleft lip with or without cleft palate (NSCL/P) represents one of the most common congenital human malformations, affecting about one in 700 live born children worldwide, varying according to ethnicity and socio economic status. Both genetic and environmental factors contribute to the etiology of NSCL/P, and most cases fit a multifactorial pattern of inheritance (Dixon, Marazita, Beaty, \& Murray, 2011; Mossey, Little, Munger, Dixon, \& Shaw, 2009).

Genome-wide association studies (GWAS) have successfully detected several common susceptibility alleles for NSCL/P (Beaty et al., 2010; Birnbaum et al., 2009; Leslie et al., 2016; Ludwig et al., 2012; Mangold et al., 2010; Sun et al., 2015). The 1 p22.1 region ranks among the most frequently replicated GWAS hits, originally implicating the gene ABCA4 (Beaty et al., 2010). However, this gene was largely excluded through its primarily retinal expression and known role in retinal disorders (Burke \& Tsang, 2011). Single nucleotide variants (SNVs) in the 1 p22.1 region have also been suggested to affect a cis-enhancer of ARHGAP29 (Attanasio et al., 2013). ARHGAP29 (Online Mendelian Inheritance in Man OMIM: 610496) is specifically expressed in the frontonasal and lateral prominences as well as the palatal shelves of murine embryos, which further reinforces it as a strong candidate underlying NSCL/P in the 1 p22.1 region (Leslie et al., 2012). About 18 possibly pathogenic rare variants (11 missense and seven loss-of-function) in ARHGAP29 have been reported in NSCL/P patients of European, Asian and African ancestries (Butali et al., 2014; Chandrasekharan \& Ramanathan, 2014; Leslie et al., 2012, 2015). However, it is not clear if both missense and loss-of-function (LoF) variants contribute to the phenotype. In order to address this issue, a systematic analysis of ARHGAP29 was conducted in a large cohort of 188 familial NSCL/P cases. We have also investigated if previously identified GWAS hits at 1p22.1 and in IRF6 contribute to the penetrance of the phenotype in individuals with pathogenic variants in ARHGAP29.

\section{Subjects and methods}

\section{Ethical compliance}


This study was approved by the Ethics Committee of the Instituto de Biociências (Universidade de São Paulo, Brazil) (CAAE: 37287314.6.0000.5464) and Great Ormond Street Hospital for Children NHS Trust Ethics Committee (REC No. 08H0713/46). Biological samples were obtained after signed informed consent by the patients, parents or legal guardians.

\section{Samples}

The NSCL/P cohort included 173 families from Brazil and 15 families from the UK. The average number of affected individuals per family was 2.6 (ranging between two and seven), with coefficients of relationship ( $r$ ) between $1 / 2$ and 1/32. ARHGAP29 sequences were screened for rare variants in 188 probands and 16 relatives (4 affected and 12 non-affected), which were included for segregation analysis. Brazilian individuals were ascertained at the Hospital das Clínicas of Universidade de São Paulo (São Paulo, Brazil), Hospital de Clínicas de Porto Alegre (Rio Grande do Sul, Brazil) or during missions of Operation Smile Brazil, in the Brazilian states of Ceará, Alagoas, Pará, Rondônia and Rio de Janeiro. British individuals were ascertained at Great Ormond Street Hospital for Children (London, UK).

DNA samples were extracted either from whole blood (following standard protocols) or saliva (collected with Oragene ${ }^{\circledR}$ DNA Collection Kits OG-500 and OG575, and purified following prepIT-L2P manufacturer's instructions; DNA Genotek, Ottawa, ON, Canada). For controls, we used in-house whole exome sequencing data from 609 Brazilian and 601 British controls as well as public databases (1000 Genomes Project: (1000 Genomes Project Consortium et al., 2015), Exome Variant Server/NHLBI ESP exomes, and Exome Aggregation Consortium - ExAC: (Lek et al., 2016).

\section{ARHGAP29 variant screening}

ARHGAP29 coding regions and exon-intron boundaries were sequenced using next-generation sequencing (NGS): 27 whole exome sequences from 15 independent UK families (15 probands, 3 affected cousins and 9 unaffected relatives), and 173 targeted gene sequences from unrelated probands from the Brazilian cohort were 
included in the analysis. Sanger sequencing was used for one affected and three nonaffected relatives from the Brazilian cohort.

ARHGAP29 targeted sequencing was performed with Illumina MiSeq (Illumina, San Diego, CA) sequencer, using Illumina's Nextera kits for library preparation. KAPA Library Quantification kit (KAPA Biosystems, Wilmington, MA) was used to quantify the libraries by real-time quantitative PCR. Whole-exome sequencing of the British samples was conducted using Agilent Exome v4 51Mb Capture Technology and enriched libraries were sequenced on an Illumina HiSeq2000 (Illumina). Sequence alignment, data processing, variant calling, and variant annotation were performed with Burrows-Wheeler Aligner (BWA; http://bio-bwa. sourceforge.net), Picard (http://broadinstitute.github.io/ picard/), Genome Analysis Toolkit package (GATK; https://www.broadinstitute.org/gatk/) and ANNOVAR (http://www.openbioinformatics.org/annovar/), respectively.

We considered as rare variants those with a frequency below $0.5 \%$ in public databases (ExAC, Exome Variant Server, and 1000 Genomes) and in our in-house control databases. Missense variants were considered as possibly pathogenic only if predicted to be possibly/probably damaging in at least three out of four in silico tools (Polyphen HumDiv and HumVar (Adzhubei, Jordan, \& Sunyaev, 2013), SIFT (Ng \& Henikoff, 2001), Mutation Taster (Schwarz, Rödelsperger, Schuelke, \& Seelow, 2010) and LRT (Chun \& Fay, 2009). Synonymous and UTR variants were excluded due to the uncertainty of their functional relevance. Splice site predictions were performed with Human Splicing Finder 3.0 (Desmet et al., 2009).

All ARHGAP29 rare variants detected by NGS were visually inspected using the Integrative Genomics Viewer software (Broad Institute of MIT and Harvard). Indels and low coverage $(<50 x)$ variants were subsequently validated by Sanger sequencing.

PCR primers for Sanger sequencing are described by Leslie et al. (2015). Capillary electrophoresis was performed on an ABI3730 DNA Analyzer (Applied Biosystems, Ann Arbor, MI) and sequences were visualized using Sequencherß 5.2 sequence analysis software(GeneCodes). The genomic position of variants are based on the hy19/GRCH37 version of the human reference genome (Genome Reference Consortium - http://www.ncbi.nlm.nih.gov/projects/genome/assembly/ grc/), and cDNA positions refer to the sequence NM_004815.3 (NCBI Reference Sequence Database - http://www.ncbi.nlm.nih.gov/refseq/). Pathogenic variants were submitted to the ClinVar public database (http://www.ncbi.nlm.nih.gov/clinvar/). 


\section{Genotyping of GWAS hits}

Genotypes for rs560426 (1p22), rs4147811 (1p22), and rs642961 (1q32) were obtained with the Illumina GoldenGate VeraCode assay, on Illumina BeadXpress platform, following manufacturer's instructions, or by Sanger sequencing. Primers and PCR amplification conditions are available on request.

\section{Statistical analyses}

A gene-based Sequence Kernel Association Test (SKAT) was used to investigate the overall burden of ARHGAP29 rare variants among patients in comparison to 1210 Brazilian and British controls. Two-tailed Fisher's exact test was performed to compare the proportion of patients and controls carrying rare variants in ARHGAP29. For these tests, rare variants were included after adjusting the sequence windows covered in all patients. Statistical significance was considered as $p \leq 0.05$. Penetrance was estimated using the PenCalc program (Horimoto, Onodera, \& Otto, 2010).

\section{Results}

Sequencing analysis of coding regions and exon-intron boundaries of ARHGAP29 in 188-unrelated affected probands from familial cases of NSCL/P, led to the identification of 10 rare variants. Of these, 5 were missense changes already described in public databases. The remaining five were unique variants, four of which were predicted to be LoF and one was an in-frame deletion (Table 1). Among the missense variants, only $c .91 \mathrm{C}>\mathrm{T}(\mathrm{p}$. $(\mathrm{L} 31 \mathrm{~F})$ ) was predicted to be possibly pathogenic by three out of four in silico programs. However, segregation analysis in family BC84 excluded a probable causal role because the missense variant was absent in another affected relative. The non-frameshift deletion c.3326_3328delCAA(p.(T1109del)) was predicted to be non-pathogenic by two out of four in silico tools, so it was also not considered further. 
Table 1: ARHGAP29 rare variants observed in the non-syndromic cleft lip with or without cleft palate (NSCL/P) probands.

\begin{tabular}{|c|c|c|c|c|c|c|c|c|c|c|c|c|c|}
\hline $\begin{array}{l}\text { Proband } \\
\text { ID }\end{array}$ & $\begin{array}{l}\text { Chromosome } \\
\text { position }\end{array}$ & $\begin{array}{l}\text { cDNA/Protein } \\
\text { alteration }\end{array}$ & NGS study & $\begin{array}{l}\text { Read depth; } \\
\text { allelic } \\
\text { balance (ref, } \\
\text { alt) } \\
\end{array}$ & Variant type & rs & $\begin{array}{l}\text { Tools predicting } \\
\text { pathogenicity }\end{array}$ & $\begin{array}{c}\text { Exac } \\
\mathrm{AC}^{1}(\mathrm{n} . \\
\text { homoz })\end{array}$ & $\begin{array}{c}1000 \mathrm{G}^{2} \\
\mathrm{AC}^{1}\end{array}$ & $\begin{array}{c}\mathrm{EVS}^{3} \\
\mathrm{AC}^{1}\end{array}$ & $\begin{array}{c}\text { NSCL/P } \\
\text { probands } \\
\mathrm{AC}^{1}\end{array}$ & $\begin{array}{c}\text { Brazilian } \\
\text { Controls } \\
\mathrm{AC}^{1}\end{array}$ & $\begin{array}{c}\text { British } \\
\text { Controls } \\
\mathrm{AC}^{1}\end{array}$ \\
\hline F7595-1 & 1:94639872A >C & $\begin{array}{l}\text { c.3339T }>\mathrm{G} \\
\text { p.(I1113M) }\end{array}$ & $\begin{array}{l}\text { Panel of } \\
\text { genes }\end{array}$ & $50 ; 28,22$ & missense & & 1 & 1 & 0 & 0 & 1 & 0 & 0 \\
\hline F1843-1 & $\begin{array}{l}\text { 1:94639883- } \\
\text { 94639885delTTG }\end{array}$ & $\begin{array}{l}\text { c.3326_3328delCAA } \\
\text { p.(T1109del) }\end{array}$ & $\begin{array}{l}\text { Panel of } \\
\text { genes }\end{array}$ & $70 ; 30,40$ & $\begin{array}{l}\text { nonframeshift } \\
\text { deletion }\end{array}$ & & 2 & 0 & 0 & 0 & 1 & 0 & 0 \\
\hline F7399-1 & $1: 94643587 \mathrm{G}>\mathrm{A}$ & $\begin{array}{l}\text { c. } 2617 \mathrm{C}>\mathrm{T} \\
\text { p. }(\mathrm{R} 873 \mathrm{C})\end{array}$ & $\begin{array}{l}\text { Panel of } \\
\text { genes }\end{array}$ & $145 ; 63,82$ & missense & rs147929232 & 2 & 10 & 0 & 0 & 1 & 0 & 0 \\
\hline $\begin{array}{l}\text { F6474-1; } \\
\text { F9121-1 }\end{array}$ & $1: 94645368 \mathrm{C}>\mathrm{T}$ & $\begin{array}{l}\text { c.2393G>A } \\
\text { p.(R798Q) }\end{array}$ & $\begin{array}{l}\text { Panel of } \\
\text { genes }\end{array}$ & $101 ; 53,49$ & missense & rs41311172 & 2 & $223(1)$ & 7 & 33 & 2 & 3 & 0 \\
\hline F9121-1 & $1: 94650427 \mathrm{C}>\mathrm{T}$ & c. $2109+1 \mathrm{G}>\mathrm{A}$ & $\begin{array}{l}\text { Panel of } \\
\text { genes }\end{array}$ & $62 ; 28,33$ & splicing site & & $1^{*}$ & 0 & 0 & 0 & 1 & 0 & 0 \\
\hline $314-379$ & $1: 94654771 \mathrm{C}>\mathrm{T}$ & c. $1576+1 \mathrm{G}>\mathrm{A}$ & $\begin{array}{l}\text { Exome } \\
\text { sequencing }\end{array}$ & & splicing site & & $1^{*}$ & 0 & 0 & 0 & 1 & 0 & 0 \\
\hline F4861-1 & $1: 94654873 \mathrm{G}>\mathrm{T}$ & $\begin{array}{l}\text { c. } 1475 \mathrm{C}>\mathrm{A} \\
\text { p. }(\mathrm{S} 492 *)\end{array}$ & $\begin{array}{l}\text { Panel of } \\
\text { genes }\end{array}$ & $80 ; 43,37$ & stopgain & & NA & 0 & 0 & 0 & 1 & 0 & 0 \\
\hline F8041-1 & $1: 94667305 \mathrm{C}>\mathrm{T}$ & c.G1252A p.(V418I) & $\begin{array}{l}\text { Panel of } \\
\text { genes }\end{array}$ & $181 ; 111,70$ & missense & rs148959325 & 1 & $181(1)$ & 6 & 0 & 1 & 0 & 1 \\
\hline F4118-1 & $1: 94669551 \mathrm{C}>\mathrm{G}$ & c. $698-1 \mathrm{G}>\mathrm{C}$ & $\begin{array}{l}\text { Panel of } \\
\text { genes }\end{array}$ & $202 ; 101,98$ & splicing site & & $1 *$ & 0 & 0 & 0 & 1 & 0 & 0 \\
\hline BC84 & 1:94697077G >A & c.91C > T p.(L31F) & $\begin{array}{l}\text { Exome } \\
\text { sequencing }\end{array}$ & $50 ; 20,30$ & missense & & 3 & 1 & 0 & 0 & 1 & 0 & 1 \\
\hline
\end{tabular}

1- Allele Count

2- 1000 Genomes Project.

3- Exome Variant Server.

* Pathogenicity evaluated only by the Human Splicing Finder 3.0 tool

Chromosome positions are based on human genome references hg19/GRCH37

cDNA position are based on RefSeq NM_004815.3 
The four LoF variants, including three splice site and one stopgain variant, were all predicted to disrupt the protein, based on in silico analysis: the splice site variants were predicted to alter canonical donor (c.2109+1G $>A$, intron18 and c.1576+1G $>A$, intron 14) or acceptor sites (c.698-1G>C, intron 7), according to the HSF tool; meanwhile, the variant $\mathrm{c} .1475 \mathrm{C}>\mathrm{A}$ was predicted to cause premature termination of protein synthesis at codon 492 (p.(S492*)) in exon 14 and lead to nonsense mediated decay (Mutation Taster; probability=1). It was possible to investigate segregation of LoF variants in two of these families (F4118 and 314) given the availability of DNA from other affected and unaffected relatives. In both cases variants segregated with NSCL/P in accordance with an autosomal dominant pattern with incomplete penetrance (Fig. 1).
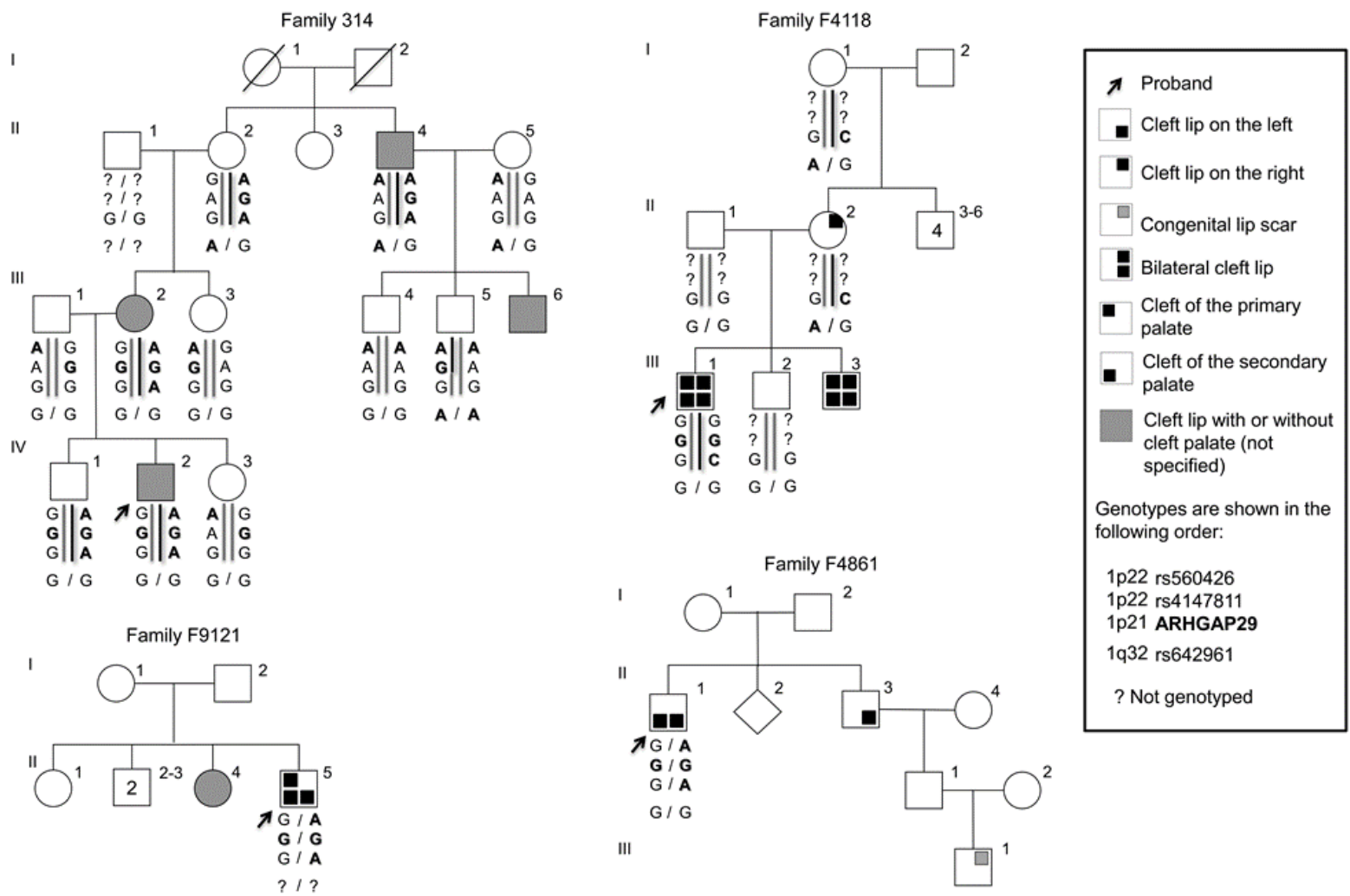

Figure 1: Pedigrees of the NSCL/P families showing genotypes for ARHGAP29 LoF variants, 1p22 SNVs (rs560426, rs4147811) and IRF6 SNV (rs642961). At-risk alleles are given in bold; the black and gray line indicate the recombination point; unavailable genotypes are indicated with "?".

A higher proportion of ARHGAP29 rare variants were found in NSCL/P probands as compared to controls (Table S1, Supporting Information) with a borderline level of significance (SKAT: $p=0.06$; Fisher's exact: $p=0.08$; patients: $11 / 188,5.85 \%$; controls: $37 / 1210,3.06 \%)$. Splitting the analysis by variant type, no significant 
difference in the distribution of missense variants with pathogenic in silico predictions was observed between groups (SKAT: $p=0.35$; Fisher: $p=0.51$; patients: $1 / 188,0.53 \%$; controls: $4 / 1210,0.33 \%)$. On the other hand, the number of LoF variants was significantly higher in patients (SKAT: $p=0.0005$; Fisher's test: $p=0.001$; patients: 4/188, 2.13\%; controls: 1/1210, 0.08\%).

Based on our findings, we hypothesized that the LoF variants are most probably implicated with NSCL/P. All four patients with LoF variants in ARHGAP29 have cleft lip (bilateral or unilateral) and cleft palate (Fig. 1). Phenotype expressivity among affected relatives ranged from a lip scar to a bilateral cleft lip/palate. Considering that NSCL/P segregates in an autosomal dominant model, penetrance in the four families was estimated as 0.595 (CI 95\%: 0.375-0.803).

To investigate whether penetrance effects in our families could be explained by common variants, we next evaluated if the LoF variants in ARHGAP29 we represent in trans or in cis with the at-risk alleles of loci rs560426 and rs4147811, at 1p22, which were shown to be associated with NSCL/P by GWAS. We observed that all the six affected genotyped individuals were homozygous for at least one of these SNVs while one of the two non-penetrant individuals was also homozygous for one of these SNVs (Fig. 1).

To take this idea further, we also tested if the at-risk allele of rs642961 (Rahimov et al., 2008), located in the IRF6 regulatory region, could influence the penetrance in individuals with ARHGAP29 LoF variants. This locus was also selected as it was previously suggested to be within the same pathway as ARHGAP29 (Biggs et al., 2014; Leslie et al., 2012). We observed that four of the nine individuals genotyped for rs642961 harbored the at-risk allele A, two were affected (Fig. 1, family 314 individual II-4 and family F4118 individual II-2), whereas the two other individuals were nonpenetrant mutation carriers (Fig. 1, family 314 individual II-2 and family F4118 individual I-1). These results suggest therefore that this SNP is unlikely to have a strong epistatic interaction with ARHGAP29.

\section{Discussion}

Exome and genome analyses have been contributing exponentially to the description of novel rare variants in several healthy and disease populations, particularly in those of European ancestry. Consequently, one of the current challenges 
is to distinguish variants leading to phenotypic variability from those that do not, particularly those in the heterozygous state. These difficulties are illustrated by the finding that healthy human genomes harbor about 100-250 LoF variants per individual (MacArthur \& Tyler-Smith, 2010). Studies of the distribution of rare variants in different populations with the phenotypes of interest are a possible approach to validate pathogenic variants.

In this study, ARHGAP29 mutation screening revealed five unique, rare heterozygous variants (one nonframeshift deletion and four LoF) and five already described rare missense variants in 188 NSCL/P families. In silico predictions of protein damage, segregation analysis and aggregation tests indicated that only the LoF variants, but not missense variants, in ARHGAP29 represent a major genetic risk factor for NSCL/P in our cohort. Indeed, according to ExAC database, whereas ARHGAP29 tolerates missense variants (ExAC Z-score: -0.27 ), it does not seem to tolerate LoF variants (ExAC Probability of LoF Intolerance: 1.00) (Lek et al., 2016). Structural variants involving ARHGAP29 are uncommon in the Database of Genomic Variants (MacDonald, Ziman, Yuen, Feuk, \& Scherer, 2014) while four of the five deletions in the Decipher database (Firth et al., 2009) involving ARHGAP29 are described with facial anomalies, including cleft palate. Further, downregulation of ARHGAP29 by genetic and epigenetic changes in both alleles have also been shown to be important in the phenotypic determination of mantle cell lymphomas (Ripperger et al., 2007; Schraders et al., 2008). Therefore, while there are evidence that LoF variants in ARHGAP29 contribute to the NSCL/P phenotype, missense variants should be functionally tested before they are defined as pathogenic.

The prevalence of rare LoF variants in our sample (2.1\%) was higher than those observed in other large NSCL/P studies (0.2-0.5\%) (Leslie et al., 2012, 2015). Possibly, these differences reflect the familial enrichment of multiplex families over population-dependent factors in our cohort. Interestingly, an enrichment of $\mathrm{CDH1}$ variants among familial cases (15\%) were also observed in a previous study of our group (Brito et al., 2015).

There is no evidence for a mutational hotspot within ARHGAP29 (Fig. 2), although the modest number of known LoF variants may obscure such a finding. In our families, these variants are associated with a broad spectrum of inter and intrafamilial clinical variability, as reported by others (Butali et al., 2014; Chandrasekharan \& Ramanathan, 2014; Leslie et al., 2012, 2015) (Table S2). 


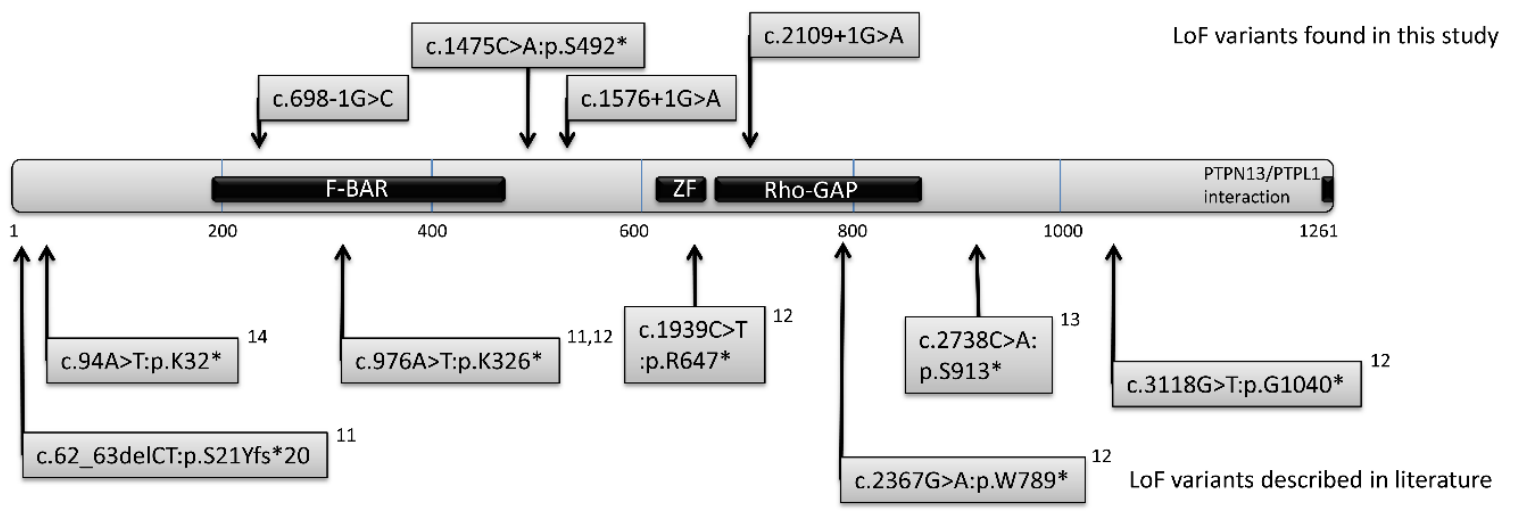

Figure 2: Scheme of the ARHGAP29 protein showing the distribution of rare germ-line LoF variants observed in NSCL/P patients. Variants described in our study are on top of the image and the variants described in the literature are below.

In all four families with LoF ARHGAP29 variants, NSCL/P segregated according to an autosomal dominant inheritance model with incomplete penetrance $(59 \%)$. We hypothesized that the NSCL/P penetrance in individuals with the LoF variants in ARHGAP29 could be modified by the presence of at-risk alleles identified by GWAS. Even though our data is based on a small sample, these preliminary results suggest that the SNVs at 1 p22 or rs642961 at IRF6 do not significantly contribute to the penetrance and do not support an interaction between ARHGAP29 and IRF6.

In summary, this study expands the mutational repertoire implicating ARHGAP29 with NSCL/P and provides evidence that heterozygous LoF variants in this gene confer a moderate risk to the disease and may be an important genetic factor at 1p22 driving the phenotype. In addition, given the incomplete penetrance observed, additional mechanisms may be required to trigger the phenotype. The study of multiplex families has proved to be an effective strategy to identify rare variants with moderate to high effect on NSCL/P because genetic factors that contribute to the etiology of the disease are likely to be more prevalent in this group of patients. Similarly, considering the relatively high proportion of families positive for LoF in ARHGAP29 ( 2\%), sequencing of this gene might be taken into consideration in genetic counseling of familial cases. 
Supplementary Table 1: ARHGAP29 rare variants found in Brazilian and UK controls.

\begin{tabular}{|c|c|c|c|c|c|c|c|c|c|c|}
\hline $\begin{array}{l}\text { Chromosome } \\
\text { position }\end{array}$ & cDNA/Protein alteration & $\begin{array}{l}\text { Variant } \\
\text { type }\end{array}$ & rs & $\begin{array}{l}\text { Tools } \\
\text { predicting } \\
\text { pathogenicity }\end{array}$ & $\begin{array}{l}\text { Exac } \\
\text { AC }^{1}(\mathrm{n} . \\
\text { homoz) }\end{array}$ & $\begin{array}{l}1000 \\
\text { Genomes } \\
A^{1}(n . \\
\text { homoz) } \\
\end{array}$ & $\begin{array}{l}\text { Exome } \\
\text { Variant } \\
\text { Server } \\
\mathrm{AC}^{1}\end{array}$ & $\begin{array}{l}\text { CLP } \\
\text { probands } \\
\mathrm{AC}^{1}\left(\mathrm{AN}^{2}=\right. \\
376)\end{array}$ & $\begin{array}{l}\text { Brazilian } \\
\text { Controls } A C^{1} \\
\left(\mathrm{AN}^{2}=1218\right)\end{array}$ & $\begin{array}{l}\text { British } \\
\text { Controls } A C^{1} \\
\left(A N^{2}=1201\right)\end{array}$ \\
\hline 1:94639475G>A & c.3736C>T:p.(R1246*) & stopgain & & & 1 & 0 & 0 & 0 & 0 & 1 \\
\hline 1:94639607C>T & c.3604G>A:p.(V1202M) & missense & rs144585524 & 0 & 18 & 0 & 0 & 0 & 0 & 1 \\
\hline 1:94639940T>C & c.3271A>G:p.(T1091A) & missense & & 0 & 0 & 0 & 0 & 0 & 0 & 2 \\
\hline 1:94639993T>C & c.3218A>G:p.(D1073G) & missense & & 2 & 15 & 0 & 0 & 0 & 1 & 0 \\
\hline $1: 94640030 \mathrm{C}>\mathrm{T}$ & c.3181G>A:p.(A1061T) & missense & rs141653334 & 0 & $25(1)$ & 0 & 3 & 0 & 1 & 0 \\
\hline $1: 94640129 C>G$ & c.3082G>C:p.(A1028P) & missense & rs146222354 & 0 & $332(6)$ & 30 & 0 & 0 & 0 & 4 \\
\hline 1:94640180G>A & c.3031C>T:p.(P1011S) & missense & & 2 & 2 & 0 & 0 & 0 & 1 & 0 \\
\hline $1: 94640188 \mathrm{C}>\mathrm{T}$ & c.3023G>A:p.(R1008K) & missense & rs140638899 & 2 & 25 & 3 & 7 & 0 & 1 & 0 \\
\hline $1: 94640208 C>G$ & c.3003G>C:p.(R1001S) & missense & & 1 & 0 & 0 & 0 & 0 & 0 & 6 \\
\hline $1: 94643236 \mathrm{C}>\mathrm{T}$ & c.2837G>A:p.(R946Q) & missense & & 0 & 5 & 1 & 1 & 0 & 0 & 1 \\
\hline $1: 94643436 A>G$ & c.2768T>C:p.(M923T) & missense & & 0 & 0 & 0 & 0 & 0 & 0 & 1 \\
\hline $1: 94643616 \mathrm{G}>\mathrm{A}$ & c.2588C>T:p.(S863F) & missense & & 3 & 0 & 0 & 0 & 0 & 0 & 1 \\
\hline 1:94643619A>G & c.2585T>C:p.(I862T) & missense & rs368604781 & 3 & 6 & 0 & 2 & 0 & 1 & 0 \\
\hline 1:94645327C>T & c.2434G >A:p. $(812 A>T)$ & missense & & 0 & 0 & 0 & 0 & 0 & 1 & 0 \\
\hline $1: 94645368 \mathrm{C}>\mathrm{T}$ & c.2393G>A:p.(R798Q) & missense & rs41311172 & 2 & $223(1)$ & 7 & 33 & 2 & 3 & 0 \\
\hline $1: 94654810 A>G$ & c.1538T>C:p.(I513T) & missense & rs61758880 & 0 & 66 & 1 & 19 & 0 & 0 & 3 \\
\hline $1: 94667305 \mathrm{C}>\mathrm{T}$ & c.G1252A:p.(V418I) & missense & rs148959325 & 1 & $181(1)$ & 6 & 0 & 1 & 0 & 1 \\
\hline 1:94668724T>C & c.805A>G:p.(N269D) & missense & & 2 & 2 & 0 & 0 & 0 & 0 & 2 \\
\hline $1: 94668734 A>C$ & c.795T>G:p.(N265K) & missense & rs61743723 & 1 & 25 & 6 & 9 & 0 & 1 & 0 \\
\hline $1: 94674437 \mathrm{~T}>\mathrm{C}$ & c.461A>G:p.(D154G) & missense & rs369329153 & 3 & 2 & 0 & 2 & 0 & 1 & 0 \\
\hline $1: 94685903 \mathrm{C}>\mathrm{T}$ & c. $251 \mathrm{G}>A: p .(\mathrm{R} 84 \mathrm{H})$ & missense & rs183410431 & 0 & 76 & $12(1)$ & 2 & 0 & 0 & 1 \\
\hline 1:94697077G>A & c.91C>T p.(L31F) & missense & & 3 & 1 & 0 & 0 & 1 & 0 & 1 \\
\hline 1:94697111T>G & c.57A>c:p.(Q19H) & missense & & 1 & 5 & 0 & 0 & 0 & 1 & 0 \\
\hline
\end{tabular}
missense

- Allele Count

Chromosome positions are based on human genome references hg19/GRCH37

cDNA position are based on RefSeq NM_004815.3 
Supplementary Table 2 ARHGAP29 rare loss-of-function variants described in patients with non-syndromic cleft lip with or without cleft palate in the literature.

\begin{tabular}{|c|c|c|c|c|c|c|c|c|c|c|}
\hline $\begin{array}{l}\text { Chromosome } \\
\text { position }\end{array}$ & $\begin{array}{l}\text { cDNA/Protein } \\
\text { alteration }\end{array}$ & Variant type & Reference & Exac MAF$^{1}$ & $\begin{array}{l}\text { Exac } \\
\mathrm{AC}^{2}\end{array}$ & & $\begin{array}{l}\text { NSCL/P } \\
\text { probands }\end{array}$ & Controls $^{3}$ & Phenotype & Inheritance \\
\hline $1: 94640093 \mathrm{C}>\mathrm{A}$ & $\begin{array}{l}\text { c. } 3118 G>T \\
\text { p. }\left(\mathrm{G} 1040^{*}\right)\end{array}$ & stopgain & Leslie et al., 2015 & 0 & & 0 & 1 & 0 & Cleft lip and palate & Unspecified parent \\
\hline $1: 94643466 \mathrm{G}>\mathrm{T}$ & $\begin{array}{l}\text { c. } 2738 \mathrm{C}>\mathrm{A} \\
\text { p. }\left(\mathrm{S} 913^{*}\right)\end{array}$ & stopgain & Butali et al., 2014 & $0^{*}$ & & $0^{*}$ & 1 & 0 & Cleft lip & Not avaliable \\
\hline $1: 94645394 \mathrm{C}>\mathrm{T}$ & $\begin{array}{l}\text { c. } 2367 G>A \\
\text { p. }\left(W 789^{*}\right)\end{array}$ & stopgain & Leslie et al., 2015 & 0 & & 0 & 1 & 0 & Cleft lip and palate & Unspecified parent \\
\hline $1: 94650427 \mathrm{C}>\mathrm{T}$ & c. $2109+1 \mathrm{G}>\mathrm{A}$ & splicing site & This study & 0 & & 0 & 1 & 0 & Unilateral cleft lip and palate & Unspecified parent \\
\hline $1: 94650598 \mathrm{G}>\mathrm{A}$ & $\begin{array}{l}\text { c. } 1939 C>T \\
\text { p. }\left(R 647^{*}\right)\end{array}$ & stopgain & Leslie et al., 2015 & 0 & & 0 & 1 & 0 & Cleft lip and palate & Unspecified parent \\
\hline $1: 94654771 \mathrm{C}>\mathrm{T}$ & c. $1576+1 G>A$ & splicing site & This study & 0 & & 0 & 1 & 0 & $\begin{array}{l}\text { Oral cleft not specified } \\
\text { (proband, mother and great- } \\
\text { uncle), unnafected } \\
\text { grandmother and brother }\end{array}$ & Mother \\
\hline $1: 94654873 \mathrm{G}>\mathrm{T}$ & $\begin{array}{l}\text { c. } 1475 \mathrm{C}>\mathrm{A} \\
\text { p. }\left(\mathrm{S} 42^{*}\right)\end{array}$ & stopgain & This study & 0 & & 0 & 1 & 0 & $\begin{array}{l}\text { Unilateral cleft lip and palate } \\
\text { (proband), unilateral cleft lip } \\
\text { (brother) }\end{array}$ & Unspecified parent \\
\hline 1:94668267T>A & $\begin{array}{l}\text { c. } 976 \mathrm{~A}>\mathrm{T} \\
\text { p. }\left(\mathrm{K} 326^{*}\right)\end{array}$ & stopgain & $\begin{array}{l}\text { Leslie et al., 2012; } \\
\text { Leslie et al., } 2015\end{array}$ & 0 & & 0 & 1 & 0 & $\begin{array}{l}\text { Bilateral cleft lip and palate } \\
\text { (proband), unnaffected mother } \\
\text { and grandfather }\end{array}$ & Mother \\
\hline $1: 94669551 C>G$ & c. $698-1 \mathrm{G}>\mathrm{C}$ & splicing site & This study & 0 & & 0 & 1 & 0 & $\begin{array}{l}\text { Bilateral cleft lip and palate } \\
\text { (proband and brother), } \\
\text { unilateral cleft lip (mother), } \\
\text { unnafected grandmother }\end{array}$ & Mother \\
\hline 1:94697074T $>A$ & $\begin{array}{l}\text { c. } 94 \mathrm{~A}>\mathrm{T} \\
\text { p. }\left(\mathrm{K} 32^{*}\right)\end{array}$ & stopgain & $\begin{array}{l}\text { Chandrasekharan } \\
\text { \& Ramanathan, } \\
2014\end{array}$ & 0 & & 0 & 1 & 0 & Cleft lip and palate & Not avaliable \\
\hline $\begin{array}{l}1: 94697105- \\
\text { 94697106delAG }\end{array}$ & $\begin{array}{l}\text { c.62 63delCT } \\
\text { p. }\left(\mathrm{S} 21 \mathrm{Yfs}^{\star} 20\right) \\
\end{array}$ & $\begin{array}{l}\text { frameshift } \\
\text { deletion }\end{array}$ & Leslie et al., 2012 & 0.00003297 & & 1 & 1 & 0 & $\begin{array}{l}\text { Bilateral cleft lip and palate } \\
\text { (proband), unnaffected sibling }\end{array}$ & Unspecified parent \\
\hline
\end{tabular}

1- Minor Allele Frequency.

2- Allele Count.

3- Control subjects included in each study

${ }^{*}$ A different variant in the same codon is described in Exac

Chromosome positions are based on human genome references hg19/GRCH37

cDNA position are based on RefSeq NM_004815.3 


\section{References}

1000 Genomes Project Consortium, Auton, A., Brooks, L. D., Durbin, R. M., Garrison, E. P., Kang, H. M., ... Abecasis, G. R. (2015). A global reference for human genetic variation. Nature, 526(7571), 68-74. doi:10.1038/nature15393

Adzhubei, I., Jordan, D. M., \& Sunyaev, S. R. (2013). Predicting functional effect of human missense mutations using PolyPhen-2. Current Protocols in Human Genetics, Chapter 7, Unit7.20. doi:10.1002/0471142905.hg0720s76

Attanasio, C., Nord, A. S., Zhu, Y., Blow, M. J., Li, Z., Liberton, D. K., ... Visel, A. (2013). Fine tuning of craniofacial morphology by distant-acting enhancers. Science, 342(6157), 1241006. doi:10.1126/science.1241006

Beaty, T. H., Murray, J. C., Marazita, M. L., Munger, R. G., Ruczinski, I., Hetmanski, J. B., ... Fallin, M. D. (2010). A genome-wide association study of cleft lip with and without cleft palate identifies risk variants near MAFB and ABCA4. Nature Genetics, 42(6), 525-529. doi:10.1038/ng.580

Biggs, L. C., Naridze, R. L., DeMali, K. A., Lusche, D. F., Kuhl, S., Soll, D. R., ... Dunnwald, M. (2014). Interferon regulatory factor 6 regulates keratinocyte migration. Journal of Cell Science, 127(Pt 13), 2840-2848. doi:10.1242/jcs. 139246

Birnbaum, S., Ludwig, K. U., Reutter, H., Herms, S., Steffens, M., Rubini, M., ... Mangold, E. (2009). Key susceptibility locus for nonsyndromic cleft lip with or without cleft palate on chromosome 8q24. Nature Genetics, 41(4), 473-477. doi:10.1038/ng.333

Brito, L. A., Yamamoto, G. L., Melo, S., Malcher, C., Ferreira, S. G., Figueiredo, J., ... Passos-Bueno, M. R. (2015). Rare Variants in the Epithelial Cadherin Gene Underlying the Genetic Etiology of Nonsyndromic Cleft Lip with or without Cleft Palate. Human Mutation, 36(11), 1029-1033. doi:10.1002/humu.22827

Burke, T. R., \& Tsang, S. H. (2011). Allelic and phenotypic heterogeneity in ABCA4 mutations. Ophthalmic Genetics, 32(3), 165-174. doi:10.3109/13816810.2011.565397

Butali, A., Mossey, P., Adeyemo, W., Eshete, M., Gaines, L., Braimah, R., ... Murray, J. (2014). Rare functional variants in genome-wide association identified candidate genes for nonsyndromic clefts in the African population. American Journal of Medical Genetics. Part A, 164A(10), 2567-2571. doi:10.1002/ajmg.a.36691

Chandrasekharan, D., \& Ramanathan, A. (2014). Identification of a novel heterozygous truncation mutation in exon 1 of ARHGAP29 in an Indian subject with nonsyndromic cleft lip with cleft palate. European Journal of Dentistry, 8(4), 528-532. doi:10.4103/1305-7456.143637 
Chun, S., \& Fay, J. C. (2009). Identification of deleterious mutations within three human genomes. Genome Research, 19(9), 1553-1561. doi:10.1101/gr.092619.109

Desmet, F.-O., Hamroun, D., Lalande, M., Collod-Béroud, G., Claustres, M., \& Béroud, C. (2009). Human Splicing Finder: an online bioinformatics tool to predict splicing signals. Nucleic Acids Research, 37(9), e67. doi:10.1093/nar/gkp215

Dixon, M. J., Marazita, M. L., Beaty, T. H., \& Murray, J. C. (2011). Cleft lip and palate: understanding genetic and environmental influences. Nature Reviews. Genetics, 12(3), 167-178. doi:10.1038/nrg2933

Firth, H. V., Richards, S. M., Bevan, A. P., Clayton, S., Corpas, M., Rajan, D., ... Carter, N. P. (2009). DECIPHER: Database of Chromosomal Imbalance and Phenotype in Humans Using Ensembl Resources. American Journal of Human Genetics, 84(4), 524-533. doi:10.1016/j.ajhg.2009.03.010

Horimoto, A. R. V. R., Onodera, M. T., \& Otto, P. A. (2010). PENCALC: A program for penetrance estimation in autosomal dominant diseases. Genetics and Molecular Biology, 33(3), 455-459. doi:10.1590/S1415-47572010005000054

Lek, M., Karczewski, K. J., Minikel, E. V., Samocha, K. E., Banks, E., Fennell, T., ... Cummings, B. B. (2016). Analysis of protein-coding genetic variation in 60,706 humans. Nature, 536(7616), 285-291. doi:10.1038/nature19057

Leslie, E. J., Carlson, J. C., Shaffer, J. R., Feingold, E., Wehby, G., Laurie, C. A., ... McHenry, T. (2016). A multi-ethnic genome-wide association study identifies novel loci for non-syndromic cleft lip with or without cleft palate on 2p24.2, 17q23 and 19q13. Human Molecular Genetics, 25(13), 2862-2872. doi:10.1093/hmg/ddw104

Leslie, E. J., Mansilla, M. A., Biggs, L. C., Schuette, K., Bullard, S., Cooper, M., ... Murray, J. C. (2012). Expression and mutation analyses implicate ARHGAP29 as the etiologic gene for the cleft lip with or without cleft palate locus identified by genome-wide association on chromosome 1p22. Birth Defects Research.

Part A, Clinical and Molecular Teratology, 94(11), 934-942. doi:10.1002/bdra.23076

Leslie, E. J., Taub, M. A., Liu, H., Steinberg, K. M., Koboldt, D. C., Zhang, Q., ... Murray, J. C. (2015). Identification of functional variants for cleft lip with or without cleft palate in or near PAX7, FGFR2, and NOG by targeted sequencing of GWAS loci. American Journal of Human Genetics, 96(3), 397411. doi:10.1016/j.ajhg.2015.01.004

Ludwig, K. U., Mangold, E., Herms, S., Nowak, S., Reutter, H., Paul, A., ... Nöthen, M. M. (2012). Genome-wide meta-analyses of nonsyndromic cleft lip with or without cleft palate identify six new risk loci. Nature Genetics, 44(9), 968-971. doi:10.1038/ng.2360 
MacArthur, D. G., \& Tyler-Smith, C. (2010). Loss-of-function variants in the genomes of healthy humans. Human Molecular Genetics, 19(R2), R125-30. doi:10.1093/hmg/ddq365

MacDonald, J. R., Ziman, R., Yuen, R. K. C., Feuk, L., \& Scherer, S. W. (2014). The Database of Genomic Variants: a curated collection of structural variation in the human genome. Nucleic Acids Research, 42(Database issue), D986-92. doi:10.1093/nar/gkt958

Mangold, E., Ludwig, K. U., Birnbaum, S., Baluardo, C., Ferrian, M., Herms, S., ... Nöthen, M. M. (2010). Genome-wide association study identifies two susceptibility loci for nonsyndromic cleft lip with or without cleft palate. Nature Genetics, 42(1), 24-26. doi:10.1038/ng.506

Mossey, P. A., Little, J., Munger, R. G., Dixon, M. J., \& Shaw, W. C. (2009). Cleft lip and palate. The Lancet, 374(9703), 1773-1785. doi:10.1016/S01406736(09)60695-4

Ng, P. C., \& Henikoff, S. (2001). Predicting deleterious amino acid substitutions. Genome Research, 11(5), 863-874. doi:10.1101/gr.176601

Rahimov, F., Marazita, M. L., Visel, A., Cooper, M. E., Hitchler, M. J., Rubini, M., ... Murray, J. C. (2008). Disruption of an AP-2alpha binding site in an IRF6 enhancer is associated with cleft lip. Nature Genetics, 40(11), 1341-1347. doi:10.1038/ng.242

Ripperger, T., von Neuhoff, N., Kamphues, K., Emura, M., Lehmann, U., Tauscher, M., ... Steinemann, D. (2007). Promoter methylation of PARG1, a novel candidate tumor suppressor gene in mantle-cell lymphomas. Haematologica, 92(4), 460-468.

Schraders, M., Jares, P., Bea, S., Schoenmakers, E. F. P. M., van Krieken, J. H. J. M., Campo, E., \& Groenen, P. J. T. A. (2008). Integrated genomic and expression profiling in mantle cell lymphoma: identification of gene-dosage regulated candidate genes. British Journal of Haematology, 143(2), 210-221. doi:10.1111/j.1365-2141.2008.07334.x

Schwarz, J. M., Rödelsperger, C., Schuelke, M., \& Seelow, D. (2010). MutationTaster evaluates disease-causing potential of sequence alterations. Nature Methods, 7(8), 575-576. doi:10.1038/nmeth0810-575

Sun, Y., Huang, Y., Yin, A., Pan, Y., Wang, Y., Wang, C., ... Yang, Y. (2015).

Genome-wide association study identifies a new susceptibility locus for cleft lip with or without a cleft palate. Nature Communications, 6, 6414.

doi:10.1038/ncomms7414 


\section{Capítulo 4}

\section{Estudo de microrganismos presentes na cavidade oral de mães com filhos portadores de fissuras labiais}

Faria AC, Ezquina S, Berselli AP, Antonio DSM, Bueno DF, Passos Bueno MR

Centro de Estudos do Genoma Humano e Células Tronco, Instituto de Biociências, Universidade de São Paulo, SP, Brasil

Nota do autor:

Esse trabalho é um estudo piloto realizado em um pequeno número amostral. $\mathrm{O}$ projeto foi reestruturado com novas colaborações e instituições co-participantes com o objetivo de aumentar o número amostral para novas análises serem realizadas. Atualmente se encontra na fase de coleta de novas amostras. 


\section{Resumo}

Apesar dos grandes avanços alcançados na busca por fatores genéticos de risco para as fissuras orofaciais não sindrômicas (FO-NS), as variantes genéticas encontradas conferem baixo risco e não explicam a alta herdabilidade dessa malformação. Por outro lado, estudos têm sugerido a importância dos fatores de risco ambientais na etiologia das FO-NS e fatores como exposição materna ao álcool, drogas, tabaco, medicamentos, desnutrição e baixo nível socioeconômico são alguns dos fatores associados a esta condição. As infecções periodontais são comuns em mulheres grávidas e estão associadas a parto prematuro, baixo peso fetal e também aumentam o risco para FO-NS nos fetos. Nesse estudo nosso objetivo foi verificar se existem diferenças consistentes entre a composição do microbioma oral de mães de crianças com FO-NS e mães de crianças sem quaisquer malformações congênitas, levando em consideração a presença ou não de doenças infecciosas periodontais maternas, através do sequenciamento da subunidade $16 \mathrm{~S}$ do RNA ribossomal de bactérias. De modo geral as análises de alfa e beta diversidades não demonstrou diferença significativa na composição do microbioma oral de mães de crianças com FO-NS e mães de crianças controle, contudo observamos que o grupo com infecções periodontais possui a diversidade taxonômica mais abundante do que o grupo hígido. Em resumo, nesse estudo piloto não foi possível identificar alterações no microbioma oral como um fator etiológico das FO-NS. Novas análises em uma casuística maior são necessárias para a confirmação desse achado.

Palavras-chave: microbioma, periodontite, fissuras orofaciais, alfa diversidade, beta diversidade. 


\begin{abstract}
Despite the great advances achieved in the search for genetic risk factors for nonsyndromic orofacial clefts (nsOFC), the genetic variants found confer low risk and do not explain the high heritability of this malformation. On the other hand, studies have suggested the importance of environmental risk factors in the etiology of nsOFC and factors such as maternal exposure to alcohol, drugs, tobacco, drugs, malnutrition and low socioeconomic status are some of the factors associated with this condition. Periodontal infections are common in pregnant women and are associated with preterm birth, low fetal weight and also increase the risk for nsOFC in fetuses. In this study our objective was to verify if there are consistent differences between the composition of the oral microbiome of mothers of children with nsOFC and mothers of children without any congenital malformations, taking into consideration the presence or absence of maternal periodontal infectious diseases, through the sequencing of the $16 \mathrm{~S}$ subunit of ribosomal RNA from bacteria. In general, the analyzes of alpha and beta diversities did not show a significant difference in the composition of the oral microbiome of mothers of children with nsOFC and mothers of control children, however, we observed that the group with periodontal infections has the most abundant taxonomic diversity healthy group. In summary, in this pilot study, it was not possible to identify alterations in the oral microbiome as an etiological factor of nsOFC. New analyzes in a larger number of samples are necessary to confirm this finding.
\end{abstract}

Key words: microbiome, periodontal infections, orofacial clefts, alpha diversity, beta diversity 


\section{Introdução}

O microbioma humano tem sido objeto de estudos em diversas áreas da saúde nos últimos anos. O avanço das tecnologias de sequenciamento do DNA, incluindo a análise do gene $16 \mathrm{~S}$ rRNA, melhorou exponencialmente a compreensão do microbioma humano e sua influência no estado de saúde e doença, e, mais especificamente, o conhecimento sobre o impacto do microbioma na gravidez (Fox \& Eichelberger, 2015).

Diversos estudos vêm explorando a possível associação entre doença periodontal e saúde sistêmica, e, nesse contexto, as infecções periodontais, muito comuns em mulheres grávidas, estão associadas a parto prematuro, baixo peso fetal, doença cardiovascular, diabetes mellitus e infecções respiratórias na criança (Mor \& Kwon, 2015). Como explicação para essas associações, acredita-se que bactérias encontradas comumente na periodontite e seus subprodutos, mediadores inflamatórios, possam modular a permeabilidade dos vasos sangüíneos permitindo que outros microrganismos atinjam a corrente sanguínea, alcançando a placenta e se espalhando pela circulação fetal e líquido amniótico (Fardini, Chung, Dumm, Joshi, \& Han, 2010; Madianos, Bobetsis, \& Offenbacher, 2013). Esses mediadores próinflamatórios induzem a resposta imune do feto podendo levar ao aborto ou ao nascimento prematuro ou também podem causar mudanças na estrutura da placenta que pode acarretar em pré-eclâmpsia e restrição de nutrientes ao feto e, consequentemente, baixo peso ao nascer (Fox \& Eichelberger, 2015). Em concordância com esses estudos, recentes estudos demonstraram que a placenta não é um órgão estéril, ao contrário do que se sempre acreditou, e que, além disso, sua microbiota é muito similar a microbiota oral em comparação com outros órgãos do corpo (Aagaard et al., 2012, 2013, 2014; Fardini et al., 2010; Guttmacher, Maddox, \& Spong, 2014; Proctor, 2011).

Ainda não existem estudos contudentes associando doenças periodontais maternas às malformações congênitas no feto, contudo, em um grande estudo de conjunto de dados populacionais de recém-nascidos com malformações congênitas, Bánhidy et al. (2010) descobriram que as mulheres grávidas com doenças infecciosas periodontais possuem um risco elevado de ter bebês com fissuras orofaciais não sindrômicas (FO-NS) (Bánhidy, Acs, Puhó, \& Czeizel, 2010). 
Diversos estudos epidemiológicos têm sugerido a importância de fatores ambientais na etiologia dos FO-NS. A exposição materna ao álcool, drogas, tabaco, medicamentos, desnutrição e baixo nível socioeconômico são alguns dos fatores ambientais já associados às FO-NS (Dixon, Marazita, Beaty, \& Murray, 2011). Nesse contexto, a fim de investigar se alterações de microbioma oral podem estar associadas à etiologia das FO-NS, contribuindo, portanto, para o entendimento da influência de fatores ambientais no surgimento dessas malformações, neste estudo buscamos verificar se existem diferenças consistentes entre a composição do microbioma oral de mães de crianças afetadas por FO-NS e de mães de crianças sem malformações congênitas.

\section{Material e Metódos}

\section{Aspectos éticos}

Este estudo foi aprovado pelo Comitê de Ética do Instituto de Biociências (Universidade de São Paulo, Brazil) (CAAE: 37287314.6.0000.5464) e pelo Comitê de Ética do Hospital Municipal Infantil Menino Jesus (CAAE: 43543615.8.3002.5639). Amostras biológicas foram obtidas após a assinatura do consentimento informado pelos pacientes, pais ou responsáveis legais.

\section{Casuística}

Doze mulheres brasileiras e residentes do estado de São Paulo não relacionadas, mães de bebês recém-nascidos (com no máximo um mês de idade) foram incluídas neste estudo. As mães foram entrevistadas no Hospital Municipal Infantil Menino Jesus (São Paulo, Brasil) (Tabela 1). O grupo de mães de neonatos afetados por FO não familiar e não sindrômica (incluindo fissura labiopalatina completa unilateral ou bilateral) foram definidas como o grupo de probandos e mães de recém-nascidos sem FO e qualquer outra malformação congênita foram definidas como o grupo controle. 
Tabela 1 - Perfil dos indivíduos sequenciados

\begin{tabular}{ccc}
\hline$N^{\circ}$ das amostras & Classificação & Saúde bucal \\
\hline F11018-1 & Controle & Hígida \\
F10984-1 & Controle & Hígida \\
F10983-1 & Controle & Hígida \\
F11292-1 & Controle & MPID \\
F11290-1 & Controle & MPID \\
F11289-1 & Controle & MPID \\
F010822-1 & Probando & MPID \\
F010878-1 & Probando & MPID \\
F011019-1 & Probando & MPID \\
F10996-1 & Probando & Hígida \\
F11005-1 & Probando & Hígida \\
F10972-1 & probando & Hígida \\
\hline
\end{tabular}

MPID: Participante possui algum tipo de doença periodontal infecciosa materna.

O exame clínico para avaliar o estado saudável do tecido dentário e periodontal foi realizado para todas as mães. Mães com algum tipo de doença gengival e/ou periodontal, como gengivite aguda e crônica, recessão gengival, periodontite aguda e crônica, outras doenças periodontais (epúlide, granuloma, cistos, pólipos, fibromatose) e também doenças periodontais não especificadas foram classificadas como portadoras de 'doenças infecciosas periodontais maternas' (ou MPIDs, do inglês, Maternal Periodontal Infectous Diseases) e mães sem gengivite, periodontite e/ou cárie foram classificadas como 'Hígidas' $(H)$. Dessa forma, tanto o grupo de mães de crianças com $\mathrm{FO}(\mathrm{N}=6)$ quanto no grupo de mães de controle $(\mathrm{N}=6)$ ainda ficou dividido entre indivíduos MPID ( $\mathrm{N}=3$ ) e indivíduos $\mathrm{H}(\mathrm{N}=3)$ (Tabela 1). Foi realizado ainda um exame clínico dos recém-nascidos para a classificação do tipo de $\mathrm{FO}$ e descartar qualquer malformação. Foram excluídas da casuística mães que, apesar de não possuírem doença periodontal, possuíam algum tipo de cárie.

No momento da entrevista também foi solicitado às mães o preenchimento de um questionário estruturado com dados sobre o histórico de saúde e hábitos de higiene da participante do estudo (abordando as doenças maternas, complicações na gravidez, uso de suplementos - particularmente ácido fólico e multivitaminas e hábitos de higiene bucal) antes e durante a gestação. O questionário também solicitou informações sobre o recém-nascido: peso ao nascer (gramas), idade gestacional no parto (semanas), tipo de parto e complicações. A assinatura do termo de 
consentimento informado foi obtida antes do questionário e coleta da amostra de saliva.

Coleta das amostras e extração de DNA

As amostras de DNA foram extraídas da saliva (coletadas com o Kit OMNIgeneDiscover® DNA Collection Kits (OM-501); DNA Genotek, Ottawa, ON, Canada) e purificadas seguindo instruções do fabricante.

Montagem da biblioteca e sequenciamento do $16 S$ rRNA

As regiões hipervariáveis v3-v4 do gene 16S do rRNA das bactérias foram amplificadas por reação em cadeia da polimerase (PCR, do inglês, polymerase chain reaction) utilizando primers universais correspondentes às posições 341 e 785 do gene 16S do rRNA de Escherichia coli e que contém sequências específicas para serem utilizadas na plataforma de sequenciamento massivo em paralelo MiSeq ${ }^{\circledR}$ Illumina (Illumina, San Diego, CA, Estados Unidos) (Klindworth et al., 2013): 5'TCGTCGGCAGCGTCAGATGTGTATAAGAGACAGCCTACGGGNGGCWGCAG (forward) 5'GTCTCGTGGGCTCGGAGATGTGTATAAGAGACAGGACTACHVGGGTATCTAATCC (reverse).

As condições da PCR foram as seguintes: 3 minutos a $95^{\circ} \mathrm{C}$, seguido de 25 ciclos de $95^{\circ} \mathrm{C}$ por 30 segundos, $55^{\circ} \mathrm{C}$ por 30 segundos, $72^{\circ} \mathrm{C}$ por 30 segundos, e uma extensão final de 5 minutos a $72^{\circ} \mathrm{C}$. As bibliotecas foram submetidas ao sequenciamento utilizando-se um protocolo de 300 ciclos, single-end (MiSeq ${ }^{\circledR}$ Reagent Kit v3; Illumina, San Diego, CA, Estados Unidos).

Processamento dos dados metagenômicos e análise estatística

Os dados brutos gerados a partir do sequenciamento das 12 amostras foram processados utilizando as ferramentas do pipeline de bioinformática chamado QIIME (do inglês, Quantitative Insights Into Microbial Ecology, version 1.8; (Caporaso et al., 2010). Para filtrar seqüências de baixa qualidade, aquelas com comprimento inferior a 200 nucleotídeos e com score de qualidade média inferior a 30 foram excluídas. As sequências foram depois atribuídas à sua amostra de origem com base em sequências identificadoras (barcodes), que foram em seguida descartadas juntamente 
com a sequência dos primers após a filtragem. Sequências quiméricas foram identificadas usando o ChimeraSlayer (Haas et al., 2011) e também foram removidas das análises subseqüentes.

Após isso, as sequências restantes foram agrupadas em unidades taxonômicas operacionais (OTUs) usando uma estratégia de coleta fechada de OTUs (closedreference OTU-picking), através da qual as sequências são comparadas diretamente contra o banco de dados Greengenes (versão 13.8; (McDonald et al., 2012), só se admitindo aquelas com um limite mínimo de $97 \%$ de similaridade com sequências do banco e então foram classificadas taxonomicamente. Esse processo resultou na formação de árvores filogenéticas, as quais foram utilizadas posteriormente.

Para a análise da alfa e beta diversidades, também utilizamos o pipeline QIIME. Primeiramente, realizamos a rarefação da tabela de OTUs, definido em 66.462 sequências, com base na amostra que possui o menor número de sequências. A diversidade alfa é definida como o número de organismos ou a diversidade taxonômica dentro de uma mesma população. Para a análise da alfa diversidade utilizamos o número de espécies observadas, que é a quantidade de OTUs presentes em cada amostra. Pode levar em conta apenas a diversidade de espécies presentes nas amostras (qualitativa ou não ponderada) ou, além disso, também considerar a abundância de cada uma das espécies (quantitativa ou ponderada) (Lozupone \& Knight, 2005).

Para a análise estatística da alfa diversidade foi realizado o teste não paramétrico de Monte Carlo. O teste t de Student foi usado para testar a significância da diversidade beta. $O$ limiar de significância estatística foi estabelecido em $p<0.05$ (ajustado pela correção de Bonferroni na beta diversidade).

\section{Resultados}

No total, 1.221.597,00 sequências foram geradas após a filtragem das 12 amostras de saliva, com uma média de 101.799,75 (intervalo 66.462,00 -162.421,00) por amostra. Detectamos 1.338 OTUs usando um limite de similaridade de $97 \%$ com base no banco de dados da Greengenes.

A curva de rarefação das amostras controle e probandos demonstrou que o número de sequências geradas a partir do sequenciamento foi suficiente para determinar a diversidade microbiana das amostras (Figura 1). 


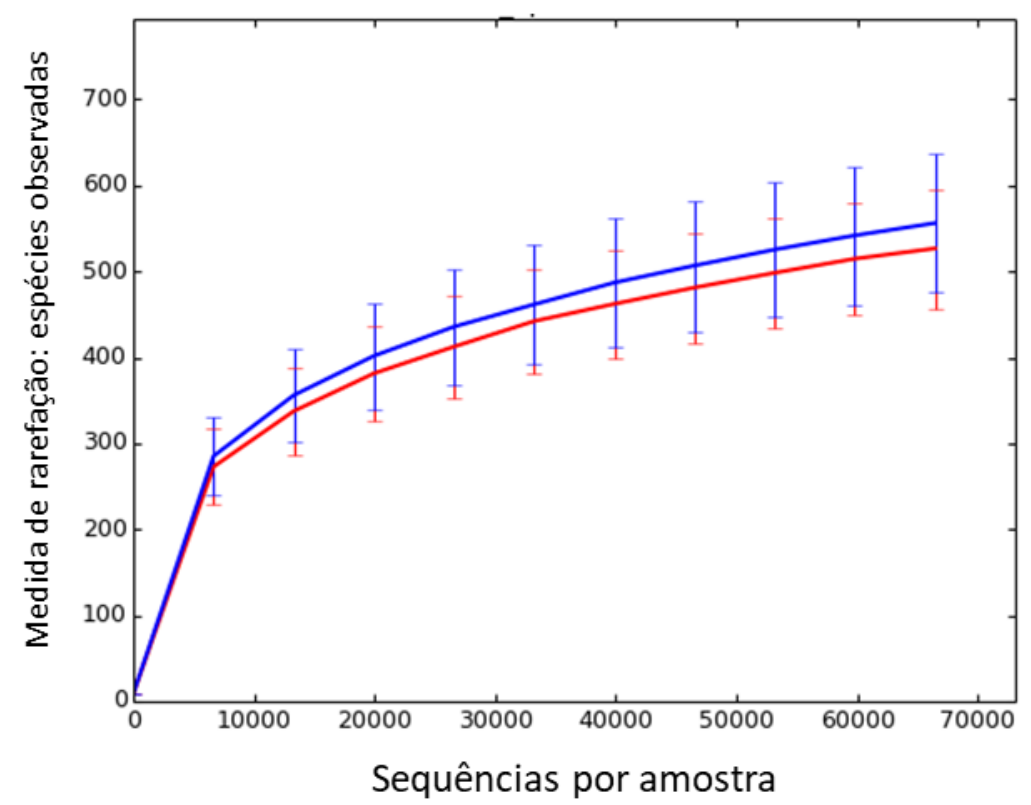

Figura 1: Curvas de rarefação demonstrando o número estimado de OTUs nas amostras probandos (azul) e controles (vermelho), em função do esforço de sequenciamento gerado a partir do QIIME. Ambas as curvas mostram os mesmos níveis de rarefação, permitindo comparações mais fáceis entre as categorias, mostrando que o esforço de sequenciamento foi suficiente para detectar a maioria das OTUs. As barras de erro mostram o erro padrão da diversidade média em cada nível de rarefação nas várias iterações.

A diversidade alfa da cavidade oral analisada através do número de espécies observadas, não diferiu significativamente entre os grupos probandos e controles (probandos (média $+/$ - desvio padrão) $=14.0+-13.0$; controles $=150.3+-222.7 ; \mathrm{t}=$ 0.8 ; $p$-valor $=0.4$; Figura $2 a$ ), entretanto, quando comparamos as amostras dividindoas entre amostras MPID e amostras $\mathrm{H}$, a diferença deste parâmetro foi estatisticamente significante $(\mathrm{MPID}=156.3+-11.3$; controles $=134.1+-18.5 ; \mathrm{t}=$ 228.4; $p$-valor $=0.038$; figura $2 b$ ). Quando estratificamos os grupos controle e probandos em $\mathrm{H}$ e MPID, também não encontramos diferença significativa na diversidade alfa entre os grupos (controle-H $=132.2+$ + 0.96; controle-MPID $=148.2$ + - 109.6; probando- $\mathrm{H}=136.1+-242.1$; probando-MPID $=16.4+-0.16$; todos $p$-valores $>0.42$; Figura 2c). 
a

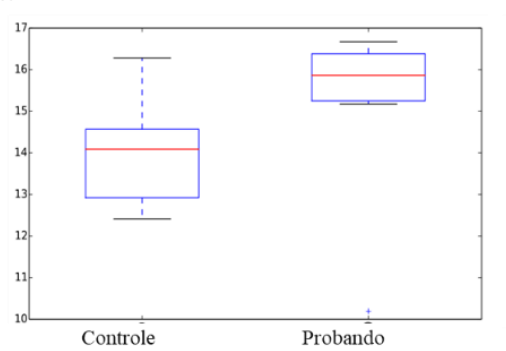

b

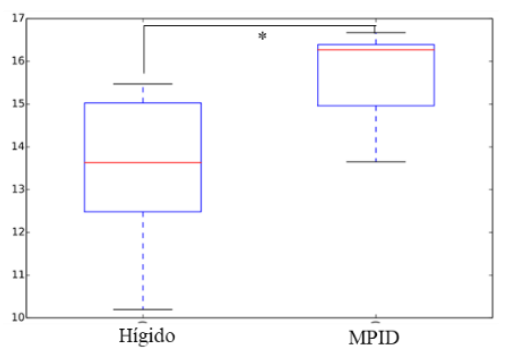

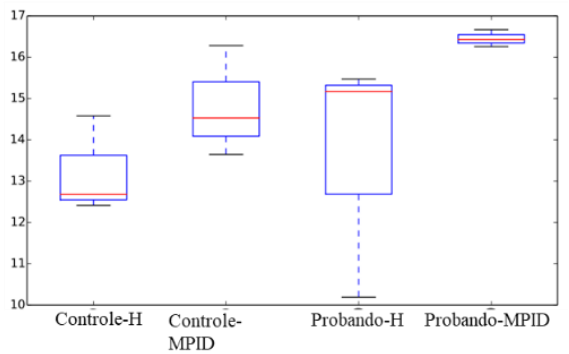

Figura 2: Diagramas da comparação da diversidade alfa medida pelo número de espécies observadas entre: a) o grupo dos probandos e dos controles; b) o grupo de amostras classificadas como Doenças Infecciosas Periodontais Maternas (MPID) e o grupo de amostras hígidas (H) e c) o grupo controlehígido, controle-MPID, probando-hígido e probando-MPID. Apenas a diferença entre a diversidade alfa entre os grupos de amostras hígidas e MPID foi estatisticamente significativo ( $p$-valor = 0.03).

A análise da beta diversidade (diversidade taxonômica entre populações) através do método de Análise de Coordenadas Principais ( $P C \circ A$ ) com base na matriz de distância UniFrac não ponderada (Figura 3a, 3c e 3e) não demonstrou uma variação clara na composição da diversidade bacteriana nas amostras probando comparadas com as amostras controles (Figura 3a), porém, demonstrou um agrupamento entre as amostras MPID (Figura 3c), sendo todas amostras de probandos (Figura $3 e$ ).

A PCoA com base na matriz de distância UniFrac ponderada (Figura 3b, 3d e 3f) também não demonstrou diferença clara entre a composição da diversidade bacteriana entre os grupos probandos e controles (Figura 3b) porém apontou uma tendência de agrupamento entre as amostras MPID (Figura 3d), e mais especificamente entre as amostras controle-H em detrimento às demais amostras (Figura 3f). 
a

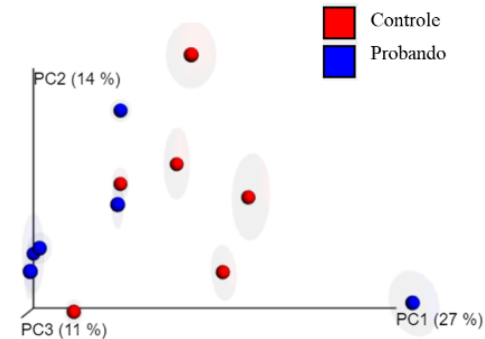

b

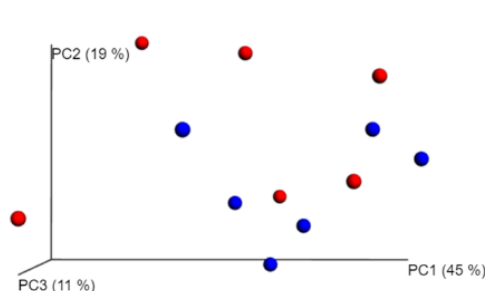

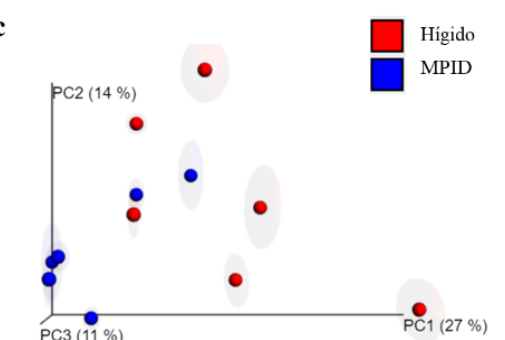

d

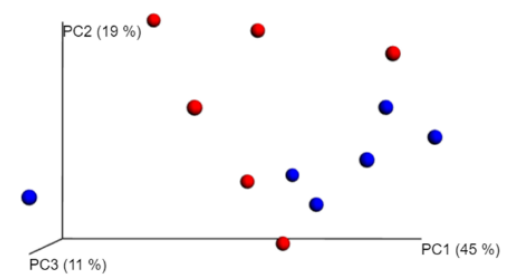

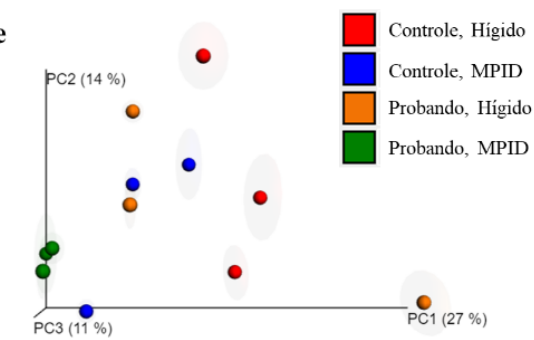

f

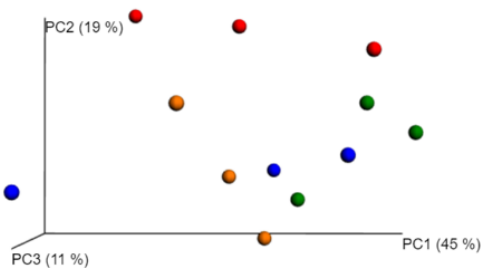

Figura 2: Análise da beta diversidade nas amostras de saliva estudadas pelo método de Análise de Coordenadas Principais (PCoA) não ponderada (a, c, e) e ponderada (b, d, f).

Adicionalmente, foram analisados gráficos de box-plots da beta diversidade (Figura 4) entre cada grupo estudado (probandos x probandos, por exemplo) e entre grupos (probandos $x$ controles, por exemplo) com base nas matrizes de distância Unifrac não ponderada (Figura 4a, 4c e 4e) e ponderada (Figura 4b, 4d e 4f). Para confirmar essas comparações, foi realizada a análise estatística através do teste de t de Student ajustado pela correção de Bonferroni. 

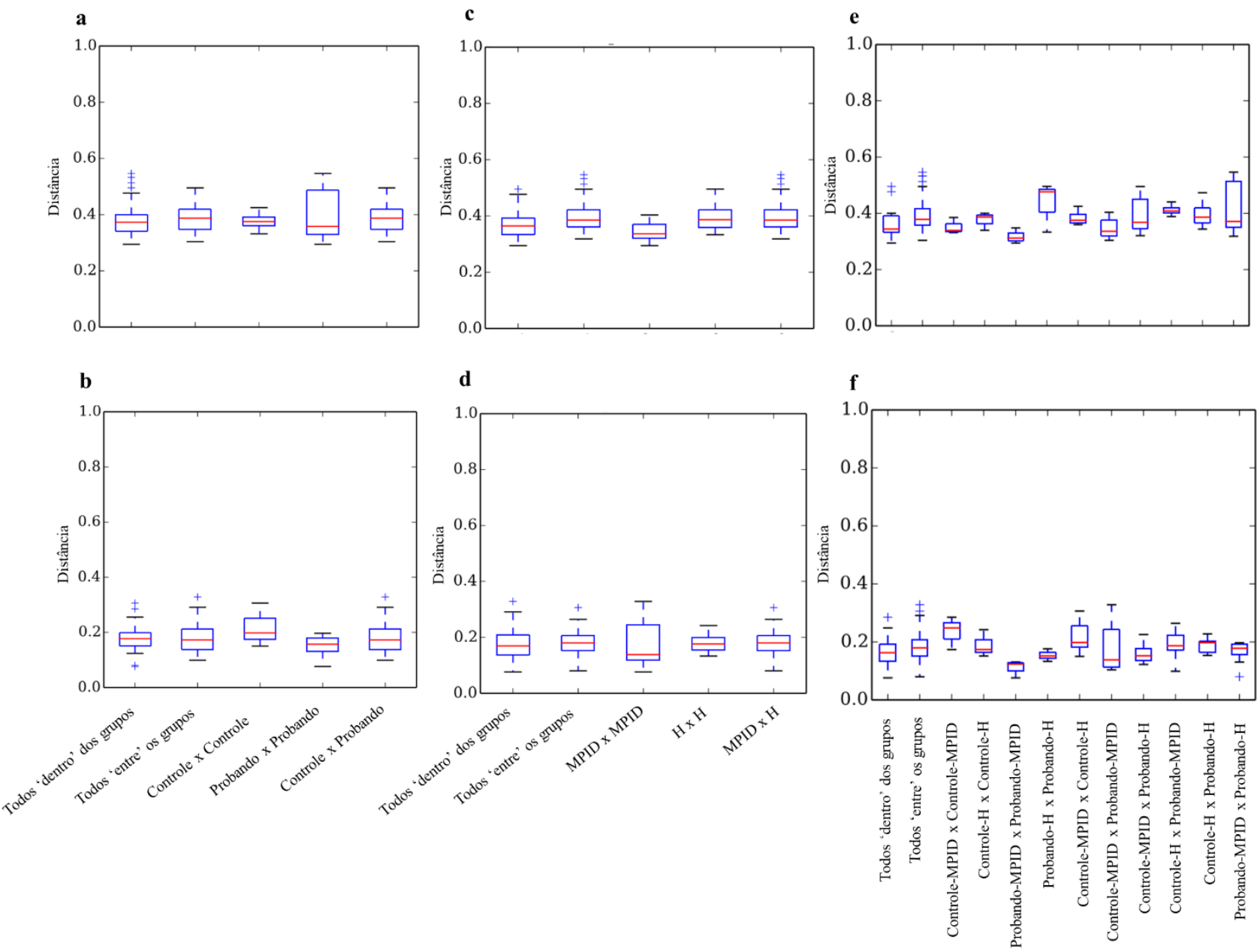

Figura 3: Gráficos box-plots das distâncias UniFrac não ponderada (a, c, e) e ponderada (b, d, f) da beta diversidade da microbiota oral em ambos grupos probandos e controles. Distâncias de 'todos' dentro dos grupos representam distâncias das amostras dentro de qualquer um dos grupos. Distâncias de 'entre' grupos mostram distâncias entre ambos os grupos. MPID: amostras com doença periodontal infecciosa materna. H: amostras hígidas. MPID x MPID e H x H representam distâncias dentro dos grupos MPID e $\mathrm{H}$ respectivamente. $\mathrm{O}$ mesmo se aplica às outras combinações.

Em relação a beta diversidade com base na distância UniFrac não ponderada, não observamos diferença significativa na composição microbiana entre os grupos probandos e controles. Por outro lado, nós observamos que a composição microbiana das amostras MPID e H é significativamente diferente ( $p$-valor $=0.008)$ e que, além disso, a composição microbiana entre as amostras MPID é mais similar entre si do que a composição microbiana das amostras $\mathrm{H}$ entre si $(\mathrm{p}$-valor $=0.02)$. Quando subdividimos os grupos, esses resultados se repetem, onde observamos que a beta diversidade das amostras probando-MPID é mais similar entre si ( $p$-valor $=0.001)$ e mais similar às amostras controle-MPID $(p$-valor $=0.01)$ do que às amostras controle$\mathrm{H}$. 
Já em relação a beta diversidade com base na distância UniFrac ponderada, encontramos que a composição microbiana entre as amostras controle é mais similar do que entre as amostras probando entre si ( $p$-valor $=0.007$ ). Nenhuma outra comparação entre os grupos foi estatisticamente significante.

\section{Discussão}

As recentes pesquisas sobre o microbioma oral vêm demonstrando o impacto que a presença de doenças periodontais na mãe durante a gravidez possui e suas possíveis consequências. As FO-NS são uma malformação congênita de herança multifatorial tendo como causa a interação de fatores de predisposição genéticos e fatores ambientais. Estudos epidemiológicos já associaram, por exemplo, o consumo de tabaco ou álcool durante a gravidez como fatores risco às FO-NS, porém ainda não existem estudos que abordem uma possível influência do microbioma oral materno nessa malformação.

Nesse aspecto, Banhidy et al., (2010) foram os primeiros a reportar o risco aumentado de grávidas com infecções periodontais terem bebês com FO-NS, sugerindo a possibilidade de influência do microbioma oral na etiologia das FO-NS, porém nenhuma análise foi realizada nesse aspecto.

Nós conduzimos o presente estudo piloto onde analisamos a diversidade taxônomica do microbioma oral de mães de crianças com FO-NS e mães de crianças sem malformações congênitas considerando a presença ou ausência de doença periodontal em ambos os grupos.

De modo geral, a análise de alfa e beta diversidades do microbioma oral derivado de amostras de saliva realizado nesse estudo não demonstrou diferença significativa entre o o microbioma oral das mães de FO-NS e nas mães controle.

Observamos que a diversidade alfa se mostrou significativamente diferente apenas entre os grupos MPID e H. Contudo é importante ressaltar que para essa comparação utilizamos apenas a contagem do número de espécies, sendo interessante a reanálise desses dados por outras métricas de medida de alfa diversidade e riqueza, como por exemplo o shannon, Simpson e chao1, disponíveis no QIIME.

Levando em conta a beta diversidade com base na distância UniFrac ponderada, ou seja, em que consideramos a diversidade e a abundância relativa das 
espécies em cada grupo, encontramos significância na comparação das distâncias das amostras controle entre si quando comparadas às distâncias das amostras probando entre si. Em outras palavras, as amostras do grupo controle possuem bactérias mais similares do que as amostras do grupo probando. Contudo, esse resultado não assume que as amostras controle e probando possuem diversidade beta distinta. Se considerarmos apenas a diversidade taxonômica entre os grupos (beta diversidade Unifrac não ponderada), não vemos essa diferença estatistica.

Encontramos uma clara diferença entre a diversidade taxonômica das amostras de mães com doenças periodontais e mães com higiene oral hígida. $\mathrm{O}$ grupo de amostras classificadas clinicamente como MPID possui diversidade alfa e beta estatisticamente diferente das amostras hígidas, isso se vê principalmente entre o grupo de amostras probando-MPID. Esse resultado está de acordo com os dados da literatura que mostram que a saúde bucal está associada à baixa diversidade e riqueza microbiana, ao passo que, o início das infecções orais e o status de doença se associa ao aumento da diversidade e riqueza da microbiota (Costalonga \& Herzberg, 2014).

Acreditamos que o número amostral utilizado não permitiu se observar diferença estatística na diversidade alfa entre os grupos probando e controle. Além disso, as análises de beta diversidade demonstraram uma discreta diferença na diversidade taxonômica entre as amostras probando- $\mathrm{H}$, ou seja, essas amostras são diferentes entre si e não representam um grupo, o que também pode ter influenciado nos resultados negativos. Faz se necessário o estudo de um maior número de mães, tanto de crianças FO-NS quanto de crianças controle, hígidas e MPID, para a confirmação desses resultados.

Outro ponto importante foi a escolha do método de seleção da OTU. Nessa primeira análise, utilizamos o método 'fechado' (closed-reference OTU-picking), que comparou as seqüências de nossas amostras com um banco de dados de seqüências e descartou todas aquelas que não possuíam similaridade de pelo menos $97 \%$. Esse método é considerado bastante estringente, por isso, é interessante refazer essa análise considerando um método menos rigoroso e comparar esses resultados para manter a confiabilidade desses dados sem perder informações relevantes. Além disso, a análise da abundância relativa das espécies presentes em cada grupo estudado é necessária, pois apesar de não termos encontrado diferença na a alfa e beta 
diversidade, é possível que algum microrganismo específico possa estar mais presente em um grupo do que em outro.

Em resumo, nesse estudo piloto não foi possível identificar alterações no microbioma oral como um fator etiológico das FO-NS. Novas análises em uma casuística maior são necessárias para a confirmação desse achado.

\section{Referências}

Aagaard, K., Ma, J., Antony, K. M., Ganu, R., Petrosino, J., \& Versalovic, J. (2014). The placenta harbors a unique microbiome. Science Translational Medicine, 6(237), 237ra65. doi:10.1126/scitranslmed.3008599

Aagaard, K., Petrosino, J., Keitel, W., Watson, M., Katancik, J., Garcia, N., ... Versalovic, J. (2013). The Human Microbiome Project strategy for comprehensive sampling of the human microbiome and why it matters. The FASEB Journal, 27(3), 1012-1022. doi:10.1096/fj.12-220806

Aagaard, K., Riehle, K., Ma, J., Segata, N., Mistretta, T.-A., Coarfa, C., ... Versalovic, J. (2012). A metagenomic approach to characterization of the vaginal microbiome signature in pregnancy. Plos One, 7(6), e36466. doi:10.1371/journal.pone.0036466

Bánhidy, F., Acs, N., Puhó, E. H., \& Czeizel, A. E. (2010). A possible association of periodontal infectious diseases in pregnant women with isolated orofacial clefts in their children: A population-based case-control study. Birth Defects Research. Part A, Clinical and Molecular Teratology, 88(6), 466-473. doi:10.1002/bdra.20664

Caporaso, J. G., Kuczynski, J., Stombaugh, J., Bittinger, K., Bushman, F. D., Costello, E. K., ... Knight, R. (2010). QIIME allows analysis of high-throughput community sequencing data. Nature Methods, 7(5), 335-336. doi:10.1038/nmeth.f.303

Costalonga, M., \& Herzberg, M. C. (2014). The oral microbiome and the immunobiology of periodontal disease and caries. Immunology Letters, 162(2 Pt A), 22-38. doi:10.1016/j.imlet.2014.08.017

Dixon, M. J., Marazita, M. L., Beaty, T. H., \& Murray, J. C. (2011). Cleft lip and palate: understanding genetic and environmental influences. Nature Reviews. Genetics, 12(3), 167-178. doi:10.1038/nrg2933

Fardini, Y., Chung, P., Dumm, R., Joshi, N., \& Han, Y. W. (2010). Transmission of diverse oral bacteria to murine placenta: evidence for the oral microbiome as a potential source of intrauterine infection. Infection and Immunity, 78(4), 17891796. doi:10.1128/IAI.01395-09 
Fox, C., \& Eichelberger, K. (2015). Maternal microbiome and pregnancy outcomes. Fertility and Sterility, 104(6), 1358-1363. doi:10.1016/j.fertnstert.2015.09.037

Guttmacher, A. E., Maddox, Y. T., \& Spong, C. Y. (2014). The Human Placenta Project: placental structure, development, and function in real time. Placenta, 35(5), 303-304. doi:10.1016/j.placenta.2014.02.012

Haas, B. J., Gevers, D., Earl, A. M., Feldgarden, M., Ward, D. V., Giannoukos, G., ... Birren, B. W. (2011). Chimeric 16S rRNA sequence formation and detection in Sanger and 454-pyrosequenced PCR amplicons. Genome Research, 21(3), 494-504. doi:10.1101/gr.112730.110

Klindworth, A., Pruesse, E., Schweer, T., Peplies, J., Quast, C., Horn, M., \& Glöckner, F. O. (2013). Evaluation of general 16S ribosomal RNA gene PCR primers for classical and next-generation sequencing-based diversity studies. Nucleic Acids Research, 41(1), e1. doi:10.1093/nar/gks808

Lozupone, C., \& Knight, R. (2005). UniFrac: a new phylogenetic method for comparing microbial communities. Applied and Environmental Microbiology, 71(12), 8228-8235. doi:10.1128/AEM.71.12.8228-8235.2005

Madianos, P. N., Bobetsis, Y. A., \& Offenbacher, S. (2013). Adverse pregnancy outcomes (APOs) and periodontal disease: pathogenic mechanisms. Journal of Periodontology, 84(4 Suppl), S170-80. doi:10.1902/jop.2013.1340015

McDonald, D., Price, M. N., Goodrich, J., Nawrocki, E. P., DeSantis, T. Z., Probst, A., ... Hugenholtz, P. (2012). An improved Greengenes taxonomy with explicit ranks for ecological and evolutionary analyses of bacteria and archaea. The ISME Journal, 6(3), 610-618. doi:10.1038/ismej.2011.139

Mor, G., \& Kwon, J.-Y. (2015). Trophoblast-microbiome interaction: a new paradigm on immune regulation. American Journal of Obstetrics and Gynecology, 213(4 Suppl), S131-7. doi:10.1016/j.ajog.2015.06.039

Proctor, L. M. (2011). The Human Microbiome Project in 2011 and beyond. Cell Host \& Microbe, 10(4), 287-291. doi:10.1016/j.chom.2011.10.001 


\section{Capítulo 5}

\section{Discussão geral e conclusões}

A busca por fatores genéticos que explicam a alta herdabilidade das fissuras orofaciais não-sindrômicas (FO-NS) tem sido realizada há muitos anos e por grupos de estudo do mundo inteiro. As metodologias utilizadas no passado, como os estudos de associação genômicos (do inglês, Genome-Wide Association Studies, GWAS), se baseavam, principalmente, na busca por uma causa comum e trouxeram à luz vários loci de susceptibilidade, sendo que alguns já foram replicados e confirmados, e ainda há muitos que ainda estão sendo alvo de estudos (Beaty, Marazita, \& Leslie, 2016).

A implementação do sequenciamento de nova geração, e posteriormente a queda no seu custo, permitiu que o foco da busca pela herdabilidade perdida das FONS mudasse e, então, as variantes raras passaram a ser 0 alvo dos estudos etiológicos genéticos desse dimorfismo. Nesse contexto, nós obtivemos sucesso no presente estudo e acrescentamos mais conhecimento sobre a etiologia genética das FO-NS e sobre as variantes raras envolvidas, que dentro das famílias estudadas parecem ter um padrão Mendeliano.

O resultado do sequenciamento das 193 famílias com FO-NS corrobora os achados da literatura sobre as variantes de perda de função (do inglês, loss-offunction, LoF) possuírem maior impacto na susceptibilidade das FO-NS do que as variantes missense. Nosso estudo demonstrou que os probandos possuem $7 \mathrm{x}$ mais variantes raras e patogênicas do tipo LoF do que os controles. E ainda, que essas variantes LoF estão presentes em genes que são intolerantes a esse tipo de mutação, ou seja, que estão sofrendo pressão seletiva. Assim, além dos programas de predição in silico de dano à proteína e priorização de variantes já conhecidos e amplamente utilizados na literatura, sugerimos o uso da métrica disponibilizada pelo banco de dados ExAC que classifica os genes como intolerantes ou não a diversos tipos de mutações (Lek et al., 2016).

Levando-se em consideração as variantes raras já reportadas em indivíduos com FO-NS familial segregando em um padrão de herança autossômico dominante com penetrância incompleta sugerimos utilizar como critério de priorização, genes 
com pLI (probabilidade de intolerância a mutações LoF) maior ou igual a 0.3. Segundo o ExAC, quanto maior o valor de $\mathrm{pLI}$ - que tem seu valor máximo $=1$, maior a probabilidade de o gene ser intolerante a variações do tipo LoF e, além disso, observou-se que todos os genes associados a doenças humanas causadas por haploinsuficiência possuem pLI > 9. Nosso estudo é o primeiro que sugere a utilização do $\mathrm{pLI}>0.3$ para priorizar genes em estudos de FO-NS. Mais estudos reportando o enriquecimento de variantes raras do tipo LoF em genes intolerantes em indivíduos com FO-NS são necessários para validar essa hipótese.

Além disso, observamos que dentro da nossa casuística das 7 variantes raras e patogênicas do tipo LoF, três estão no gene ARHGAP29. Esse gene foi sugerido como possível fator de susceptibilidade às FO-NS da região 1p22, um importante lócus replicado por estudos de GWAS. Juntamente com os dados do sequenciamento de exoma de 15 famílias provenientes do Reino Unido, e o estudo de segregação das variantes nos outros membros das famílias, concluímos que as variantes LoF nesse gene seriam as responsáveis pela segregação da FO-NS nas famílias estudadas (Brasileiras e Inglesas) e sendo, portanto, um importante fator de susceptibilidade às FO-NS, contribuindo para a elucidação da herdabilidade perdida. Ademais, esse achado demonstra a validez no re-sequenciamento de genes candidatos por estudos de GWAS em estudos etiológicos de FO-NS.

Apesar da ampla disponibilidade e do fácil acesso aos programas de predição in silico de dano a proteína e priorização de variantes, de modo geral, a classificação da patogenicidade das variantes missense ainda é duvidosa (Adzhubei, Jordan, \& Sunyaev, 2013; Ghosh, Oak, \& Plon, 2017). Mesmo seguindo as diretrizes do American College of Medical Genetics and Genomics (ACMG) (Richards et al., 2015), ainda faltam na literatura informações funcionais sobre os genes e descrições de casos de FO-NS reportados com mutações raras e patogênicas do tipo missense. Por esse motivo, a grande maioria das variantes raras missense que encontramos na nossa casuística foram classificadas como VUS (variante de significado incerto, ou variant of uncertain significance, VUS) (Richards et al., 2015). Assim, é impossível afirmar no momento se as variantes raras missense encontradas na nossa casuística são realmente neutras ou patogênicas.

$\mathrm{Na}$ tentativa de explorar o possível papel do microbioma oral na etiologia da FO-NS nós conduzimos o estudo piloto descrito no capítulo 4. A partir da metodologia de análise utilizada não foi observado diferença significativa na alfa e beta 
diversidades entre o microbioma oral das mães de crianças com FO-NS e mães controle. Apesar do pequeno número amostral, conseguimos observar diferença na alfa e beta diversidade entre os grupos de mães com algum tipo de infecção periodontal e mães com higiene oral hígida e, mais especificamente, entre o grupo de mães de crianças com FO-NS que possuem infecções periodontais. Esses resultados estão conforme a literatura, onde se sabe que infecções orais são representadas pelo microbioma oral mais diverso e abundante. Para confirmar se as amostras de mães de crianças com FO-NS e infecção periodontal são diferentes que mães de crianças controle com infecção periodontal, e também, analisar se há algum microrganismo que esteja presente em um maior número em um dos grupos, será necessário a replicação dessa análise em um número amostral maior. Caso nossa hipótese seja confirmada, uma nova etapa do estudo será desenvolvida para entender quais processos epigenéticos podem estar sendo modificados com a presença desse microbioma específico.

Em conclusão, o presente estudo confirma o importante papel das variantes raras na etiologia das FO-NS, mais especificamente das variantes do tipo LoF. Adicionalmente, também reportamos novas variantes raras e patogênicas que nunca haviam sido descritas na literatura e sugerimos como critério de priorização de genes em estudos etiológicos das FO-NS pLI > 0.3 (ExAC; (Lek et al., 2016). Por fim, não encontramos diferença no microbioma oral de mães de crianças com FO-NS e mães controle que possa apontar o microbioma oral como um fator de risco ambiental na etiologia das FO-NS. 


\section{Capítulo 6}

\section{Referências gerais}

1000 Genomes Project Consortium, Auton, A., Brooks, L. D., Durbin, R. M., Garrison, E. P., Kang, H. M., ... Abecasis, G. R. (2015). A global reference for human genetic variation. Nature, 526(7571), 68-74. doi:10.1038/nature15393

Aagaard, K., Ma, J., Antony, K. M., Ganu, R., Petrosino, J., \& Versalovic, J. (2014). The placenta harbors a unique microbiome. Science Translational Medicine, 6(237), 237ra65. doi:10.1126/scitranslmed.3008599

Aagaard, K., Petrosino, J., Keitel, W., Watson, M., Katancik, J., Garcia, N., ... Versalovic, J. (2013). The Human Microbiome Project strategy for comprehensive sampling of the human microbiome and why it matters. The FASEB Journal, 27(3), 1012-1022. doi:10.1096/fj.12-220806

Aagaard, K., Riehle, K., Ma, J., Segata, N., Mistretta, T.-A., Coarfa, C., ... Versalovic, J. (2012). A metagenomic approach to characterization of the vaginal microbiome signature in pregnancy. Plos One, 7(6), e36466. doi:10.1371/journal.pone.0036466

Acuña-González, G., Medina-Solís, C. E., Maupomé, G., Escoffie-Ramírez, M., Hernández-Romano, J., Márquez-Corona, M. de L., ... Villalobos-Rodelo, J. J. (2011). Family history and socioeconomic risk factors for non-syndromic cleft lip and palate: a matched case-control study in a less developed country. Biomedica: Revista Del Instituto Nacional de Salud, 31(3), 381-391. doi:10.1590/S0120-41572011000300010

Adzhubei, I., Jordan, D. M., \& Sunyaev, S. R. (2013). Predicting functional effect of human missense mutations using PolyPhen-2. Current Protocols in Human Genetics, Chapter 7, Unit7.20. doi:10.1002/0471142905.hg0720s76

Al Chawa, T., Ludwig, K. U., Fier, H., Pötzsch, B., Reich, R. H., Schmidt, G., ... Mangold, E. (2014). Nonsyndromic cleft lip with or without cleft palate: Increased burden of rare variants within Gremlin-1, a component of the bone morphogenetic protein 4 pathway. Birth Defects Research. Part A, Clinical and Molecular Teratology, 100(6), 493-498. doi:10.1002/bdra.23244

Alfwaress, F. S. D., Khwaileh, F. A., Rawashdeh, M. A., Alomari, M. A., \& Nazzal, M. S. (2017). Cleft lip and palate: demographic patterns and the associated communication disorders. The Journal of Craniofacial Surgery, 28(8), 21172121. doi:10.1097/SCS.0000000000003984

Alvizi, L., Ke, X., Brito, L. A., Seselgyte, R., Moore, G. E., Stanier, P., \& PassosBueno, M. R. (2017). Differential methylation is associated with non-syndromic cleft lip and palate and contributes to penetrance effects. Scientific Reports, 7(1), 2441. doi:10.1038/s41598-017-02721-0 
Aschard, H., Qiu, W., Pasaniuc, B., Zaitlen, N., Cho, M. H., \& Carey, V. (2011). Combining effects from rare and common genetic variants in an exome-wide association study of sequence data. BMC Proceedings, 5 Supp/ 9, S44. doi:10.1186/1753-6561-5-S9-S44

Bánhidy, F., Acs, N., Puhó, E. H., \& Czeizel, A. E. (2010). A possible association of periodontal infectious diseases in pregnant women with isolated orofacial clefts in their children: A population-based case-control study. Birth Defects Research. Part A, Clinical and Molecular Teratology, 88(6), 466-473. doi:10.1002/bdra.20664

Bansal, V., Libiger, O., Torkamani, A., \& Schork, N. J. (2010). Statistical analysis strategies for association studies involving rare variants. Nature Reviews. Genetics, 11(11), 773-785. doi:10.1038/nrg2867

Beaty, T H, Taub, M. A., Scott, A. F., Murray, J. C., Marazita, M. L., Schwender, H., ... Ruczinski, I. (2013). Confirming genes influencing risk to cleft lip with/without cleft palate in a case-parent trio study. Human Genetics, 132(7), 771-781. doi:10.1007/s00439-013-1283-6

Beaty, Terri H, Marazita, M. L., \& Leslie, E. J. (2016). Genetic factors influencing risk to orofacial clefts: today's challenges and tomorrow's opportunities. [version 1; referees: 2 approved]. F1000Research, 5, 2800. doi:10.12688/f1000research.9503.1

Bik, E. M., Long, C. D., Armitage, G. C., Loomer, P., Emerson, J., Mongodin, E. F., ... Relman, D. A. (2010). Bacterial diversity in the oral cavity of 10 healthy individuals. The ISME Journal, 4(8), 962-974. doi:10.1038/ismej.2010.30

Brito, Luciano A, Bassi, C. F. S., Masotti, C., Malcher, C., Rocha, K. M., Schlesinger, D., ... Passos-Bueno, M. R. (2012). IRF6 is a risk factor for nonsyndromic cleft lip in the Brazilian population. American Journal of Medical Genetics. Part A, 158A(9), 2170-2175. doi:10.1002/ajmg.a.35526

Brito, Luciano A, Cruz, L. A., Rocha, K. M., Barbara, L. K., Silva, C. B. F., Bueno, D. F., ... Passos-Bueno, M. R. (2011). Genetic contribution for non-syndromic cleft lip with or without cleft palate (NS CL/P) in different regions of Brazil and implications for association studies. American Journal of Medical Genetics. Part A, 155A(7), 1581-1587. doi:10.1002/ajmg.a.34036

Brito, Luciano Abreu, Meira, J. G. C., Kobayashi, G. S., \& Passos-Bueno, M. R. (2012). Genetics and management of the patient with orofacial cleft. Plastic Surgery International, 2012, 782821. doi:10.1155/2012/782821

Brito, Luciano Abreu, Yamamoto, G. L., Melo, S., Malcher, C., Ferreira, S. G., Figueiredo, J., ... Passos-Bueno, M. R. (2015). Rare Variants in the Epithelial Cadherin Gene Underlying the Genetic Etiology of Nonsyndromic Cleft Lip with or without Cleft Palate. Human Mutation, 36(11), 1029-1033. doi:10.1002/humu.22827 
Bureau, A., Parker, M. M., Ruczinski, I., Taub, M. A., Marazita, M. L., Murray, J. C., ... Beaty, T. H. (2014). Whole exome sequencing of distant relatives in multiplex families implicates rare variants in candidate genes for oral clefts. Genetics, 197(3), 1039-1044. doi:10.1534/genetics.114.165225

Christensen, K., \& Fogh-Andersen, P. (1993). Cleft lip (+/- cleft palate) in Danish twins, 1970-1990. American Journal of Medical Genetics, 47(6), 910-916. doi:10.1002/ajmg.1320470620

Clark, J. D., Mossey, P. A., Sharp, L., \& Little, J. (2003). Socioeconomic status and orofacial clefts in Scotland, 1989 to 1998. The Cleft Palate-Craniofacial Journal, 40(5), 481-485. doi:10.1597/1545-

1569_2003_040_0481_ssaoci_2.0.co_2

Cohen, J. C., Kiss, R. S., Pertsemlidis, A., Marcel, Y. L., McPherson, R., \& Hobbs, H. $\mathrm{H}$. (2004). Multiple rare alleles contribute to low plasma levels of HDL cholesterol. Science, 305(5685), 869-872. doi:10.1126/science.1099870

Dickson, S. P., Wang, K., Krantz, I., Hakonarson, H., \& Goldstein, D. B. (2010). Rare variants create synthetic genome-wide associations. PLoS Biology, 8(1), e1000294. doi:10.1371/journal.pbio.1000294

Dixon, M. J., Marazita, M. L., Beaty, T. H., \& Murray, J. C. (2011). Cleft lip and palate: understanding genetic and environmental influences. Nature Reviews. Genetics, 12(3), 167-178. doi:10.1038/nrg2933

Fardini, Y., Chung, P., Dumm, R., Joshi, N., \& Han, Y. W. (2010). Transmission of diverse oral bacteria to murine placenta: evidence for the oral microbiome as a potential source of intrauterine infection. Infection and Immunity, 78(4), 17891796. doi:10.1128/IAI.01395-09

Feil, R., \& Fraga, M. F. (2012). Epigenetics and the environment: emerging patterns and implications. Nature Reviews. Genetics, 13(2), 97-109. doi:10.1038/nrg3142

Ghosh, R., Oak, N., \& Plon, S. E. (2017). Evaluation of in silico algorithms for use with ACMG/AMP clinical variant interpretation guidelines. Genome Biology, 18(1), 225. doi:10.1186/s13059-017-1353-5

Grosen, D., Bille, C., Petersen, I., Skytthe, A., Hjelmborg, J. von B., Pedersen, J. K., ... Christensen, K. (2011). Risk of oral clefts in twins. Epidemiology, 22(3), 313-319. doi:10.1097/EDE.0b013e3182125f9c

Gur, T. L., Shay, L., Palkar, A. V., Fisher, S., Varaljay, V. A., Dowd, S., \& Bailey, M. T. (2017). Prenatal stress affects placental cytokines and neurotrophins, commensal microbes, and anxiety-like behavior in adult female offspring. Brain, Behavior, and Immunity, 64, 50-58. doi:10.1016/j.bbi.2016.12.021

Guttmacher, A. E., Maddox, Y. T., \& Spong, C. Y. (2014). The Human Placenta Project: placental structure, development, and function in real time. Placenta, 35(5), 303-304. doi:10.1016/j.placenta.2014.02.012 
Handel, A. E., Ebers, G. C., \& Ramagopalan, S. V. (2010). Epigenetics: molecular mechanisms and implications for disease. Trends in Molecular Medicine, 16(1), 7-16. doi:10.1016/j.molmed.2009.11.003

Hou, L., Zhang, X., Wang, D., \& Baccarelli, A. (2012). Environmental chemical exposures and human epigenetics. International Journal of Epidemiology, 41(1), 79-105. doi:10.1093/ije/dyr154

Hunt, K. A., Smyth, D. J., Balschun, T., Ban, M., Mistry, V., Ahmad, T., ... Bockett, N. A. (2012). Rare and functional SIAE variants are not associated with autoimmune disease risk in up to 66,924 individuals of European ancestry. Nature Genetics, 44(1), 3-5. doi:10.1038/ng.1037

IPDTOC Working Group. (2011). Prevalence at birth of cleft lip with or without cleft palate: data from the International Perinatal Database of Typical Oral Clefts (IPDTOC). The Cleft Palate-Craniofacial Journal, 48(1), 66-81. doi:10.1597/09-217

Jiang, Y., Yuen, R. K. C., Jin, X., Wang, M., Chen, N., Wu, X., ... Scherer, S. W. (2013). Detection of clinically relevant genetic variants in autism spectrum disorder by whole-genome sequencing. American Journal of Human Genetics, 93(2), 249-263. doi:10.1016/j.ajhg.2013.06.012

Johansen, C. T., Wang, J., Lanktree, M. B., Cao, H., Mclntyre, A. D., Ban, M. R., ... Hegele, R. A. (2010). Excess of rare variants in genes identified by genomewide association study of hypertriglyceridemia. Nature Genetics, 42(8), 684687. doi:10.1038/ng.628

Johansen, C. T., Wang, J., Mclntyre, A. D., Martins, R. A., Ban, M. R., Lanktree, M. B., ... Hegele, R. A. (2012). Excess of rare variants in non-genome-wide association study candidate genes in patients with hypertriglyceridemia. Circulation. Cardiovascular Genetics, 5(1), 66-72. doi:10.1161/CIRCGENETICS.111.960864

Koo, J., \& Zavras, A. (2013). Antiepileptic drugs (AEDs) during pregnancy and risk of congenital jaw and oral malformation. Oral Diseases, 19(7), 712-720. doi:10.1111/odi.12061

Lee, S., Abecasis, G. R., Boehnke, M., \& Lin, X. (2014). Rare-variant association analysis: study designs and statistical tests. American Journal of Human Genetics, 95(1), 5-23. doi:10.1016/j.ajhg.2014.06.009

Lek, M., Karczewski, K. J., Minikel, E. V., Samocha, K. E., Banks, E., Fennell, T., ... Cummings, B. B. (2016). Analysis of protein-coding genetic variation in 60,706 humans. Nature, 536(7616), 285-291. doi:10.1038/nature19057

Leslie, E J, \& Murray, J. C. (2013). Evaluating rare coding variants as contributing causes to non-syndromic cleft lip and palate. Clinical Genetics, 84(5), 496500. doi:10.1111/cge.12018 
Leslie, Elizabeth J, \& Marazita, M. L. (2013). Genetics of cleft lip and cleft palate. American Journal of Medical Genetics. Part C, Seminars in Medical Genetics, 163C(4), 246-258. doi:10.1002/ajmg.c.31381

Leslie, Elizabeth J., \& Marazita, M. L. (2015). Genetics of orofacial cleft birth defects. Current Genetic Medicine Reports, 3(3), 118-126. doi:10.1007/s40142-0150074-x

Maher, B. (2008). Personal genomes: The case of the missing heritability. Nature, 456(7218), 18-21. doi:10.1038/456018a

Manolio, T. A., Collins, F. S., Cox, N. J., Goldstein, D. B., Hindorff, L. A., Hunter, D. J., ... Visscher, P. M. (2009). Finding the missing heritability of complex diseases. Nature, 461(7265), 747-753. doi:10.1038/nature08494

Marazita, M. L., Lidral, A. C., Murray, J. C., Field, L. L., Maher, B. S., Goldstein McHenry, T., ... Arcos-Burgos, M. (2009). Genome scan, fine-mapping, and candidate gene analysis of non-syndromic cleft lip with or without cleft palate reveals phenotype-specific differences in linkage and association results. Human Heredity, 68(3), 151-170. doi:10.1159/000224636

McKusick, V. A. (2007). Mendelian Inheritance in Man and its online version, OMIM. American Journal of Human Genetics, 80(4), 588-604. doi:10.1086/514346

Monteiro, F. P., Vieira, T. P., Sgardioli, I. C., Molck, M. C., Damiano, A. P., Souza, J., ... Gil-da-Silva-Lopes, V. L. (2013). Defining new guidelines for screening the 22q11.2 deletion based on a clinical and dysmorphologic evaluation of 194 individuals and review of the literature. European Journal of Pediatrics, 172(7), 927-945. doi:10.1007/s00431-013-1964-0

Mor, G., \& Kwon, J.-Y. (2015). Trophoblast-microbiome interaction: a new paradigm on immune regulation. American Journal of Obstetrics and Gynecology, 213(4 Suppl), S131-7. doi:10.1016/j.ajog.2015.06.039

Mossey, P A, \& Modell, B. (2012). Epidemiology of oral clefts 2012: an international perspective. Frontiers of Oral Biology, 16, 1-18. doi:10.1159/000337464

Mossey, Peter A, Little, J., Munger, R. G., Dixon, M. J., \& Shaw, W. C. (2009). Cleft lip and palate. The Lancet, 374(9703), 1773-1785. doi:10.1016/S01406736(09)60695-4

Munger, R. G., Sauberlich, H. E., Corcoran, C., Nepomuceno, B., Daack-Hirsch, S., \& Solon, F. S. (2004). Maternal vitamin B-6 and folate status and risk of oral cleft birth defects in the Philippines. Birth Defects Research. Part A, Clinical and Molecular Teratology, 70(7), 464-471. doi:10.1002/bdra.20037

Proctor, L. M. (2011). The Human Microbiome Project in 2011 and beyond. Cell Host \& Microbe, 10(4), 287-291. doi:10.1016/j.chom.2011.10.001

Reich, D. E., \& Lander, E. S. (2001). On the allelic spectrum of human disease. Trends in Genetics, 17(9), 502-510. doi:10.1016/S0168-9525(01)02410-6 
Richards, S., Aziz, N., Bale, S., Bick, D., Das, S., Gastier-Foster, J., ... ACMG Laboratory Quality Assurance Committee. (2015). Standards and guidelines for the interpretation of sequence variants: a joint consensus recommendation of the American College of Medical Genetics and Genomics and the Association for Molecular Pathology. Genetics in Medicine, 17(5), 405-424. doi:10.1038/gim.2015.30

Rivas, M. A., Beaudoin, M., Gardet, A., Stevens, C., Sharma, Y., Zhang, C. K., ... Daly, M. J. (2011). Deep resequencing of GWAS loci identifies independent rare variants associated with inflammatory bowel disease. Nature Genetics, 43(11), 1066-1073. doi:10.1038/ng.952

Sivertsen, A., Wilcox, A. J., Skjaerven, R., Vindenes, H. A., Abyholm, F., Harville, E., \& Lie, R. T. (2008). Familial risk of oral clefts by morphological type and severity: population based cohort study of first degree relatives. BMJ (Clinical Research Ed.), 336(7641), 432-434. doi:10.1136/bmj.39458.563611.AE

Stanier, P., \& Moore, G. E. (2004). Genetics of cleft lip and palate: syndromic genes contribute to the incidence of non-syndromic clefts. Human Molecular Genetics, 13 Spec No 1, R73-81. doi:10.1093/hmg/ddh052

Vieira, A. R. (2012). Genetic and environmental factors in human cleft lip and palate. Frontiers of Oral Biology, 16, 19-31. doi:10.1159/000337521

Visscher, P. M., Hill, W. G., \& Wray, N. R. (2008). Heritability in the genomics era-concepts and misconceptions. Nature Reviews. Genetics, 9(4), 255-266. doi:10.1038/nrg2322

Vissers, L. E. L. M., de Ligt, J., Gilissen, C., Janssen, I., Steehouwer, M., de Vries, P., ... Veltman, J. A. (2010). A de novo paradigm for mental retardation. Nature Genetics, 42(12), 1109-1112. doi:10.1038/ng.712

Vogelaar, I. P., Figueiredo, J., van Rooij, I. A. L. M., Simões-Correia, J., van der Post, R. S., Melo, S., ... Hoogerbrugge, N. (2013). Identification of germline mutations in the cancer predisposing gene $\mathrm{CDH} 1$ in patients with orofacial clefts. Human Molecular Genetics, 22(5), 919-926. doi:10.1093/hmg/dds497

Wade, W. G. (2013). The oral microbiome in health and disease. Pharmacological Research, 69(1), 137-143. doi:10.1016/j.phrs.2012.11.006

Watkins, S. E., Meyer, R. E., Strauss, R. P., \& Aylsworth, A. S. (2014). Classification, epidemiology, and genetics of orofacial clefts. Clinics in Plastic Surgery, 41(2), 149-163. doi:10.1016/j.cps.2013.12.003

Zhang, Q. (2015). Associating rare genetic variants with human diseases. Frontiers in Genetics, 6, 133. doi:10.3389/fgene.2015.00133

Zucchero, T. M., Cooper, M. E., Maher, B. S., Daack-Hirsch, S., Nepomuceno, B., Ribeiro, L., ... Murray, J. C. (2004). Interferon regulatory factor 6 (IRF6) gene variants and the risk of isolated cleft lip or palate. The New England Journal of Medicine, 351(8), 769-780. doi:10.1056/NEJMoa032909 


\section{Capítulo 7}

\section{Resumo}

As fissuras orofaciais não-sindrômicas (FO-NS) correspondem a $70 \%$ de todos os casos de FO, possuem etiologia complexa e pouco compreendida, sendo consideradas de herança multifatorial com forte influência de fatores genéticos e ambientais. Apesar de estudos de análise de ligação e associação apontarem vários loci de susceptibilidade às FO-NS, o componente genético ainda não está totalmente explicado. Fatores ambientais também possuem um importante papel na etiologia das FO, e alguns já foram replicados em várias populações. Fatores como exposição materna ao álcool, drogas, tabaco, medicamentos, desnutrição e baixo nível socioeconômico são alguns dos fatores já associados a esta condição. As infecções periodontais são comuns em mulheres grávidas e estão associadas a parto prematuro, baixo peso fetal e, mais recentemente, foram reportadas como fator de risco aumentado para FO-NS nos fetos. Adicionalmente, o avanço das tecnologias de sequenciamento do DNA melhorou exponencialmente a compreensão do microbioma humano e sua influência no estado de saúde e doença, e, mais especificamente, o conhecimento sobre o impacto do microbioma na gravidez. O objetivo deste projeto foi identificar novos fatores etiológicos genéticos e ambientais das FO-NS. Para isso, primeiramente, sequenciamos 68 genes candidatos a FO por sequenciamento de nova geração em 193 indivíduos com FO-NS familial. Nós encontramos enriquecimento significativo de variantes raras e patogênicas de perda de função nos indivíduos com FO-NS e observamos que essas variantes estão em genes intolerantes a esse tipo de mutação. Também reportamos novas variantes raras do tipo perda de função no gene ARHGAP29 e sua importância na susceptibilidade as FO-NS familiais. Além disso, sugerimos o uso de um ponto de corte baseado no escore pLI do banco de dados ExAC como parâmetro para priorizar variantes em estudos de FO-NS familiares, assumindo modelo de herança mono ou oligogênico. Adicionalmente, estudamos o microbioma oral de mães de crianças com FO-NS e mães de crianças sem malformações, utilizando o sequenciamento da subunidade $16 S$ do rRNA das bactérias com o objetivo de verificar diferenças consistentes na composição do microbioma oral de mães de crianças com FO-NS, levando em consideração a presença ou não de doenças infecciosas periodontais maternas. A casuística foi composta de 6 mães de recém-nascidos de até 1 mês que apresentaram FO-NS ao nascimento e mães de crianças sem qualquer malformação congênita. As análises de alfa e beta diversidades não demonstraram diferença significativa na composição do microbioma oral de mães de crianças com FO-NS e mães de crianças controle, contudo observamos que o grupo com infecções periodontais possui a diversidade taxonômica mais abundante do que o grupo hígido. Em resumo, nesse estudo piloto não foi possível identificar alterações no microbioma oral como um fator etiológico das FO-NS. Novas análises em uma casuística maior são necessárias para a confirmação desse achado 


\begin{abstract}
The non-syndromic orofacial clefts (nsOFC) correspond to $70 \%$ of all OFC cases, have complex etiology and are poorly understood, being considered multifactorial inheritance with a strong influence of genetic and environmental factors. Although linkage and association analysis studies point to several nsOFC susceptibility loci, the genetic component is not yet fully explained. Environmental factors also play an important role in OFC etiology, and some have been replicated in several populations. Factors such as maternal exposure to alcohol, drugs, tobacco, drugs, malnutrition and low socioeconomic status are some of the factors already associated with this condition. Periodontal infections are common in pregnant women and are associated with preterm birth, low birth weight and, more recently, have been reported as an increased risk factor for nsOFC in fetuses. Additionally, the advancement of DNA sequencing technologies has exponentially improved the understanding of the human microbiome and its influence on health and disease status, and, more specifically, knowledge about the impact of the microbiome on pregnancy. The objective of this project was to identify new genetic and environmental etiological factors of nsOFC. For this, we first sequenced 68 candidate genes by next generation sequencing in 193 individuals with familial nsOFC. We found significant enrichment of rare and pathogenic loss of function variants in individuals with nsOFC and we observed that these variants were in genes intolerant to this type of mutation. We also reported new rare loss-of-function variants in the ARHGAP29 gene and its importance in the liability of familial nsOFC. In addition, we suggested the use of a cutoff point based on the ExAC database $\mathrm{pLI}$ score as a parameter to prioritize variants in familial nsOFC studies, assuming a mono or oligogenic inheritance model. In addition, we studied the oral microbiome of 6 mothers of newborns up to 1-month-old with nsOFC and 6 mothers of newborns without congenital malformations using the 16S rRNA sequencing in order to verify consistent differences in the composition of the oral microbiome of mothers of children with nsOFC, taking into account the presence or absence of maternal periodontal infectious diseases. The analysis of alpha and beta diversities did not show a significant difference in the composition of the oral microbiome of mothers of nsOFC children and mothers of control children, however, we observed that the group with periodontal infectious diseases has more abundant taxonomic diversity than the healthy group. In summary, in this pilot study, it was not possible to identify alterations in the oral microbiome as an etiological factor of FO-NS. New analyzes in a larger cohort are necessary to confirm this finding
\end{abstract}




\title{
Apêndice: Publicações adicionais
}

I- Meira JGC, Sarno MAC, Faria ÁCO, Yamamoto GL, Bertola DR, Scheibler GG,Tavares DF, Acosta AX. Diagnosis of Atelosteogenesis Type I suggested by Fetal Ultrasonography and Atypical Paternal Phenotype with Mosaicism. Rev Bras Ginecol Obstet. 2018 Sep;40(9):570-576. doi: 10.1055/s-0038-1670684.

\section{Diagnosis of Atelosteogenesis Type I suggested by Fetal Ultrasonography and Atypical Paternal Phenotype with Mosaicism}

\section{Diagnóstico de atelosteogênese tipo I sugerido por ultrassonografia fetal e fenótipo paterno atípico com mosaicismo}

\author{
Joanna Goes Castro Meira ${ }^{1}$ Manoel Alfredo Curvelo Sarno ${ }^{2}$ Ágatha Cristhina Oliveira Faria ${ }^{3}$ \\ Guilherme Lopes Yamamoto ${ }^{3}$ Débora Romeo Bertola ${ }^{3}$ Gabriela Gayer Scheibler ${ }^{1}$ \\ Dione Fernandes Tavares ${ }^{1}$ Angelina Xavier Acosta ${ }^{1}$
}

\footnotetext{
${ }^{1}$ Department of Medical Genetics, Hospital Universitário Professor Edgard Santos, Universidade Federal da Bahia, Salvador, BA, Brazil

2 Maternidade Climério de Oliveira, Universidade Federal da Bahia, Salvador, BA, Brazil

${ }^{3}$ Center for Studies of the Human Genome and of Stem Cells Department of Genetics and Evolutionary Biology, Institute of Biosciences, Universidade de São Paulo, São Paulo, SP, Brazil

Rev Bras Ginecol Obstet 2018;40:570-575.
}

Address for correspondence Joanna Goes Castro Meira, MD, MSc, Departamento de Genética Médica. Hospital Universitário Professor Edgard Santos, Universidade Federal da Bahia, Rua Dr. Augusto Viana, 40110-060, Canela, Salvador, BA, Brazil (e-mail: joannagcm@gmail.com).

$\begin{array}{ll}\text { Abstract } & \begin{array}{l}\text { Atelosteogenesis type I (AOI) is an autosomal dominant skeletal dysplasia caused by } \\ \text { mutations in the filamin B (FLNB) gene with classic and well-recognizable clinical } \\ \text { findings. However, parents affected with a mild phenotype, probably with somatic } \\ \text { mosaicism, can generate offspring with a much more severe phenotype of AOI. In the } \\ \text { present report, we describe a female newborn with classic AOI leading to early neonatal } \\ \text { death, whose diagnostic was based on prenatal radiological findings and on the } \\ \text { physical examination of the father. Since her father had limb deformities and corporal }\end{array} \\ \begin{array}{ll}\text { Keywords } & \text { asymmetry, suggesting somatic mosaicism, his biological samples were analyzed } \\ \text { - atelosteogenesis } & \text { through a gene panel for skeletal dysplasias. A missense mutation not previously } \\ \text { - somatic mosaicism } & \text { described in the literature was detected in the FLNB gene, affecting 20\% of the } \\ \text { - skeletal dysplasia } & \text { evaluated cells and, therefore, confirming the diagnosis of mosaic AOI in the father. The } \\ \text { - FLNB } & \text { molecular analysis of the father was crucial to suggest the diagnosis of AOI in the } \\ \text { - exome-target } & \text { newborn, since she died early and there were no biological samples available. }\end{array} \\ \begin{array}{l}\text { sequencing } \\ \text { - fetal ultrasonography }\end{array}\end{array}$

Esse artigo reporta um caso grave de Atelosteogenesis tipo I herdado do pai, que é portador de um grau leve do fenótipo causado por um mosaicismo somático nunca diagnosticado. Nosso grupo participou do diagnóstico clínico e molecular do paciente. 
II - Zane, LS; Rebouças, MRGO; Perrone, AMS; Errera, FIV; Pinto, IA; Costa, JVF; Faria, ACO; Paulo, MSL. Anomalias cromossômicas em abortos espontâneos em uma maternidade pública do município de Vitória, ES, Brasil. Salus Journal of Health Sciences, v. 2, p. 50-57, 2016.

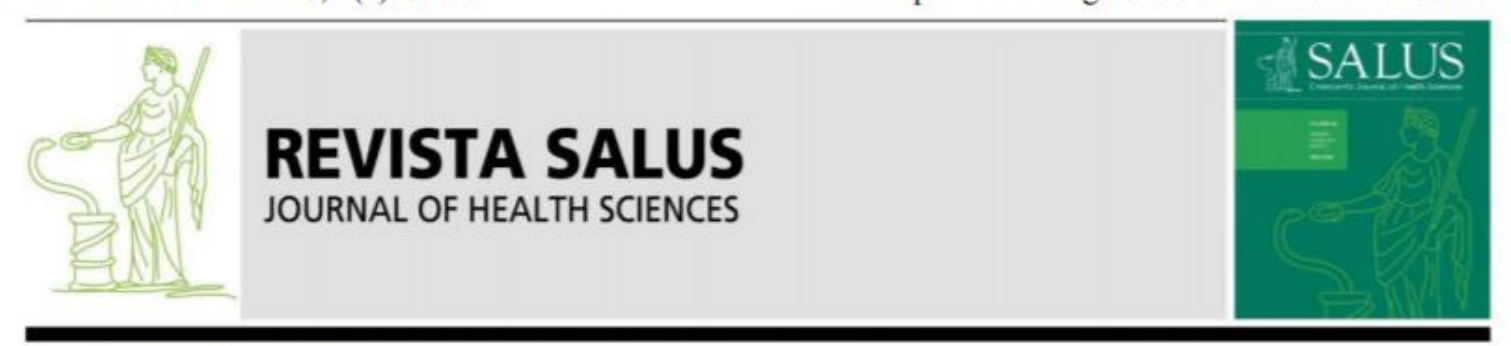

ARTIGO ORIGINAL

\section{Anomalias cromossômicas em abortos espontâneos em uma maternidade pública do município de Vitória, Espirito Santo, Brasil.}

Larissa Silva Zane ${ }^{1 *}$; Angela Maria Spagnol Perrone ${ }^{2}$; Iara Almeida Pinto ${ }^{3}$; Josivany Valério de Freitas Costa ${ }^{4}$ : Marcela Souza Lima Paulo ${ }^{5}$ Agatha Cristhina Oliveira Faria ${ }^{6}$; Flavia Imbroisi Valle Errera ${ }^{7}$ Maria Regina Galvêas Oliveira Rebouças ${ }^{8}$

\footnotetext{
${ }^{1}$ Bióloga - Mestranda em Biotecnologia (UFES), bolsista FAPES.

${ }^{2}$ Especialização em citogenetica, Bióloga (Laboratório Genoma do Espírito Santo).

${ }^{3}$ Farmacêutica pela Escola Superior de Ciência da Santa Casa de Misericórdia de Vitória EMESCAM, Bolsista CNPq.

${ }^{4}$ Bióloga - Doutoranda na Rede Nordeste de Biotecnologia - RENORBIO - Universidade Federal do Espirito Santo - UFES.

${ }^{5}$ Doutora pela Universidade Federal de Minas Gerais - UFMG, Bióloga, Professora de Medicina, Ciência e Tecnologia (EMESCAM)

${ }^{6}$ Farmacêutica - Doutoranda em ciências - Genética (USP)

${ }^{7}$ Doutora em Ciências - Genética (USP), Bióloga - Professora de Genética,Biologia Molecular (EMESCAM).

${ }^{8}$ Mestre em Ciências - Genética (USP), Médica Geneticista do HINSG e Professora de Genética (UVV).
}

Nesse artigo foi estudada e reportada a frequência de anomalias cromossômicas em material de aborto espontâneo de uma Maternidade pública da cidade de Vitória/ES. Nosso grupo participou da análise dos resultados do cariótipo e na elaboração do manuscrito. 